\title{
Effects of electronic communication on culture shock of spouses of international students
}

\author{
Diana Bennett \\ West Virginia University
}

Follow this and additional works at: https://researchrepository.wvu.edu/etd

\section{Recommended Citation}

Bennett, Diana, "Effects of electronic communication on culture shock of spouses of international students" (2002). Graduate Theses, Dissertations, and Problem Reports. 2408.

https://researchrepository.wvu.edu/etd/2408

This Dissertation is protected by copyright and/or related rights. It has been brought to you by the The Research Repository @ WVU with permission from the rights-holder(s). You are free to use this Dissertation in any way that is permitted by the copyright and related rights legislation that applies to your use. For other uses you must obtain permission from the rights-holder(s) directly, unless additional rights are indicated by a Creative Commons license in the record and/ or on the work itself. This Dissertation has been accepted for inclusion in WVU Graduate Theses, Dissertations, and Problem Reports collection by an authorized administrator of The Research Repository @ WVU.

For more information, please contact researchrepository@mail.wvu.edu. 
Effects of Electronic Communication on Culture Shock of Spouses of

International Students

Diana Bennett

Dissertation submitted to the

College of Human Resources and Education

at West Virginia University

for the degree of

Doctor of Education

in

Technology Education

John G. Wells, Chair

Peter Li

Edward Pytlik

Joy Faini Saab

Richard Walls

Department of Technology Education

Morgantown, West Virginia

2002

Keywords: International Students, Communication, Telecommunication, Acculturation, Cultural Adaptation, Cultural Adjustment 


\section{Abstract \\ Effects of Electronic Communication on Culture Shock of Spouses of International Students}

\section{Diana Bennett}

Culture shock is a serious problem for spouses of international students. This recollection study looked at use of telephone, web phone, email, chat, and online newspapers as predictors for culture shock. Fifteen spouses of international students at a mid-Atlantic university were interviewed with the same rated questions asking them to recall how they felt: When they first arrived in the United States, during their first six months here, during their second six months here, during their third six months here, and at the time of the interview. For the same time periods, they were also asked how many times a week they used telephone, web phone, email, chat, and online newspapers from back home. In addition, three open-ended questions were asked for each time period to provide explanations of the quantitative data.

Analyses of variance were conducted to determine whether participants' feelings related to culture shock (loneliness and isolation, missing family and people of national origin, not belonging here, sadness because ways of doing things here are not familiar) changed over time. Tukey tests were then used to determine where the significant changes occurred. Pearson Correlations and Chi-squares were computed to determine relationships between the modes of electronic communication and feelings related to culture shock. Multiple stepwise regressions were conducted to determine if any of the communication modes was a predictor for culture shock.

Data were reported in tables and figures. Feelings related to culture shock did improve over time. There were significant findings for phone, web phone, chat, and email. Recommendations included orienting new students and their spouses to electronic communication modes available, providing access to electronic communication for spouses, and providing a web board with information for spouses of international students. Suggestions for further research included a controlled study with spouses using various modes of communication, comparison of levels of culture shock among various groups - sex, age, country of origin, for example - and an investigation as to why usage of various modes of electronic communication decreased. 
Acknowledgements

Words cannot express the depth of gratitude I have toward so many. As I told my advisor many times, the thing I did best on my doctorate was selecting my committee. They were extremely supportive. When we realized that the population needed for my original research design was not available to me, the committee allowed me to rewrite chapters I and III to reflect what could be done. When I needed help from any one of them, he or she was ready to provide it. Dr. Joy Faini Saab encouraged me every step of the way, lending me qualitative research books, helping me to understand qualitative research, patting me on the back, and telling me I could do it. Dr. Edward Pytlik, although retired, tirelessly combed through the dissertation for errors and suggestions for improvement of the text as well as areas to research. He also helped me to come up with the original topic and suggested my international committee member, Mr. Peter Li. Mr. Li was my source for participants. He had many suggestions for finding and contacting spouses of international students and helped me to meet many new friends along the way. Dr. Richard Walls was my statistics guru. When I couldn't add two and two and get four, he calmly and patiently helped me to know what to do. I will never forget his kindness as we worked through the Results chapter. He truly follows his motto of "Teach unto others as you would be taught unto." Had it not been for my advisor, Dr. John G. Wells, and Dr. Walls, I probably 
would never have completed the project. When I had virtually given up, Dr. Wells asked me to phone him about another matter and then encouraged me to continue the dissertation. Dr. Walls and Dr. Wells met with me and helped me to get over that hurdle and many others. I will always remain deeply indebted to my wonderful committee.

I also owe a huge debt of gratitude to my family, who gave up their wife and mother to this project. They seldom complained when I was out late at night working on interviews or at the library. They learned to like eating out, to live in a dirty house, and they even put up with the grumpy old woman I had become. Thank you to my soul-mate Art, and to my wonderful sons: Lynn, Barry, John, Frank, and Brian, for always being there for me through both good times and bad. I also need to express my thanks to my parents, Wesley and Kay VanDruff for tolerating my neglect through so many months of this project and for supporting my endeavor. What a thrill when Dad put his hand under my chin and called me "doctor." Thanks also to a great sister, Marilee, and brother-in-law Allen, and my wonderful brother Stan and sister-in-law Carol. They not only tolerated me as I went through all the stages of being a doctoral student, but they also sat through my dissertation defense (though not without asking questions). Most of all, I need to thank my heavenly Father without Whose grace none of this could have happened. 


\section{Table of Contents}

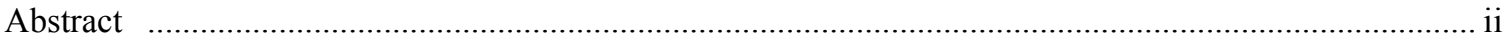

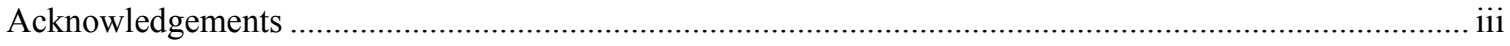

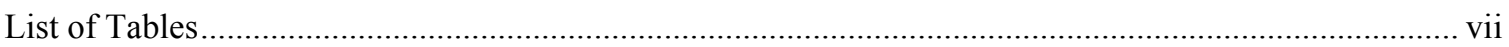

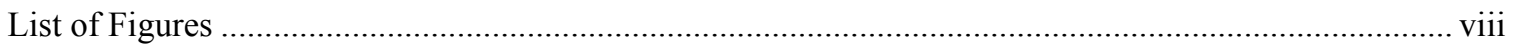

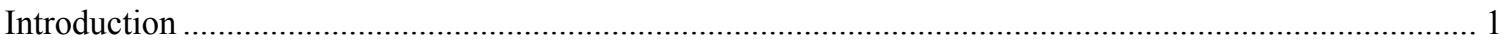

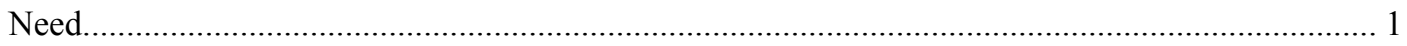

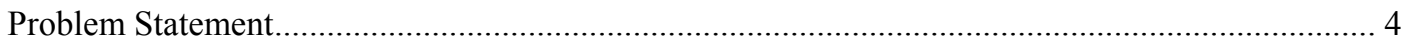

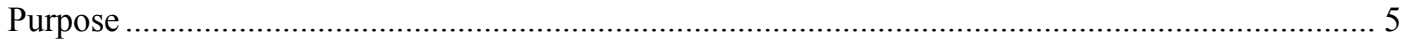

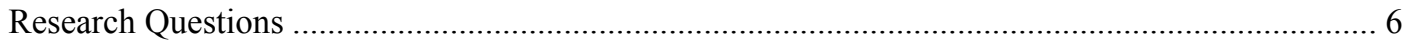

Assumptions

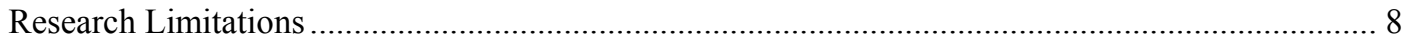

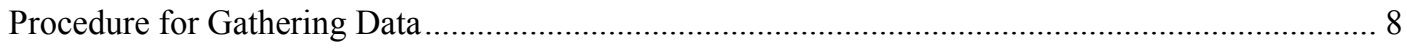

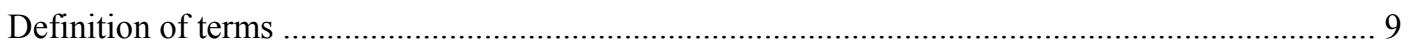

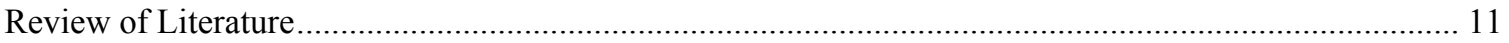

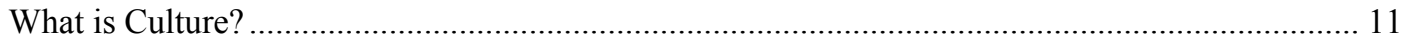

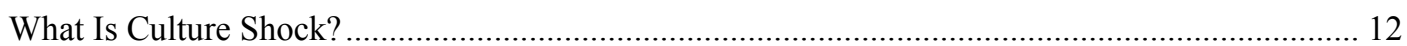

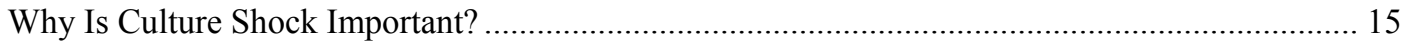

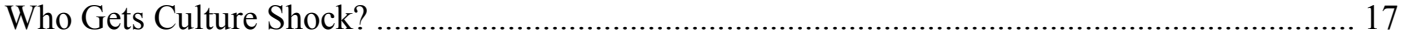

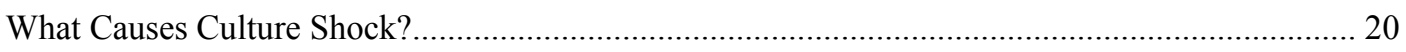

What Are the Levels and Symptoms of Culture Shock? .................................................... 25

What Has Been Done or Could be Done to Alleviate Culture Shock? .................................... 29

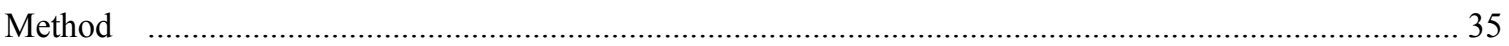

Research Questions ................................................................................................... 35

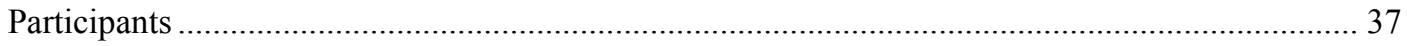

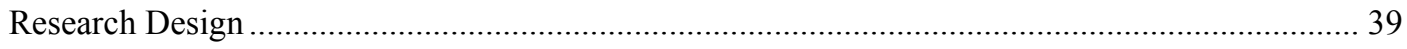

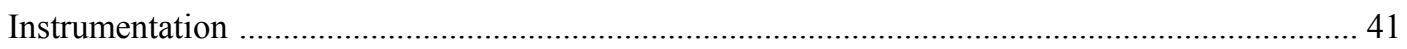

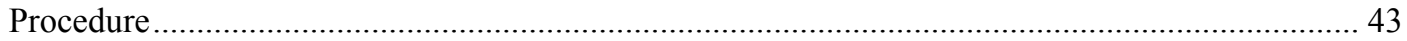




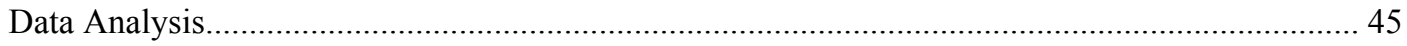

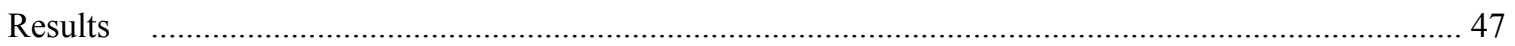

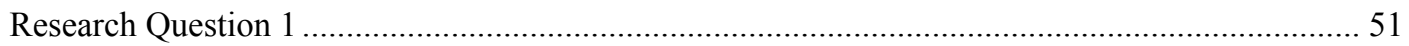

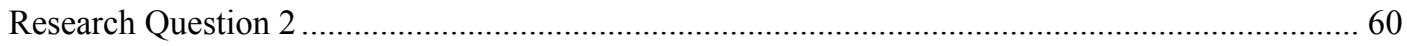

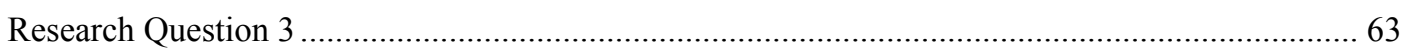

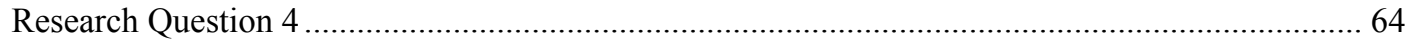

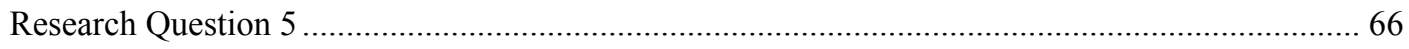

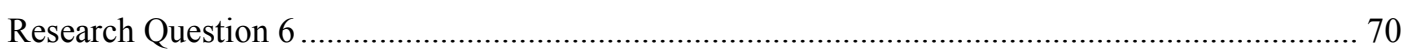

Supplemental Analyses Related to Research Questions 2-6 ............................................................ 72

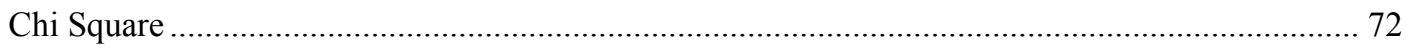

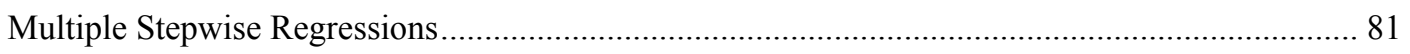

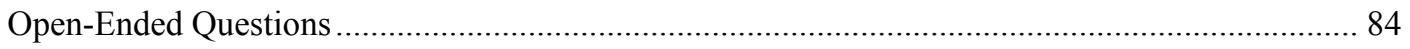

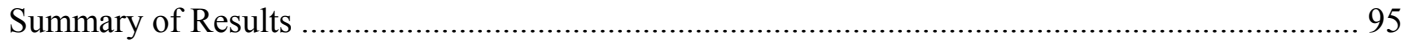

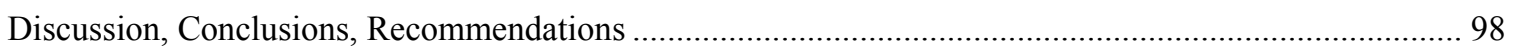

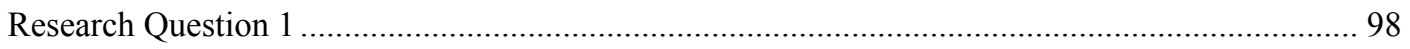

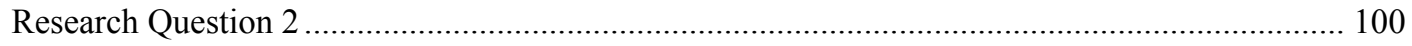

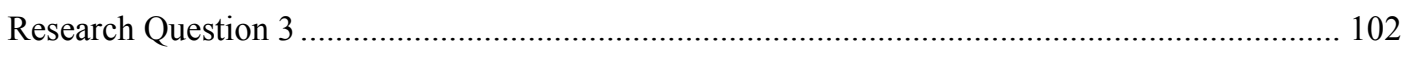

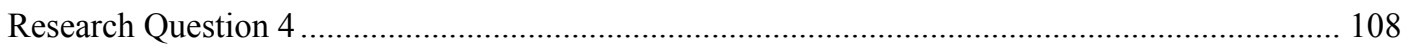

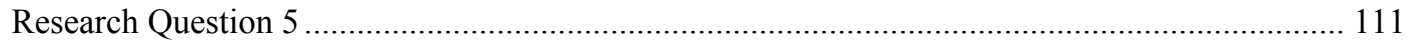

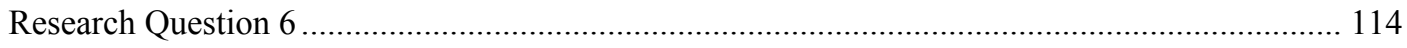

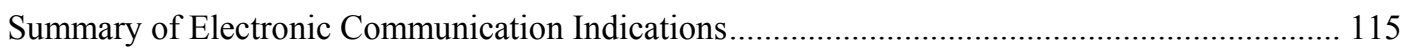

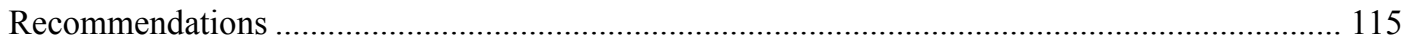

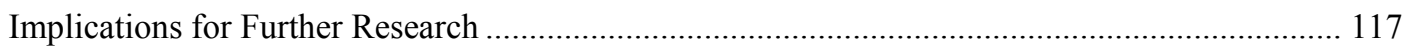

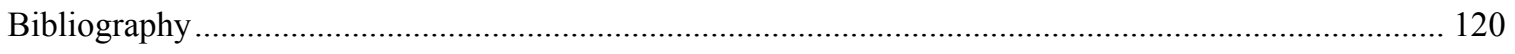

Appendix A …

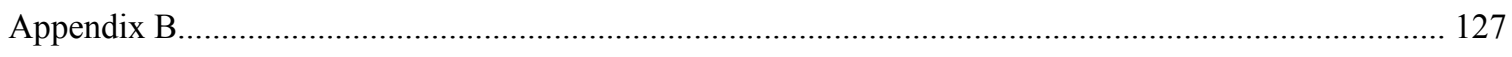

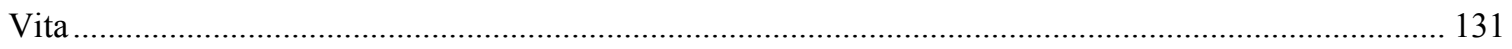




\section{List of Tables}

Table 1 Demographic Characteristics of the 15 Participants .......................................................... 38

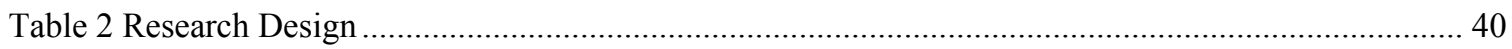

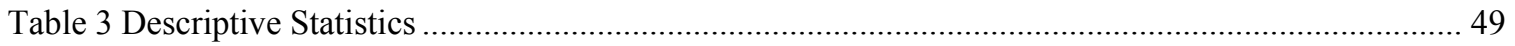

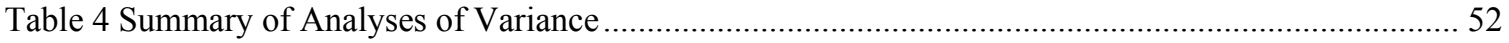

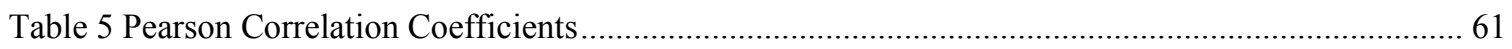

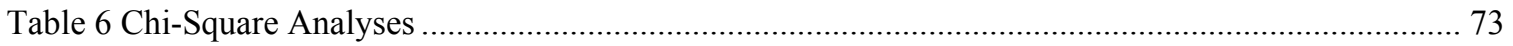

Table 7 Multiple Stepwise Regressions Analyses for Feelings by Potential Correlates.......................... 83

Table 8 Themes and Categories from Open-Ended Questions ........................................................... 86

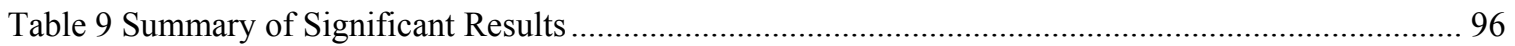




\section{Table of Figures}

Figure 1 Mean Feelings of Loneliness and Isolation Ratings Across the Recollection Periods

Figure 2 Mean Feelings of Missing Family and People of National Origin Across the

Recollection Periods.

Figure 3 Mean Feelings of Not Belonging Across the Recollection Periods .....

Figure 4 Mean Feelings of Sadness Because Ways of Doing Things Here Are Not Familiar

Ratings Across Recollection Periods.

Figure 5 Pearson Correlation Coefficients Ratings Phone Across Recollection Periods ......................... 62

Figure 6 Pearson Correlation Coefficients Ratings Web Phone Across Recollection Periods ................... 65

Figure 7 Pearson Correlation Coefficients Email Across Recollection Periods ..................................... 67

Figure 8 Pearson Correlation Coefficients Ratings Chat Across Recollection Periods ............................. 69

Figure 9 Pearson Correlation Coefficients Ratings Reading Online Newspaper Across

Recollection Periods................................................................................................ 71

Figure 10 Chi-Square Analysis for Feelings of Loneliness and Isolation by Chat ................................. 75

Figure 11 Chi-Square Analysis for Feelings of Missing Family and People of National Origin

by Web Phone

Figure 12 Chi-Square Analysis for Feelings of Missing Family and People of

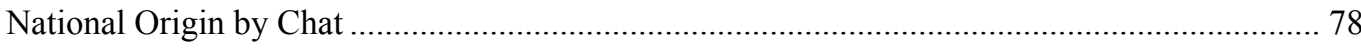

Figure 13 Chi-Square Analysis for Feelings of Not Belonging by Web Phone ................................... 79

Figure 14 Chi-Square Analysis for Feelings of Not Belonging by Chat ......................................... 80

Figure 15 Chi-Square Analysis for Feelings of Sadness Because Ways of Doing Things

Here Are not Familiar by Chat 


\section{CHAPTER I}

\section{Introduction}

Thousands of international students come to the United States every year to further their education in colleges and universities. Often, they bring their spouses and children with them. While the students interact with their peers and professors at their university, the spouses may be left alone at home, isolated. These spouses often have no clear-cut role in their new community. They have difficulty in dealing with cultural differences; problems may arise with their children's schooling; and there is often a lack of self-growth (Renata, 1996). Often, with no or little English, many newly arrived spouses feel trapped in their homes (Canada and the World Backgrounder, 1998). Separation and divorce are common (Gao, 1997).

\section{Need}

Culture shock is a "reaction to a change in the cultural environment" (McKinlay, Pattison, and Gross, 1996, p. 379), the difficulty of understanding the behavior of others, and/or an inability to predict what others will say or do (Bock, 1970, pp. ix-x). It can be very debilitating.

Many studies show the need to address culture shock for international students (Ninggal, 1998; Gao, 1997; Spencer, 1997). Peter Li of West Virginia University (Phone interview, April 16, 1999) has stated that culture 
shock is a main issue, especially with newer students in this country. He stated that sometimes spouses face more problems because their social circle is even smaller. The husband goes to school and keeps busy with schoolwork and perhaps a research or teaching assistantship. The spouse runs out of things to do and runs out of connections to reach out and get better acclimated. The spouse may have had a very important position back home, but due to visa and language problems is relegated to the position of homemaker in the new country. According to Byrnes (1966) and Winkelman (1994), dependence relationships may change, thus causing role shock, which is a loss of one's identity. In the home country, the role of the spouse was defined. Perhaps the spouse had an important career and many responsibilities outside the home. In the new country, this career cannot be advanced because of visa problems, so the spouse has to redefine his or her role in the new situation. The identity of an individual is partially based on the social roles that one has. When these are eliminated or changed in the new environment, culture (role) shock can result. Al-Ibrahim found that isolation from social interaction with people from the United States, either on campus or where they lived, limited social contacts to co-national or international groups. He found that "The wives of Syrian students suffered intensely and were extremely isolated, confined to the home and lacking in 
educational opportunities" (1983, p. 82). Although the problem of culture shock for international students has been studied (Ninggal, 1998; Gao, 1997; Spencer, 1997), the issue of culture shock for spouses has been little addressed, even though it is a very important issue. At least one university has recorded a suicide related to culture shock, and it is suspected that this was not a unique situation. While these suicides may not be directly attributed to culture shock, it is safe to say that culture shock was a contributing factor.

Culture shock may create psychological crises or social dysfunctions. Reactions from others to cultural differences may impede performance. Winkelman pointed out that "Because our society is becoming increasingly multicultural, we all experience varying degrees of cultural shock in unfamiliar cultural or subcultural settings" (1994, p. 1). Culture shock may cause physical and psychosomatic illness, temporary emotional disorders and even acute psychosis (Kohls, 1979; Rhinesmith, 1985; Winkelman, 1994). Taft (1977) indicated that culture shock requires a special case of human adaptation. Taft and Rhinesmith (1985) recommended a process of diagnosis of the cause of culture shock, analysis of the reaction to the cause, and adjustments to the new culture. Something needs to be done to get these spouses involved and help them adjust to their new situation. 


\section{Problem Statement}

Because part of the problem of culture shock has been defined as a lack of connections to the outside world (Li, phone interview, April 16, 1999), it would appear that having a way to communicate with others could alleviate culture shock. Electronic communication such as telephone, web phone, email, chat, and online newspapers from the home country could provide this method of communication. Web phone is a way of using the computer as a telephone to communicate very cheaply or free. Email is an asynchronous mode of communication via the Internet by which one who has an Internet connection can send a message to another who has an Internet connection at any time. The one who receives the email communication can read it and respond to it at his/her convenience. Chat is a synchronous mode of communication through which people can communicate with each other by typing messages back and forth, receiving and responding to them almost instantaneously. Online newspapers are newspapers placed on a website so that readers can access them at any time, providing one-way communication about the home country. Special software and Internet connections are necessary, but available without cost for web phone, chat, email, and online newspapers. 
The problem of this research was to determine if the use of electronic communication had an effect on the level of culture shock experienced by spouses of international students in the United States.

\section{Purpose}

The results of this study will be useful in planning for improvement of international student life by colleges. It is anticipated that the results of this study will indicate that culture shock can be reduced through electronic communication via the Internet with others of both the native culture and the new culture.

Admissions personnel from the home country will be able to use the information gained from this study to reduce the cultural shock experienced by new international student spouses. The study will provide a way for universities (or countries) to provide common links for students and their spouses who will study in the universities of the United States. Those who are in the study group would be able to communicate with people in their home country who will be coming to the United States to study. This interaction would reduce the anxiety of the newcomers as well as build the confidence of those already here. The research will provide information for U.S. admissions, along with other interested groups (counselors, faculty, staff of the university) to assist them in working with new arrivals. Colleges 
then could implement an electronic communications program following the findings of the study to alleviate some of the culture shock right up front.

\section{Research Questions}

Research Question 1

Is there a difference across time in the levels experienced by participants of feelings of loneliness and isolation, missing family and people of national origin, not belonging here, and sadness because ways of doing things here are not familiar?

Research Question 2

Is there a correlation between number of phone calls and levels of feelings of loneliness and isolation, missing family and people of national origin, not belonging here, and sadness because ways of doing things here are not familiar?

Research Question 3

Is there a correlation between number of web phone calls and levels of feelings of loneliness and isolation, missing family and people of national origin, not belonging here, and sadness because ways of doing things here are not familiar? 


\section{Research Question 4}

Is there a correlation between number of emails and levels of feelings of loneliness and isolation, missing family and people of national origin, not belonging here, and sadness because ways of doing things here are not familiar?

\section{Research Question 5}

Is there a correlation between number of chats and levels of feelings of loneliness and isolation, missing family and people of national origin, not belonging here, and sadness because ways of doing things here are not familiar?

Research Question 6

Is there a correlation between number of times an online newspaper is read and levels of feelings of loneliness and isolation, missing family and people of national origin, not belonging here, and sadness because ways of doing things here are not familiar?

\section{Assumptions}

The assumptions of this research were:

1. Participants had access to computers and the Internet..

2. Translations of the interviews were accurate.

3. Everyone experiences culture shock at some level. 


\section{Research Limitations}

This study was limited to 15 spouses of international students at West Virginia University who arrived in the United States as non-students and non-employees in the United States.

\section{Procedure for Gathering Data}

- Sample consisted of 15 spouses of international students at West Virginia University. These spouses were recruited through the Office of International Students and Scholars at WVU. Due to difficulty of obtaining participants, the sample consisted of all those willing to participate.

- Data gathering instruments were designed. Participants were asked to complete the instruments as an autobiographical memory test of when they first arrived in the US, during their first six months in the US, during their second six months in the US, during their third six months in the US, and right now (at the time of the interview).

- Participants completed data gathering instruments and responded to interview questions. Interpreters were used as needed to facilitate communication between the researcher and the participants.

- The data were analyzed. 


\section{Definition of terms}

- Chat - "Chat rooms allow people to correspond in real time by typing back and forth to each other synchronously" over the Internet (Harris, 1994 p. 88).

- Culture shock - Oberg $(1954 ; 1960)$ conceptualized cultural shock as the consequence of strain and anxiety resulting from contact with a new culture and the feelings of loss, confusion, and impotence resulting from loss of accustomed cultural cues and social rules. Church defined culture shock as "a normal process of adaptation to cultural stress involving such symptoms as anxiety, helplessness, irritability and a longing for a more predictable environment" (1982, p. 540).

- E-mail - "E-mail, stated simply, is a text-based cross between a personal letter and a telephone message" (Harris, 1994, p. 4). "Electronic mail involves sending and receiving messages over the network [Internet]" (Gilster, 1994, p. 287).

- Internet - "The Internet is a network of autonomous data networks that electronically links host computers at universities, research centers, government offices, and corporations around the globe" (Kahin \& Abbate, 1995, p. 131). 
- Online Newspapers - newspapers placed on a website so that readers can access them at any time, providing one-way communication

- Role shock - "One's identity is maintained in part by social roles that contribute to well-being through structuring social interaction. In the new cultural setting, the prior roles are largely eliminated and replaced with unfamiliar roles and expectations. This leads to role shock resulting from an ambiguity about one's social position, the loss of normal social relations and roles, and new roles inconsistent with previous selfconcept" (Winkelman, 1994, p. 3).

- Telephone - a "system for conveying speech over distances by converting sound into electric impulses sent through a wire" (Webster's new world dictionary of the American language, 1968, p. 1498).

- Web Phone - a way of using the computer as a telephone to communicate very cheaply or free. 


\section{CHAPTER II}

\section{Review of Literature}

\section{What is Culture?}

Bock defined culture as "what makes you a stranger when you are away from home" (1970, p. ix). Kelly and Reekie (1987) pointed out that the best way to learn about another culture is to experience it directly.

Zapf explained culture as a "network of shared meanings taken for granted as reality by those who interact with the network" (1993, p. 696). Culture is what makes a group of people comfortable with each other in a variety of situations. Murdock defined culture as "habits that are shared by members of a society" (1971, p. 320), including both customs and collective ideas. These include such social expectations as behaviors, rewards and punishments, and responses to behaviors.

Storti (1989) separated country and culture. He included climate, communications infrastructure, transportation, the list of things "they don't have here," and the fear of getting sick as part of country. Storti defined culture as a "system of beliefs and values shared by a particular group of people," as behavior, (p. 14), and as the "minutiae of day-to-day existence" (p. 7). Coping with these minutiae can lead to culture shock, which is defined in the next section of this paper. 


\section{What Is Culture Shock?}

McKinlay, Pattison, and Gross indicated that Bock defined culture shock as an "inability to understand, control or predict another person's behavior" (1996, p. 379). Specifically, Bock said, "The outstanding features of culture shock include inability to make any sense out of the behavior of others or to predict what they will say or do" (1970, pp. ix-x). Church described culture shock as "a normal process of adaptation to cultural stress involving such symptoms as anxiety, helplessness, irritability and a longing for a more predictable environment" (1982, p. 540).

According to Armes and Ward (1989, p. 273), and McKinlay et al. (1996, p. 379), “Oberg (1960) first coined the term culture shock to refer to the disorientation and accompanying anxiety experienced by sojourners in cross-cultural transition" (p. 273).

Storti defined culture shock as the disruption caused in one's life by the impact of so much that is new and unfamiliar. One must pay very close attention to the finest detail whether greeting a neighbor, buying a stamp, or shopping for dinner: "Everything takes longer and seems to require an extra step" (1989, p. 7). One begins to feel frustrated and overwhelmed.

Churchman and Mitrani defined culture shock as "the potentially confusing and disorienting experience when one enters a new culture" 
(1997, p. 68), while Olson, defined culture shock as "emotional upset and tension brought on by the stress of a move from one culture to another" (1985, p. 190).

According to Taylor (1990), adapting to another culture can be painful. One's own cultural behavior is very strong and subconscious. Taylor indicated that much of a person's being is cultural rather than individual. One's cultural learning often defines "correctness," thus leading one to believe that cultural differences are "wrong." Readjusting this thinking can be very difficult, and it can affect every area of life from eating, sleeping, dressing, visiting, and speaking to working, visiting a doctor, and more. Those things, which were always taken for granted, can no longer be taken for granted. Taylor (p. 201) pointed out that Bock described culture shock as the emotional reaction caused by being unable to understand, control, and predict someone else's behavior.

Ling, O’Shea, Pszonak, and Bertram (1994) defined culture shock as the disorientation caused by an abrupt change from one set of assumptions to another.

Winkelman (1994, p. 12) and Merta, Stringham, and Ponterotto (1988, p. 242) quoted Taft's "most common definition" of culture shock as "the feeling of impotence on the part of the stranger who cannot deal competently 
with his environment owing to unfamiliarity with the cognitive aspects of the culture and inability to perform the necessary role-playing skills" (Taft, 1977, p. 142). Following this definition, everyone, not just travelers, experiences culture shock in varying degrees as unfamiliar cultural or subcultural settings are encountered.

Winkelman defined culture shock as a "multifaceted experience resulting from numerous stressors occurring in contact with a different culture" (1994, p. 121). Winkelman agreed with Rhinesmith (1985) that culture shock is caused both by the challenge of a new cultural environment and the loss of familiar cultural surroundings.

Taft (1977, p. 139) defined culture shock as a degree of emotional shock caused by finding oneself in an unfamiliar cultural environment where previous learning is not adequate for coping. Weissman and Furnham said that:

Culture shock is a stress reaction where salient physiological and physical rewards are generally uncertain, difficult to control or predict. Thus, a sojourner remains anxious, confused, and sometimes apathetic or angry until he or she has had time to develop a new set of behavioral assumptions that help him or 
her to understand and predict the social behavior of the local natives. (1987, p. 314)

In summary, culture shock is a reaction to a feeling of impotence in a new cultural experience, or a different way of doing things, which can manifest itself in mild to severe physical and emotional ways. The importance of culture shock is discussed in the next section.

\section{Why Is Culture Shock Important?}

According to Ory, Simons, Verhulst, Leenders, and Wolters, "The end of the cold war has contributed to an increase in international mobility" (1991, p. 29). Therefore, more people will experience new cultures and hence culture shock. Churchman and Mitrani (1997) pointed out that migration is traumatic for both the immigrant and the host culture. According to Wilson (1991), Native American students who leave the reservation to study in public schools experience culture shock to the extent that they fail in school. Wilson pointed to several studies (Borish, 1988; Homberger, 1988; Trueba, 1989; Heiskovitz, 1948; Hall, 1983) that indicated serious conflicts might result when students are taught by educators with backgrounds different from their own. In her own study, 
Wilson found that of 23 students from a reserve enrolled in a public high school in September, 1988, 18 had dropped out by May, 1989.

"International students are a large and growing presence on many American campuses" (Ling et al., 1994, p. 39). Many U.S. colleges and universities regularly recruit students from other countries to enrich the multicultural flavor of their schools. Shigaki and Smith (1997) pointed out that international students, especially those from non-western cultures have many problems with culture shock. These problems included feelings of isolation, exclusion, confusion, feeling disconnected, difficulties with classes, and differing cultural expectations such as gift-giving, appropriate behavior in classes, and teacher/student relationships.

Weissman and Furnham (1987) stated that the relationship between what a sojourner expects from a culture and the reality of that culture is crucial in determining adjustment. Olson (1985) pointed out that the stress of culture shock often attacks the weakest part of an individual or a relationship. Culture shock may intensify other problems in a relationship.

Taylor (1990) said that companies invest a lot of money assigning home office people abroad. Then, culture shock may cause them to leave that assignment to come home early, before they have accomplished what they were sent overseas to do. This can be very expensive. Also, according 
to Storti (1989), being comfortable with the culture helps people to be more effective in their work. Understanding the culture also makes it more difficult for the natives to hide behind it. Understanding a culture makes one feel more secure in it, and allows one to get in touch with who one is again.

According to Winkelman, culture shock causes "both psychological and physiological reactions. Psychological reactions include physiological, emotional, interpersonal, cognitive, and social components, as well as the effects resulting from changes in sociocultural relations, cognitive fatigue, role stress, and identity loss" (1994, p. 122). Because culture shock can be so debilitating, it begs understanding and alleviation so that businessmen, international students, Peace Corps volunteers, children, and a myriad of others can function in their new cultural environments. More discussion of who gets culture shock can be found in the next section.

\section{Who Gets Culture Shock?}

Winkelman (1994) stated that businessmen on overseas assignments, business institutions undergoing reorganization, societies experiencing massive technological change, and staff in schools and hospitals, among others, experience culture shock. He indicated that the multicultural nature of the United States leads to culture shock on a daily basis. 
Zapf indicated that individual variables might predict the length and intensity of culture shock: "demographics, personal history (for example, past environmental mobility, breadth of education, related work experiences, understanding of culture shock), and attitudes (for example, openmindedness, comfort with social diversity)" (1993, p. 697). He also suggested some structural variables: "general characteristics of the new environment, (for example, presence of colleagues) and features of the new job (for example, role clarity)" (p. 697). Tobin and Friedman (1983) indicated that refugees from war-torn countries are particularly susceptible to culture shock.

Crossing cultures can be very difficult for children (Van Leeuwen, 1987; Ory et al., 1991). Scheper-Hughes (1987) pointed out that children might not have the cognition and development to be able to cope with cultural and behavioral diversity encountered in a new setting.

Ling et al. (1994) stated that one using a health care system in a culture different from one's own could experience culture shock. For example, people in some countries may be treated by the first doctor they see while in the United States people may be referred to specialist after specialist for test after test before treatment is begun. 
Kerr (1985) discussed cultural problems of technology such as the fear of losing control and being unable to determine outcomes. Changing the world creates problems of morality and faith from First-World versus ThirdWorld perspectives. Kerr gave the example of the birth control pill, which can solve the problems of overpopulation and unwanted pregnancies, but can also provide sexual freedom, changing the relationship between men and women. Women who leave jobs often feel a loss of self-esteem. There may be physical symptoms, such as "insomnia, headaches, stomach upset, lack of appetite or compulsive eating, weight loss or gain and fatigue," as well as an increased dependence on alcohol or drugs, according to Olson (1985).

Lalive d'Epinay (1985) pointed out that depressed elderly women in Switzerland are suffering from culture shock caused by a decaying and expanding society. Their old, hard farm life was highly valued by religious tradition. The new, easier urban ways of life are considered decadent and immoral. The change to a more urban way of life has made their roles in society unclear: Should they accept "morally right," but difficult life styles, or should they take the "immoral" easier life?

According to Shigaki and Smith (1997), students from non-western countries, particularly Asia, experience pervasive culture shock when they begin their studies on U.S. college campuses. McKinlay et al. (1996), 
Hefferon (1997), and Dodge (1990) also indicated that international students are likely to suffer culture shock. Tompson and Tompson (1996) discussed strategies to improve satisfaction of international students in order to retain them.

Because of the fact that virtually anyone can suffer from culture shock and the fact that it creates physiological, sociological, emotional, and financial problems, the next section will examine the causes of culture shock.

\section{What Causes Culture Shock?}

Winkelman indicated a variety of factors that can provoke culture shock including "previous experience with other cultures and cross-cultural adaptation; the degree of differences in one's own and the host culture; the degree of preparation; social support networks; and individual psychological characteristics" (1994, p. 121). He further stated that culture shock is "normal in a foreign culture environment" (p. 121).

According to Winkelman (1994) the causes of culture shock include stress reactions, which can create physiological symptoms; cognitive fatigue, which is getting tired of trying to figure out what's going on and why; role shock, changes in one's social role due to cultural differences; personal 
shock, which may include loss of personal intimacy with significant others; and value conflicts.

Oberg believed that culture stress was "precipitated by the anxiety that results from losing all our familiar signs and symbols of social intercourse" (1960, p. 177). Zwingman and Gunn (1983) reported severe cases of psychological problems caused by "uprooting." Prejudice and discrimination have also been shown to produce negative effects on students' mental health. McKinlay et al. (1996) also reported that students whose experiences did not measure up to their expectations were much more homesick.

According to Kelly and Reekie (1987), B.J. Broome listed three levels of difficulties related to culture shock: structural (dependence versus independence, friendships, status, school and class size, anonymity, etc.), situational (communication skills; such as, greetings, social gatherings, celebrations), and meaning (lack of sincere criticism; being unable to distinguish a reprimand from a major censure). Zapf stated that "there is general agreement that a stress reaction derived from the inability to understand cultural cues is inevitable in cross-cultural encounters" (1993, p. 697).

Storti (1989) explained that behaviors of others in the new culture that annoy us, along with our behaviors that annoy others in the new culture, are 
what cause culture shock. He also stated that we expect everyone to behave like us and others expect us to behave like them. This failure to meet the expectation is more of a problem than the behavior itself.

Olson (1985) stated that people react differently and with different levels of severity to cultural change. She indicated that a move from one part of a country to another could cause as much culture shock as one from Pittsburgh to Beijing. Storti (1989) agreed. Olson pointed out Reverend Ian Macleod's factors that affect the degree of culture shock experienced: The degree of change, personal commitment to the move, flexibility, emotional stability, emotional support in the new environment, economic security, the availability of mental health services and support, tension relievers, worthwhile work, and acceptance of different values and beliefs.

Churchman and Mitrani (1997) indicated a direct relationship of culture shock to the disparity between the sojourner's culture and that of the host society. They also listed predictor variables:

1. Control factors - how much control one has over initiating the other-culture experience.

2. Intrapersonal factors - such things as age, extent of previous travel, language skills, resourcefulness, independence, 
fortitude, capacity to tolerate ambiguity and frustrations, appearance, etc.

3. Organismic-biological factors - physical condition, medical or dietary needs, and ability to tolerate physically the demands of stressful disruption on tempo of familiar routine.

4. Interpersonal factors - the nature and extent of one's support group, mutual expectation of support from the group.

5. Spatial-temporal factors - where one is and for how long.

6. Geopolitical factors - level of international, national, regional or local tension.

7. The degree and nature of the differences between one's original culture and the new one. Culture here is used in the broadest of senses to include all aspects of the context, including the physical environment.

8. The degree and quality of information one has about the new environment and through what communication means obtained.

9. The attitudes and policies toward immigrants in the host country. (p. 68) 
According to Wilson, "Lack of culturally appropriate interfacing mechanisms to ease the transition from a rural to an urban environment create cultural discontinuities and cognitive ambiguities resulting in underachievement for the present" (1991, p. 381). Simpson (1990) pointed out that wearing oneself out preparing for a trip, jet lag, climate and diet differences, strange beds, and the need to see and do everything sets one up for culture shock.

Shigaki and Smith (1997) pointed out that differing cultural expectations such as gift giving practices, methods of communicating, and ways of addressing others, could lead to misunderstandings and discomfort. Tian (1994) described situations in which cultural expectations in greetings, answering questions fully and truthfully, gift giving, eating customs, and other areas did not match cultural reality. $\mathrm{Bu}(1988)$ pointed out his discomfort in making independent decisions in the United States and his difficulty in adjusting to American informality, both of which were practically unheard of in his native China.

In the next section, symptoms and levels of culture shock are described. 


\section{What Are the Levels and Symptoms of Culture Shock?}

Oberg (1960) listed the stages of culture shock as fascination, hostility, adjustment, and bi-culturalism. McKinlay et al. indicated that the symptoms of culture shock include "evidence of psychological disturbance, a negative reaction to the new surroundings and a longing for a more familiar environment" (1996, p. 383). They also indicated that homesickness comes and goes in waves and does not correlate with level of English or evaluation of their experience.

Kohák (1985) stated that when he first went to Europe everything seemed familiar and he didn't experience culture shock. Culture shock didn't come until months later when he began to notice more detail in his environment. Rhinesmith grouped symptoms of culture shock as "depression, lethargy, and fatigue; irregular sleeping and eating patterns; psychosomatic physical ailments; generalized anxiety and discomfort; fear for safety or excessive concern with hygiene" (1985, pp. 147-8).

Tsai reported that Lysgaard's U-curve theory described three stages of attitudinal adjustment: A stage of "elation or optimism; a period of frustration, depression, and confusion; and a period of recovery" (1995, p. 524). Zapf (1993) reported a study that supported the U-curve hypothesis. Tsai pointed out that culture shock had been commonly viewed as a normal 
part of adaptation indicated by "anxiety, helplessness, irritability, and a longing for a more predictable and gratifying environment" (p. 524). Finally, Tsai stated that more recent models classified adjustment in terms of “'acculturation attitudes,' such as assimilation, integration, separation, and marginalization" (p. 524) with a need for "cultural maintenance and intergroup contact" (p. 524).

Even though cross-cultural adjustment theories indicated that "Sojourners usually bottom out after several weeks or months in their new environment" (Hannigan, 1988, p. 91), Hannigan stated that she had experienced culture shock in less than 24 hours, and again after she had been in Spain for several months.

Oberg (1960) listed the following aspects of culture shock: Excessive health and cleanliness concerns, helplessness, anger, delay in or refusal to learn the language of the new culture, excessive fear of being cheated or being a victim of crime, and a terrible longing for home. Oberg (1960) listed four stages of culture shock although not everyone reaches the fourth stage: The first stage is the honeymoon stage when the traveler will experience excitement. The second stage is when reality sets in with language problems and hostility in meeting problems of daily life. The third stage is signified by a move to accept the new culture. There is still a struggle with feelings of 
ambivalence toward the new culture, but changes are being made. Humor is seen in this stage where hostility was seen in the second stage. Finally, the fourth stage is when the new culture is truly accepted and enjoyed. Olson (1985) stated that the stages of culture shock might be compared to the stages of grief.

Winkelman defined the four primary phases of culture shock as:

1. The honeymoon or tourist phase

2. The crises [sic] or cultural [sic] shock phase

3. The adjustment, reorientation, and gradual recovery phase

4. The adaptation, resolution, or acculturation phase. (1994, p. 122)

Winkelman indicated that the phases are not only sequential, but also cyclical. If one becomes truly bicultural, one remains in phase four permanently.

According to Winkelman (1994), the first phase or honeymoon phase is that typically experienced by honeymooners or travelers who remain a short time in a country or new culture. It is characterized by excitement, almost euphoria. Everything is interesting and beautiful and few if any problems are encountered. 
Winkelman's second phase is the crisis phase. This phase can occur at any time, depending on factors such as personality, experience, preparation, etc., but it usually occurs within the first few weeks or months in the new culture. As the name implies, the crisis phase emerges with a crisis, which may be a sudden crisis or a series of smaller problems, or bad experiences, which accumulate until they become major problems or crises:

Life does not make sense and one may feel helpless, confused, disliked by others, or treated like a child. A sense of lack of control of one's life may lead to depression, isolation, anger, or hostility. Excessive emotionality and fatigue may be accompanied by physical or psychosomatic illness. Feeling as if one is being taken advantage of or being cheated is typical.

Becoming overly sensitive, suspicious, and paranoid with fears of being robbed or assaulted are also typical reactions. (1994, p. 122)

Winkelman's (1994) third phase is adjustment and reorientation. During this phase, one begins to make sense of the new culture; hence negative reactions are reduced. Problems don't really end in this phase, but one learns to handle them. 
Finally, according to Winkelman (1994), there is the stage of adaptation, resolution, or acculturation. Full assimilation may be impossible but one goes through significant change and becomes bicultural. In order to reach this stage, one must be able to react constructively to culture shock.

Symptoms of culture shock may include "withdrawal and excessive sleeping, compulsive eating and drinking, excessive irritability and hostility, marital and family tensions and conflicts, loss of work effectiveness, and unaccountable episodes of crying" (Winkelman, 1994, p. 123). According to Shigaki and Smith (1997), international students frequently feel lonely, isolated, and confused, often because of problems with a roommate.

What Has Been Done or Could be Done to Alleviate Culture Shock?

Winkelman (1994) agreed with Furnham and Bochner (1986) that preparation, orientation, and acquisition of culturally appropriate skills are necessary to lessen culture shock. Winkelman stated that one must be aware of culture shock occurrences and implement appropriate behavior to overcome culture shock through adaptation. He further stated that a combination of behavioral and cognitive approaches have been shown to improve cultural adaptation and communication, because culture shock is caused by "cognitive overload [trying to understand what is going on] and 
behavioral inadequacies" (p. 121). Winkelman believed programs to help or prevent culture shock should foster learning, awareness, and adaptation.

Being aware of culture shock, developing skills in crisis resolution, and being aware of the need to change personally in such a way as to achieve emotional comfort, achieving a sense of belonging through changing reference groups, and adoption of new social roles defined by the new culture can help one to adapt to a new culture and overcome culture shock. Assessing one's ability to adapt to a new culture before departure is a good first step. Also, anticipating problems before they develop and being prepared are also good adaptation strategies. Cross-cultural training will also support successful adjustment to a new culture. Being aware of potential value conflicts with the new culture is also important. "Cultures are ethnocentric, and their members typically view their own cultural ways as superior" (Winkelman, 1994, p. 124). Transition resources are also necessary, as is stress management. Managing culture shock requires a network of significant others including placement families. Social support favorably affects stressors. Organizational support such as clubs, sports teams, boosters, etc., can also be helpful. "Participation in the daily life of the host culture is essential for cultural adjustment and adaptation" (p. 125). 
One who has adapted to a new culture recognizes problems and seeks their solution rather than denying their existence.

Olson (1985) found that it is possible to ease adjustment stress by providing information that is not readily available to foreigners. Kelly and Reekie (1987) made the following suggestions for international students: read about the area you will be studying and about the culture you will be experiencing; practice the language; be prepared to educate others about your country; go out and visit others rather than waiting to be invited; expect to be misunderstood sometimes; and write to your family and friends at home.

McKinlay et al. (1996) agreed with Kinnell (1990) that orientation programs for students before they begin classes are especially helpful. They also stated that other studies have indicated that culture training could relieve stress for students. Fisher suggested encouraging the homesick to "positively restructure the qualities, opportunities and facilities offered by the new environment" (1990, p. 307). Pennebaker, Colder, \& Sharp (1990) found that having students write about their experiences improved their ability to cope. McKinlay et al. said that studies in Canada and Australia found that pairing home and international student peers is helpful. They recommended a sophisticated analysis of international student needs and 
problems, coherent management strategies, a support system for students, good dissemination of information about the support system, and less emphasis on integration of international students, instead emphasizing links with home and with co-nationals. Also, they pointed out that receiving accurate information about the new culture before departure is essential.

Storti stated that awareness of our emotions is critical. Understanding why we are angry, for example, helps to abate that anger. Being a keen observer is also important. He provides a model of the process of adjustment:

We expect others to be like us, but they aren't. Thus, a cultural incident occurs, causing a reaction (anger, fear, etc.), and we withdraw. We become aware of our reaction. We reflect on its cause. And our reaction subsides. We observe the situation, which results in developing culturally appropriate expectations. In the experience of actually being in another culture, the incidents occur rapidly and intervention becomes necessary for prompt adjustment. Often we see things without becoming aware of their cultural significance. (1989, pp. 61-62)

Learning the language is also helpful, particularly because part of the culture is in how the people express themselves. Shigaki and Smith (1997) 
reported that international students who have positive relationships with American students adjust more easily to the American culture than those who do not. Recommendations included having American buddies, an international peer buddy and support network, and faculty mentors. They recommended dyads consisting of an American and an international student paired with a similar dyad to share their cultures with each other. For many this sharing was done on both a personal and an educational level. They became truly interested in each other, alleviating culture shock for both.

Neves and Sanyal developed a game called UPSIDE DOWN to help any group interested in examining cross-cultural differences "to confront, understand and to effectively overcome culture shock" (1992, p. 370). The players are divided into two groups who represent two different cultures. The two groups learn about each other's culture and then negotiate with each other in order to accomplish an assigned mission.

Merta et al. (1988) reported on two forms of treatment for culture shock called culture assimilator and behavioral interaction. The culture assimilator teaches about another culture through programmed learning while behavioral interaction allows interaction with a member of another culture. 
According to Churchman and Mitrani (1997)," The three most important factors that appear extensively in the literature are the existence of a social support network, the ability to control and predict and the ability to choose" (p. 66). Storti (1989) recommended eating right and getting enough exercise and sleep, keeping in touch with people back home, seeking out other people in the new culture, and being patient. Culture shock affects everyone and causes loss of self-esteem, time, and money. Therefore, it is worthy of further study to find ways to alleviate culture shock. 


\section{CHAPTER III}

\section{Method}

In order to test the effects of electronic communication on the culture shock of spouses of international students, specific data gathering instruments and an autobiographical data design were used. These are described below, along with the research questions, participants, and procedure.

\section{Research Questions}

Based on the spouses' feelings of being trapped in their homes when they arrive in the United States (Canada and the World Backgrounder, 1998), the following research questions were proposed:

\section{Research Question 1}

Is there a difference across time in the levels reported by participants of feelings of loneliness and isolation, missing family and people of national origin, not belonging here, and sadness because ways of doing things here are not familiar?

Research Question 2

Is there a correlation between number of phone calls and levels of feelings of loneliness and isolation, missing family and people of national 
origin, not belonging here, and sadness because ways of doing things here are not familiar?

Research Question 3

Is there a correlation between number of web phone calls and levels of feelings of loneliness and isolation, missing family and people of national origin, not belonging here, and sadness because ways of doing things here are not familiar?

Research Question 4

Is there a correlation between number of emails and levels of feelings of loneliness and isolation, missing family and people of national origin, not belonging here, and sadness because ways of doing things here are not familiar?

Research Question 5

Is there a correlation between number of chats and levels of feelings of loneliness and isolation, missing family and people of national origin, not belonging here, and sadness because ways of doing things here are not familiar?

Research Question 6

Is there a correlation between number of times an online newspaper is read and levels of feelings of loneliness and isolation, missing family and 
people of national origin, not belonging here, and sadness because ways of doing things here are not familiar?

\section{Participants}

Participants were a convenience sample of 15 spouses of international students at West Virginia University. Most of these spouses came to the United States as non-students and were not employed in the U.S. Most of them had followed their spouses to the United States rather than coming with them on their first arrival. At the time of the interview, nine of the spouses had become students at West Virginia University, while six had not. A few had also become graduate assistants or had taken jobs at levels far below jobs they had held in their countries of origin.

Demographic characteristics of the 15 participants are reported in Table 1. Included in the study were both female and male spouses from nine countries in Africa, Asia, Europe, and Latin America. Some had children in the United States; some left children behind in the country of origin, while others had no children at the time of the interview. Many were professionals in their country of origin. Some had become students, graduate assistants, research assistants, dental assistants, and clerks, while others remained unemployed homemakers. None was employed at as high a level as in the country of origin. The demographics are summarized in Table 1. 


\section{Table 1}

Demographic Characteristics of the 15 Participants

\begin{tabular}{|c|c|}
\hline Variable & $\mathrm{n}$ \\
\hline \multicolumn{2}{|l|}{ Gender } \\
\hline Female & 13 \\
\hline Male & 2 \\
\hline \multicolumn{2}{|l|}{ Age Category } \\
\hline $20 \mathrm{~s}$ & 6 \\
\hline $30 \mathrm{~s}$ & 6 \\
\hline $40 \mathrm{~s}$ & 3 \\
\hline \multicolumn{2}{|l|}{ Country of Origin } \\
\hline Armenia & 1 \\
\hline Colombia & 3 \\
\hline Indonesia & 1 \\
\hline Kenya & 2 \\
\hline Mexico & 1 \\
\hline Nepal & 2 \\
\hline Peoples' Republic of China & 3 \\
\hline Poland & 1 \\
\hline Taiwan & 1 \\
\hline \multicolumn{2}{|l|}{ Participants with Children } \\
\hline Living in United States & 7 \\
\hline Living in Country of Origin & 2 \\
\hline No children & 6 \\
\hline \multicolumn{2}{|l|}{ Student Status } \\
\hline University Student at Interview Time & 9 \\
\hline Not a Student at Interview Time & 6 \\
\hline \multicolumn{2}{|l|}{ U.S. Employment Status } \\
\hline Graduate Assistant & 4 \\
\hline Other Employment & 3 \\
\hline Unemployed & 8 \\
\hline \multicolumn{2}{|l|}{ Employment Status in Country of Origin } \\
\hline Professional & 9 \\
\hline Worked in a Bank & 3 \\
\hline Other & 2 \\
\hline Not Employed & 1 \\
\hline \multicolumn{2}{|l|}{ Length of Time in the United States } \\
\hline Less than 18 Months & 5 \\
\hline 1.5 to 3 Years & 5 \\
\hline 4 to 14 Years & 5 \\
\hline \multicolumn{2}{|l|}{ Travel to Other Foreign Countries } \\
\hline Yes & 8 \\
\hline No & 7 \\
\hline
\end{tabular}




\section{Research Design}

The research format was a within-subjects design in which

Recollection Period was an independent variable. The design incorporated five Recollection Periods (Arrival, During the First Six Months Here, During the Second Six Months Here, During the Third Six Months Here, and Right Now - at the time of the interview). This was a within-subjects independent variable because each participant reported for each of the recollection periods. Secondly, this independent variable, Recollection Period, was hypothesized to be influential on the dependent variables. The dependent variables were ratings from 1 (strongly disagree) to 4 (strongly agree) of: (a) I feel lonely and isolated, (b) I miss my family and people of my national origin, (c) I don't feel like I belong here, and (d) I feel sad because ways of doing things here are not familiar to me. Potential correlates of those feelings (dependent variables) were five types of Electronic Communication Modes. These modes are Telephone, Web Phone, Email, Chat, and Online Newspaper of country of origin. In addition to overall correlations of Electronic Communication Modes with the variables measuring feelings, the relationships of those modes to those feelings were tested to identify differential relationships at the five Recollection Periods. The research design is illustrated in Table 2. 


\section{Table 2}

\section{Research Design}

\begin{tabular}{lccccc} 
& \multicolumn{4}{c}{ Recollection Period (within-subjects Independent Variable) } \\
\cline { 2 - 5 } Electronic Communication & Arrival & $1^{\text {st }} 6$ Months & $2^{\text {nd }} 6$ Months & $3^{\text {rd }}$ 6 Months & Right Now \\
Potential Correlates) & & & & \\
\hline Telephone & $\mathrm{N}=1-15$ & $\mathrm{~N}=1-15$ & $\mathrm{~N}=1-15$ & $\mathrm{~N}=1-12$ & $\mathrm{~N}=1-15$ \\
Web Phone & $\mathrm{N}=1-15$ & $\mathrm{~N}=1-15$ & $\mathrm{~N}=1-15$ & $\mathrm{~N}=1-12$ & $\mathrm{~N}=1-15$ \\
Email & $\mathrm{N}=1-15$ & $\mathrm{~N}=1-15$ & $\mathrm{~N}=1-15$ & $\mathrm{~N}=1-12$ & $\mathrm{~N}=1-15$ \\
Chat & $\mathrm{N}=1-15$ & $\mathrm{~N}=1-15$ & $\mathrm{~N}=1-15$ & $\mathrm{~N}=1-12$ & $\mathrm{~N}=1-15$ \\
Online Newspapers & $\mathrm{N}=1-15$ & $\mathrm{~N}=1-15$ & $\mathrm{~N}=1-15$ & $\mathrm{~N}=1-12$ & $\mathrm{~N}=1-15$ \\
\hline
\end{tabular}

\section{Feelings (Dependent Variables)}

Dependent variables are ratings from 1 (Strongly Disagree) to 4 (Strongly Agree) of:

I feel lonely and isolated.

I miss my family and people from my country.

I don't feel like I belong here.

I feel sad because ways of doing things here are not familiar to me. 


\section{Instrumentation}

The demographic data listed in Appendix A were collected from each participant. Demographic characteristics collected include gender, age, country of origin, children, location of children (here with the spouse or home in the country of origin), student status, employment status in the United States and in the country of origin, length of time in the United States, and travel to other foreign countries as well as self ratings of Englishlanguage proficiency and electronic communication access. The demographic characteristics were summarized in Table 1.

The measures constituting the dependent variables (feelings) are shown in Appendix B. Four of the items were rated on a four-point Likert scale from 1 (strongly disagree) to 4 (strongly agree). These four items are: (1) When I first arrived here, I felt lonely and isolated. (2) When I first arrived here, I missed my family and people of my national origin. (3) When I first arrived here, I didn't feel like I belonged here. (4) When I first arrived here, I felt sad because ways of doing things here are not familiar. The prefixes of the questions (dependent variables) were modified as appropriate for the five recollection periods. For example, when asked to recall feelings during the second six-month period, the prefix was "During the second six 
months I was here,...." Similarly, the prefix for the last recollection period was "Right now,...."

As described in the design of this investigation, potential correlates are Electronic Communication Modes (5 types). The questions are recorded in Appendix B for the Phone, Web Phone, Email, Chat, and Online Newspaper Reading. The intent was to determine how many times each of these modes was used per week in each particular Recollection Period. Although the four Likert-rated dependent variables (feelings of loneliness and isolation, missing family and people of country of origin, not belonging here, and sadness because was of doing things here are not familiar) lend themselves to direct analysis via statistical procedures, three open-ended questions were constructed to allow further interpretation of the feelings that the participants reported. These three items are shown in the following sentences: (1) When you first arrived here, what would have helped you to feel more at home? (2) When you first arrived here, what things made your move here hard (or difficult)? (3) When you first arrived here, what did you do to feel better or to make things easier? As with the rated items, the prefixes were changed to reflect each recollection period. These open-ended items were sorted into various themes, summarized, and 
analyzed for possible relationships to and explanations of the Likert-rated variables.

\section{Procedure}

The research and data gathering took place during February and March 2002. The demographic data-gathering instrument is shown in Appendix A. The rated dependent variables and the interview questions are shown in Appendix B.

Several recruiting methods were used. A list of international students was obtained from the Office of International Students and Scholars (OISS) at West Virginia University. Email messages were sent, and telephone calls were made to invite those students to encourage their spouses to participate in the research. During international student orientation, a table was set up to invite spouses of international students to participate in the research. Letters were placed on doors of international students' homes to invite their spouses to participate in the study. When international students applied for visas for their spouses to come to the United States, the director of OISS gave them a flyer inviting their spouses to join the study. The director of OISS provided the researcher with the names of international students who applied for visas for their wives to come to the United States. The researcher telephoned and/or emailed these students, inviting their spouses to be in the study. 
Participants in the study referred other participants to the researcher. The first 15 spouses who agreed to participate were accepted for the study. Institutional approval for research with human subjects was obtained.

Those who agreed to participate in the study were asked to complete a demographic information sheet (Appendix A). All participants had access to computers and the Internet, either from their homes or on campus. The researcher telephoned and/or emailed the students or their spouses to set up a mutually convenient time for an interview. Spouses were interviewed one time, individually. They were asked to answer the same four scaled questions: When I first arrived here, I felt lonely and isolated; when I first arrived here, I missed my family and people of my national origin; when I first arrived here, I didn't feel like I belonged here; and when I first arrived here, I felt sad because ways of doing things here are not familiar; and the same three open-ended questions: When you first arrived here, what would have helped you to feel more at home? When you first arrived here, what things made your move here hard (or difficult)? and When you first arrived here, what did you do to feel better or to make things easier? for various periods of their time (Recollection Period) here. They were asked about when they first arrived, during the first six months they were here, during the second six months they were here, during the third six months they were 
here, and right now - at the time of the interview (Appendix B). This information was collected and compared across time to assess any changes in culture shock that might be attributed to the use of electronic communication. No interpreter was needed because the only interviews not conducted in English were in Spanish, the researcher's second language. The interviews lasted approximately 1.5 hours each.

\section{Data Analysis}

Descriptive data are reported for the measures used at each Recollection Period. Each of the rated items (feelings) at each Recollection Period had a score ranging from 1 (strongly disagree) to 4 (strongly agree). For example, Feelings of Loneliness and Isolation were reported as means, standard deviations, and ranges at each of the five recollection periods. Analyses of variance were reported for Recollection Period as the independent variable and ratings of feelings as the dependent variables. Multiple comparisons by the Tukey test were reported to show which recollection periods differed in terms of the dependent variables (feelings). Correlations were presented to explicate relationships between electronic communication modes and ratings of feelings, individually by Recollection Period as well as overall (across recollection periods). Chi-square analyses across recollection periods compared expected and observed frequencies of 
ratings of feelings (at and above the median versus below the median) with Electronic Communication Modes (used versus not used). Multiple Stepwise Regressions were computed to determine predictors of feelings of loneliness and isolation, feelings of missing family and people of national origin, feelings of not belonging here and feelings of sadness because ways of doing things here are not familiar. Finally, the interviews were audio taped, transcribed and reviewed by the researcher. As the tapes and transcriptions were reviewed, units of general meaning began to emerge and were categorized into nine themes to further clarify and delineate the information. Common elements were noted, and the open-ended questions were analyzed further to provide additional context for interpretation. 


\section{CHAPTER IV}

Results

In this chapter, results will be reported for Research Questions One through Six as listed in Chapter III. To find the answers to these questions, 15 participants were asked to respond to a series of questions (Appendix B), recalling how they felt when they first arrived in the United States (Recollection Period 1), during the first six months they were here (Recollection Period 2), during the second six months they were here (Recollection Period 3), during the third six months they were here (Recollection Period 4), and right now, at the time of the interview (Recollection Period 5). For the same recollection periods, they were asked to recall (a) how many phone calls per week they made to family back home, to friends back home, to family in the United States, to friends in the United States;

(b) how many web phone calls per week they made to family back home, to friends back home, to family in the United States, to friends in the United States; (c) how many emails per week they sent to family back home, to friends back home, to family in the United States, to friends in the United States; (d) how many chats per week they had with family back home, with friends back home, with family in the United States, with friends in the United States; and (e) how many times per week they read an online newspaper with information from or about back home. This communication information then was collapsed into number of phone calls per 
recollection period, number of web phone calls per recollection period, number of emails per recollection period, number of chats per recollection period, and number of online newspapers read per recollection period.

Means, Standard Deviations, and Ranges are shown in Table 3 for the four Dependent Variables, Feelings of Loneliness and Isolation, Missing Family and People of National Origin, Not Belonging Here, and Sadness Because Ways of Doing Things Here Are Not Familiar. In addition to these four Dependent Variables, there are five Potential Correlates. The Potential Correlates are (a) Phone, which includes the collapsed variables of phone calls to family back home, phone calls to friends back home, phone calls to family in the United States, and Phone calls to friends in the United States; (b) Web Phone, which includes the collapsed variables of web phone calls to family back home, web phone calls to friends back home, web phone calls to family in the United States, and web phone calls to friends in the United States; (c) Email, which includes the collapsed variables of emails to family back home, emails to friends back home, emails to family in the United States, and emails to friends in the United States; (d) Chats, which includes the collapsed variables of chats to family back home, chats to friends back home, chats to family in the United States, and chats to friends in the 
Table 3

Descriptive Statistics

$\begin{array}{lrr}\text { Variable } & \text { Mean } & \begin{array}{c}\text { Standard } \\ \text { Deviation }\end{array}\end{array}$

Feelings of Loneliness and Isolation

Loneliness Recollection Period 1

Loneliness Recollection Period 2

Loneliness Recollection Period 3

Loneliness Recollection Period 4

Loneliness Recollection Period 5
3.07

3.13

2.50

2.08

1.67
1.10

0.92

0.91

0.79

0.72

$1-4$

$1-4$

$1-4$

$1-4$

$1-3$

Missing Family and People of National Origin

Missing Family Recollection Period 1

Missing Family Recollection Period 2

Missing Family Recollection Period 3

Missing Family Recollection Period 4

Missing Family Recollection Period 5
3.73

3.27

2.93

2.83

2.80
0.59

0.88

0.88

1.11

1.01
2-4

$1-4$

$1-4$

$1-4$

$1-4$

Not Belonging Here

Not Belonging Recollection Period 1

Not Belonging Recollection Period 2

Not Belonging Recollection Period 3

Not Belonging Recollection Period 4

Not Belonging Recollection Period 5
2.93

2.73

2.20

2.33

2.00
0.96

0.96

0.86

1.07

0.93
$1-4$

$1-4$

$1-4$

$1-4$

$1-4$

Sadness Because Ways of Doing Things Here Are Not Familiar

Sadness Recollection Period 1

Sadness Recollection Period 2

Sadness Recollection Period 3

Sadness Recollection Period 4

Sadness Recollection Period 5
2.60

2.47

2.00

1.75

1.60
1.06

1.06

0.76

0.75

0.51
$1-4$

1-4

1-3

1-3

1-2 
Table 3 continued

\begin{tabular}{lrrr}
\hline Variable & Mean & Standard & Deviation \\
\end{tabular}

Phone

Phone Recollection Period 1

Phone Recollection Period 2

Phone Recollection Period 3

Phone Recollection Period 4

Phone Recollection Period 5

$\begin{array}{lrr}8.33 & 11.443 & 0-39.5 \\ 5.98 & 9.78 & 0.3-38.0 \\ 6.22 & 10.09 & 0.3-38.0 \\ 4.26 & 5.36 & 0.3-20.2 \\ 6.45 & 8.48 & 0.5-30.3\end{array}$

Web Phone
Web Phone Recollection Period 1

Web Phone Recollection Period 2

Web Phone Recollection Period 3

Web Phone Recollection Period 4

Web Phone Recollection Period 5

Email Recollection Period 1

Email Recollection Period 2

Email Recollection Period 3

Email Recollection Period 4

Email Recollection Period 5

Chat Recollection Period 1

Chat Recollection Period 2

Chat Recollection Period 3

Chat Recollection Period 4

Chat Recollection Period 5

$\begin{array}{llr}1.42 & 3.03 & 0-11 \\ 1.36 & 3.32 & 0-12.5 \\ 1.02 & 2.37 & 0-8.7 \\ 0.14 & 0.31 & 0-1.0 \\ 0.59 & 1.34 & 0-4.5\end{array}$

Email

$\begin{array}{rrr}5.53 & 11.41 & 0-45 \\ 2.62 & 3.34 & 0-12 \\ 2.79 & 3.99 & 0-12.9 \\ 3.05 & 3.55 & 0-9.1 \\ 6.15 & 7.24 & 0-27.5\end{array}$

Chat

$\begin{array}{llr}1.13 & 2.61 & 0-9 \\ 0.45 & 1.30 & 0-5 \\ 0.46 & 0.92 & 0-3 \\ 0.27 & 0.65 & 0-2 \\ 1.01 & 1.53 & 0-4.5\end{array}$

Online News

Online News Recollection Period 1

4.73

5.62

5.66

$0-21$

6.13

7.08

$0-28$

Online News Recollection Period 3

6.28

7.83

$0-28$

8.27

6.96

$0-21$

6.64 
United States; and (e) Online Newspapers, which includes online newspapers containing information about back home. These descriptive statistics appear in Table 3.

Research Question 1

Research Question 1 concerned whether the participants would differ across time (the five recollection periods) in their feelings of loneliness and isolation, missing family and people of their national origin, not belonging here, and sadness because ways of doing things here are not familiar. To provide a partial answer to this question, a one-way analysis of variance was computed for each of the four Dependent Variables (Feelings of Loneliness and Isolation, Missing Family and People of their National Origin, Not Belonging Here, and Sadness Because Ways of Doing Things Here Are Not Familiar). The Independent Variable in each of these analyses of variance was Recollection Period (Arrival - Time 1, During the First Six Months Here - Time 2, During the Second Six Months Here - Time 3, During the Third Six Months Here - Time 4, and Right Now - Time 5).

The one-way analysis of variance for Feelings of Loneliness and Isolation as a Dependent Variable is summarized in Table 4. This analysis of variance with Recollection Period as the Independent Variable, yielded $F(4,53)=11.92, p<$ .01 , indicating a statistically significant finding. Multiple comparisons were computed by the Tukey test to determine which recollection periods differed in 
Table 4

Summary of Analyses of Variance

\begin{tabular}{|c|c|c|c|c|}
\hline $\begin{array}{l}\text { Independent } \\
\text { Variable }\end{array}$ & $\begin{array}{l}\text { Dependent } \\
\text { Variable }\end{array}$ & $d f$ & $F$ & $\begin{array}{l}\text { Level of } \\
\text { Significance }\end{array}$ \\
\hline $\begin{array}{l}\text { Recollection } \\
\text { Period }\end{array}$ & $\begin{array}{l}\text { Loneliness and } \\
\text { Isolation }\end{array}$ & 4,53 & 11.92 & $p<.01$ \\
\hline $\begin{array}{l}\text { Recollection } \\
\text { Period }\end{array}$ & $\begin{array}{l}\text { Missing Family } \\
\text { and People of } \\
\text { National Origin }\end{array}$ & 4,53 & 6.75 & $p<.01$ \\
\hline $\begin{array}{l}\text { Recollection } \\
\text { Period }\end{array}$ & $\begin{array}{l}\text { Not Belonging } \\
\text { Here }\end{array}$ & 4,53 & 8.71 & $p<.01$ \\
\hline $\begin{array}{l}\text { Recollection } \\
\text { Period }\end{array}$ & $\begin{array}{l}\text { Sadness Because } \\
\text { Ways of Doing } \\
\text { Things Are Not } \\
\text { Unfamiliar }\end{array}$ & 4,53 & 6.29 & $p<.01$ \\
\hline
\end{tabular}


terms of Loneliness and Isolation. The means for feelings of Loneliness and Isolation across the recollection periods are depicted in Figure 1, and the Tukey multiple comparisons are reported in Figure 1. The Tukey tests showed that Recollection Period One (Arrival) differed significantly at the .01 level from Recollection Periods Four (During the Third Six Months) and Five (Right Now). Recollection Period Two (During the First Six Months) differed significantly from Recollection Periods Three (During the Second Six Months) at the .05 level, Four (During the Third Six Months) at the .01 level, and Five (Right Now) at the .01 level. Recollection Period Three (During the Second Six Months) differed from Recollection Period Five (Right Now) significantly at the .05 level. A summary of these results is shown in Figure 1.

The one-way analysis of variance for feelings of Missing Family and People of National Origin as a Dependent Variable is summarized in Table 4. This analysis of variance with Recollection Period as the Independent Variable, yielded $\mathrm{F}(4,53)=6.75, \mathrm{p}<.01$, indicating a statistically significant finding. Multiple comparisons were computed by the Tukey test to determine which recollection periods differed in terms of feelings of Missing Family and People of National Origin. The means for feelings of Missing Family and People of National Origin across the recollection periods are depicted in Figure 2. The Tukey tests showed 
Figure 1

Mean Feelings of Loneliness and Isolation Ratings Across the Recollection Periods

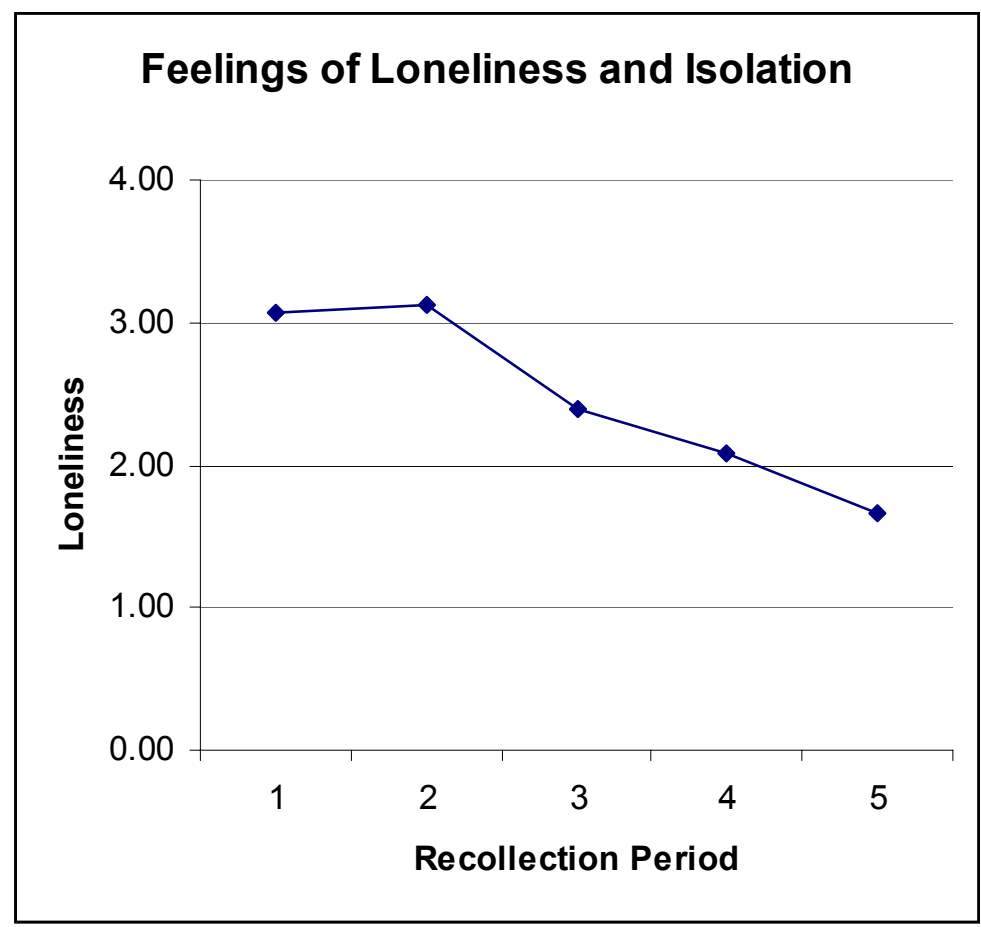

Multiple Comparisons of Means by the Tukey Test

1-2 NS 2-3.05 3-4 NS 4-5 NS

1-3 NS 2-4.01 3-5.05

$1-4.01 \quad 2-5.01$

$1-5.01$

Note. Period $1=$ Arrival.

Period $2=$ During First Six Months Here

Period 3 = During Second Six Months Here

Period $4=$ During Third Six Months Here

Period $5=$ Right Now (Time of Interview) 
Figure 2

Mean Feelings of Missing Family and People of National Origin Ratings Across the Recollection Periods

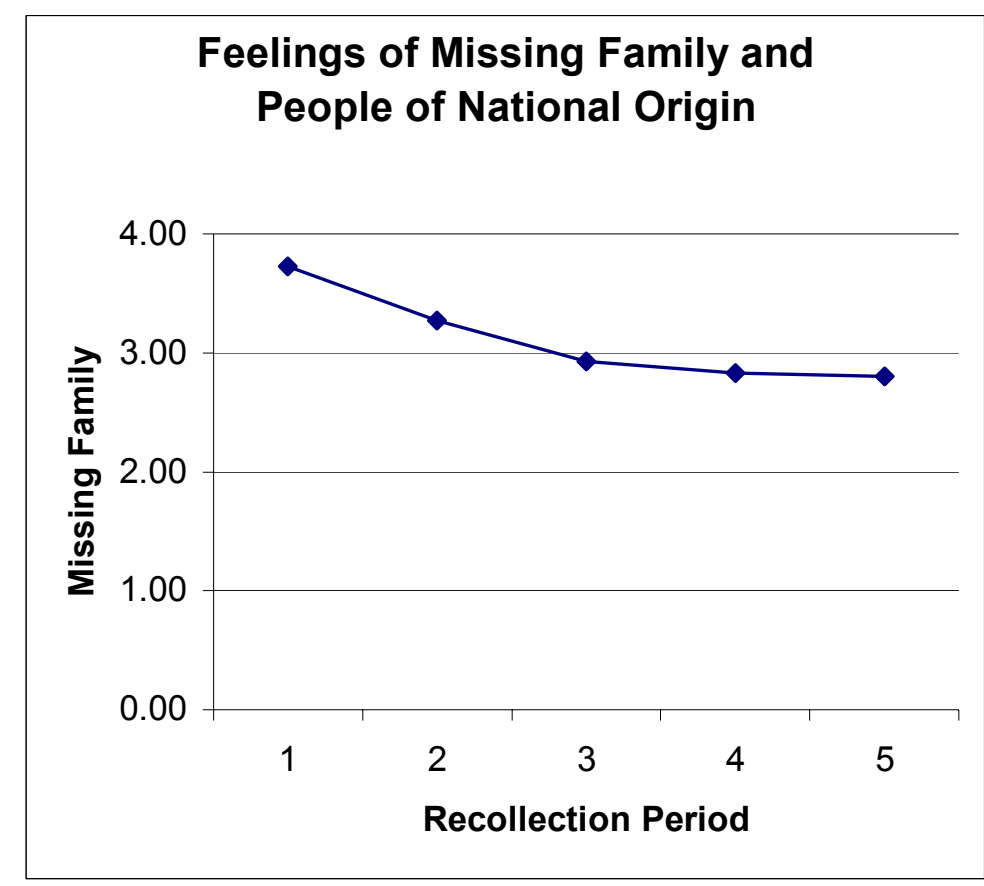

Multiple Comparisons of Means by the Tukey Test

1-2 NS 2-3 NS 3-4 NS 4-5 NS

1-3.01 2-4 NS 3-5 NS

$1-4.01 \quad 2-5 \mathrm{NS}$

$1-5.01$

Note. Period $1=$ Arrival.

Period 2 = During First Six Months Here

Period $3=$ During Second Six Months Here

Period $4=$ During Third Six Months Here

Period $5=$ Right Now (Time of Interview) 
that Recollection Period One (Arrival) differed significantly at the .01 level from Recollection Periods Three (During the Second Six Months), Four (During the Third Six Months), and Five (Right Now). A summary of these results is shown in Figure 2.

The one-way analysis of variance for feelings of Not Belonging Here as a Dependent Variable is summarized in Table 4. This analysis of variance with Recollection Period as the Independent Variable, yielded F $(4,53)=8.71, \mathrm{p}<.01$, indicating a statistically significant finding. Multiple comparisons were computed by the Tukey test to determine which recollection periods differed in terms of feelings of Not Belonging Here. The means for feelings of Not Belonging Here across the recollection periods are depicted in Figure 3. The Tukey tests showed that Recollection Period One (Arrival) differed significantly at the .01 level from Recollection Periods Three (During the Second Six Months) and Five (Right Now), and at the .05 level from Recollection Period Four (During the Third Six Months). Recollection Period Two (During the First Six Months) differed significantly from Recollection Period Three (During the Second Six Months) at the .05 level, and from Five (Right Now) at the .01 level. A summary of these results is shown in Figure 3. 
Figure 3.

Mean Feelings of Not Belonging Across the Recollection Periods

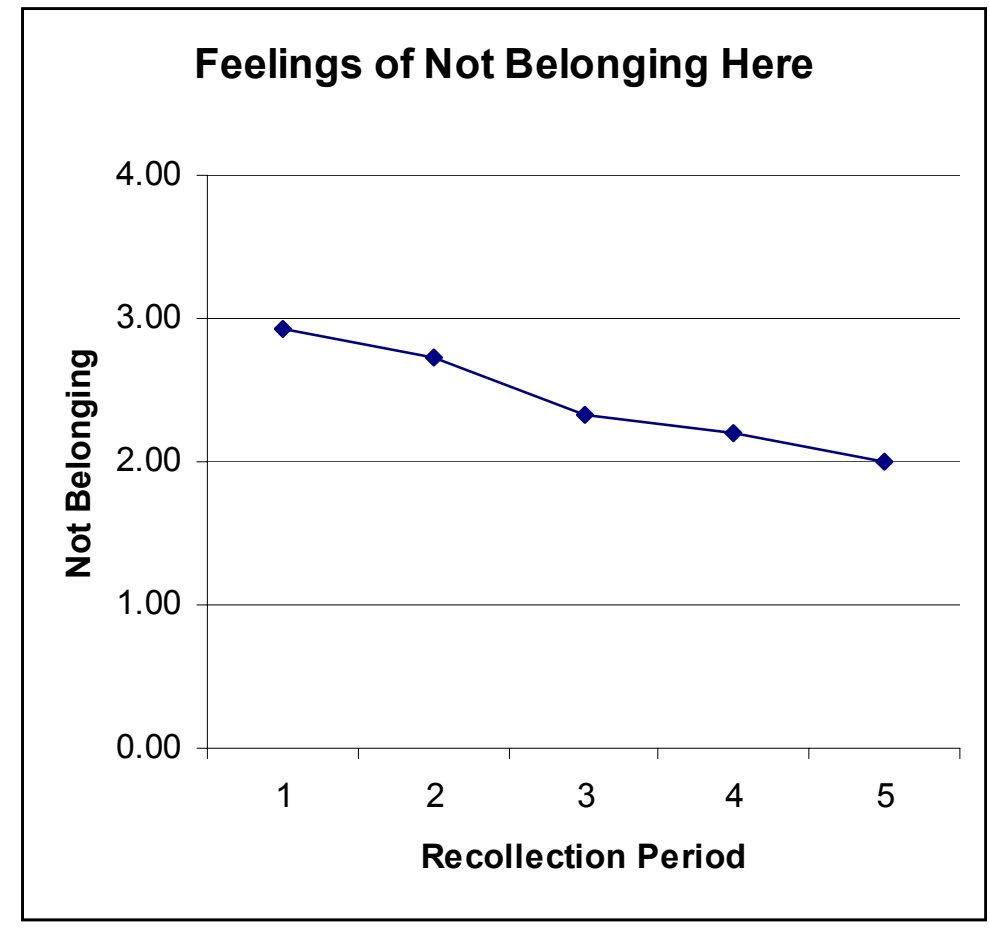

Multiple Comparisons of Means by the Tukey Test

1-2 NS 2-3.05 3-4 NS 4-5 NS

1-3.01 2-4 NS 3-5 NS

$1-4.05 \quad 2-5.01$

$1-5.01$

Note. Period $1=$ Arrival.

Period $2=$ During First Six Months Here

Period 3 = During Second Six Months Here

Period $4=$ During Third Six Months Here

Period 5 = Right Now (Time of Interview) 
The one-way analysis of variance for feelings of Sadness Because Ways of Doing Things Here Are Not Familiar as a Dependent Variable is summarized in Table 4. This analysis of variance with Recollection Period as the Independent Variable, yielded $F(4,53)=6.29, p<.01$, indicating a statistically significant finding. Multiple comparisons were computed by the Tukey test to determine which recollection time periods differed in terms of feelings of Sadness Because Ways of Doing Things Here Are Not Familiar. The means for feelings of Sadness Because Ways of Doing Things Here Are Not Familiar across the recollection periods are depicted in Figure 4. The Tukey tests showed that Recollection Period One (Arrival) differed significantly at the .01 level from Recollection Periods Four (During the Third Six Months) and Five (Right Now). Recollection Period Two (During the First Six Months) differed significantly from Recollection Periods Four (During the Third Six Months) and Five (Right Now) at the .01 level. Recollection Period Three (During the Second Six Months) differed from Recollection Periods Four (During the Third Six Months) and Five (Right Now) significantly at the .01 level. A summary of these results is shown in Figure 4. 
Figure 4

Mean Feelings of Sadness Because Ways of Doing Things Here Are Not Familiar Ratings Across the Recollection Periods

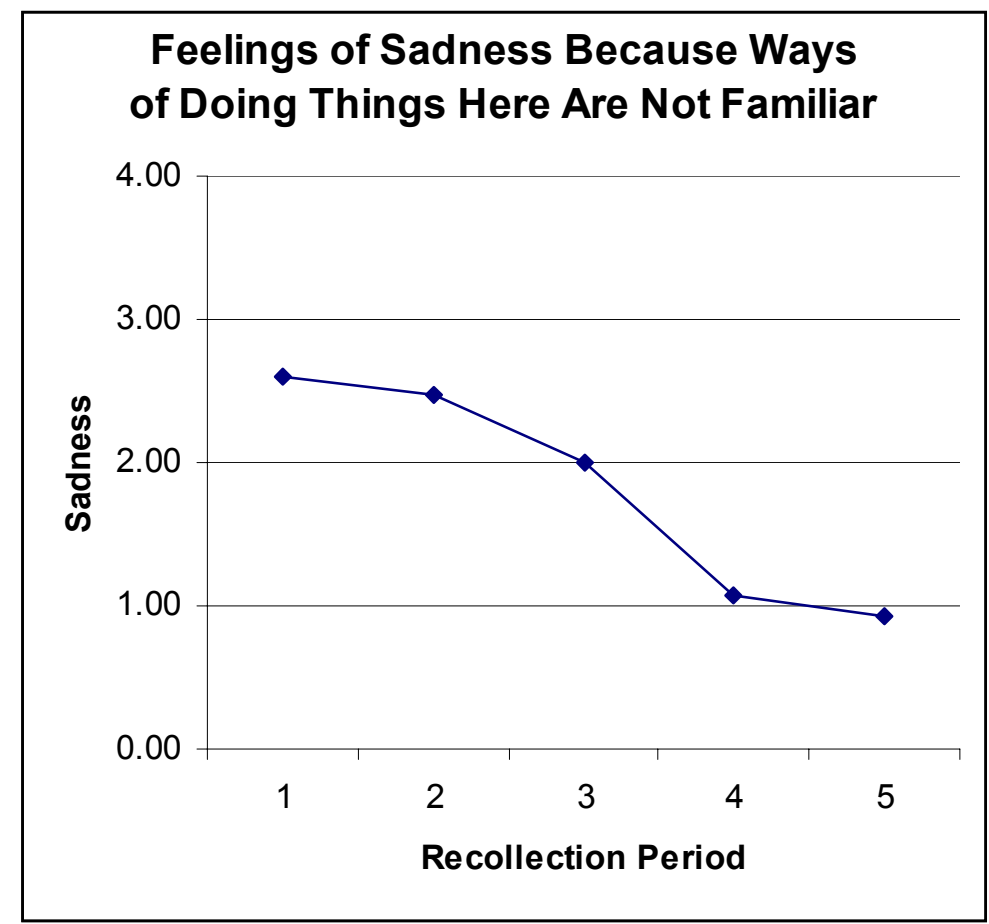

Multiple Comparisons of Means by the Tukey Test

$\begin{array}{llll}1-2 \mathrm{NS} & 2-3 \mathrm{NS} & 3-4.01 & 4-5 \mathrm{NS} \\ 1-3 \mathrm{NS} & 2-4.01 & 3-5.01 & \\ 1-4.01 & 2-5.01 & \\ 1-5.01 & & \end{array}$

Note. Period $1=$ Arrival.

Period $2=$ During First Six Months Here

Period $3=$ During Second Six Months Here

Period $4=$ During Third Six Months Here

Period 5 = Right Now (Time of Interview) 


\section{Research Question 2}

Research Question 2 concerned whether there is a correlation between number of phone calls and levels of feelings of loneliness and isolation, missing family and people of national origin, not belonging here, and sadness because ways of doing things here are not familiar. To provide a partial answer to this question, Pearson correlations were computed between number of phone calls and feelings of loneliness and isolation, between number of phone calls and feelings of missing family and people of national origin, between number of phone calls and feelings of not belonging here, and between number of phone calls and feelings of sadness because ways of doing things here are not familiar. The results are summarized in Table 5. When the observations were not separated by recollection period, phone calls correlated significantly with feelings of sadness because ways of doing things here are not familiar, $r=0.23, p<.05$. When correlation analyses were separated by recollection period, the correlations did not reach significance except in Recollection Period Three. In Recollection Period Three (Second Six Months Here), phone calls correlated significantly with Feelings of Sadness Because Ways of Doing Things Here Are Not Familiar, $r=0.52, p<.05$. The correlations across recollection periods for Research Question 2 are illustrated in Figure 5. 


\section{Table 5}

Pearson Correlation Coefficients

\begin{tabular}{|c|c|c|c|c|}
\hline & $\begin{array}{l}\text { Loneliness and } \\
\text { Isolation }\end{array}$ & $\begin{array}{l}\text { Missing Family } \\
\text { and People of } \\
\text { National Origin }\end{array}$ & $\begin{array}{l}\text { Not Belonging } \\
\text { Here }\end{array}$ & $\begin{array}{l}\text { Sadness Because } \\
\text { Ways of Doing } \\
\text { Things Are Not } \\
\text { Familiar }\end{array}$ \\
\hline \multicolumn{5}{|c|}{ Pearson Correlations Not Separated by Recollection Period } \\
\hline Phone & 0.17 & 0.04 & 0.06 & $0.23 * *$ \\
\hline Web Phone & -0.04 & 0.05 & $-0.30 * * *$ & -0.10 \\
\hline Email & $-0.27 * *$ & -0.17 & $-0.29 * * *$ & $-0.20 *$ \\
\hline Chat & $-0.37 * * *$ & -0.10 & $-0.33 * * *$ & $-0.39 * * *$ \\
\hline Online News & 0.02 & 0.06 & 0.03 & 0.10 \\
\hline \multicolumn{5}{|c|}{ Pearson Correlations Separated by Recollection Period } \\
\hline Recollection P & One & & & \\
\hline Phone & 0.06 & -0.20 & -0.16 & 0.21 \\
\hline Web Phone & $-0.45^{*}$ & $-0.65 * * *$ & $-0.53 * *$ & -0.37 \\
\hline Email & $-0.49 *$ & $-0.72 * * *$ & $-0.59 * *$ & -0.38 \\
\hline Chat & $-0.60 * *$ & $-0.62 * * *$ & $-0.54 * *$ & $-0.63 * * *$ \\
\hline Online News & 0.18 & 0.10 & -0.04 & 0.17 \\
\hline \multicolumn{5}{|c|}{ Recollection Period Two } \\
\hline Phone & 0.30 & 0.26 & 0.21 & 0.34 \\
\hline Web Phone & -0.11 & 0.06 & $-0.50 *$ & 0.04 \\
\hline Email & 0.05 & 0.21 & -0.43 & -0.04 \\
\hline Chat & -0.36 & 0.26 & -0.27 & -0.38 \\
\hline Online News & 0.27 & 0.31 & 0.02 & 0.36 \\
\hline \multicolumn{5}{|c|}{ Recollection Period Three } \\
\hline Phone & 0.30 & 0.03 & 0.07 & $0.52 * *$ \\
\hline Web Phone & 0.01 & 0.24 & -0.41 & $-0.44 *$ \\
\hline Email & -0.09 & 0.20 & -0.26 & -0.38 \\
\hline Chat & $-0.54 * *$ & 0.38 & -0.28 & $-0.51 * *$ \\
\hline Online News & 0.06 & -0.01 & 0.03 & 0.17 \\
\hline \multicolumn{5}{|c|}{ Recollection Period Four } \\
\hline Phone & 0.20 & -0.12 & 0.40 & 0.04 \\
\hline Web Phone & -0.05 & 0.47 & -0.29 & 0.03 \\
\hline Email & -0.24 & -0.02 & -0.19 & -0.13 \\
\hline Chat & -0.26 & 0.02 & $-0.56^{*}$ & -0.45 \\
\hline Online News & 0.13 & 0.17 & 0.21 & 0.36 \\
\hline \multicolumn{5}{|c|}{ Recollection Period Five } \\
\hline Phone & -0.02 & -0.05 & -0.09 & -0.40 \\
\hline Web Phone & 0.15 & 0.20 & -0.13 & -0.22 \\
\hline Email & -0.23 & -0.32 & -0.05 & 0.05 \\
\hline Chat & -0.36 & $-0.47^{*}$ & -0.33 & -0.30 \\
\hline Online News & 0.02 & 0.06 & 0.24 & -0.24 \\
\hline
\end{tabular}

$* * * p<.01$

$* * \quad p<.05$

$* \quad p<.10$ (trend) 
Figure 5

Pearson Correlation Coefficients Ratings Phone Across Recollection Periods

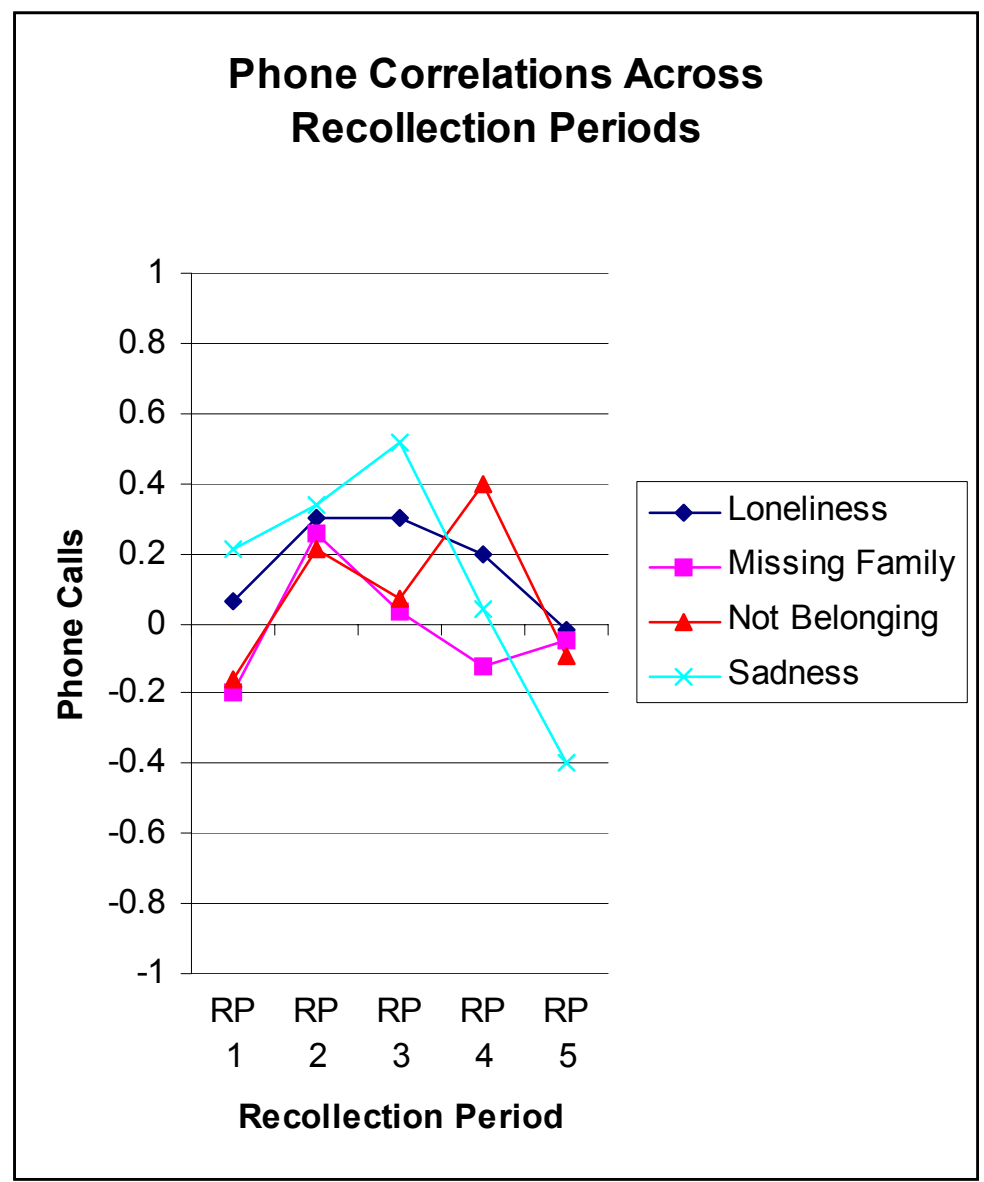




\section{Research Question 3}

Research Question 3 concerned whether there is a correlation between number of web phone calls and levels of feelings of loneliness and isolation, missing family and people of national origin, not belonging here, and sadness because ways of doing things here are not familiar. To provide a partial answer to this question, Pearson correlations were computed between number of web phone calls and feelings of loneliness and isolation, between number of web phone calls and feelings of missing family and people of national origin, between number of web phone calls and feelings of not belonging here, and between number of web phone calls and feelings of sadness because ways of doing things here are not familiar. The results are summarized in Table 5. When the observations were not separated by recollection period, web phone calls correlated significantly with feelings of not belonging here, $r=-0.30, p<.01$. When the observations were separated by recollection period, in Recollection Period One, there was a significant correlation between web phone calls and feelings of missing family and people of national origin, $r=-0.65, p<.01$, and between web phone calls and feelings of not belonging here, $r=-0.53, p<.05$, and there was a trend between web phone calls and feelings of loneliness and isolation, $r=-0.45, p<.10$ (trend). In Recollection Period Two, correlations did not reach significance. However, there was a trend in Recollection Period Two (First Six Months Here) between web 
phone calls and feelings of not belonging here, $r=-0.50, p<.10$ (trend). In Recollection Period Three, correlations did not reach significance. However, there was a trend between web phone calls and feelings of sadness because ways of doing things here are not familiar, $r=-0.44, p<.10$ (trend). Correlations across recollection periods four and five did not reach significance. The correlations across recollection periods for Research Question 3 are illustrated in Figure 6.

\section{Research Question 4}

Research Question 4 concerned whether there is a correlation between number of emails and levels of feelings of loneliness and isolation, missing family and people of national origin, not belonging here, and sadness because ways of doing things here are not familiar. To provide a partial answer to this question, Pearson correlations were computed between number of emails and feelings of loneliness and isolation, between number of emails and feelings of missing family and people of national origin, between number of emails and feelings of not belonging here, and between number of emails and feelings of sadness because ways of doing things here are not familiar. The results are summarized in Table 5 . When the observations were not separated by recollection period, emails correlated significantly with feelings of not belonging here, $r=-0.29, p<.01$ and with

feelings of loneliness and isolation, $r=-0.27, p<.05$. There was also a trend 
Figure 6

Pearson Correlation Coefficients Ratings Web Phone Across Recollection Periods

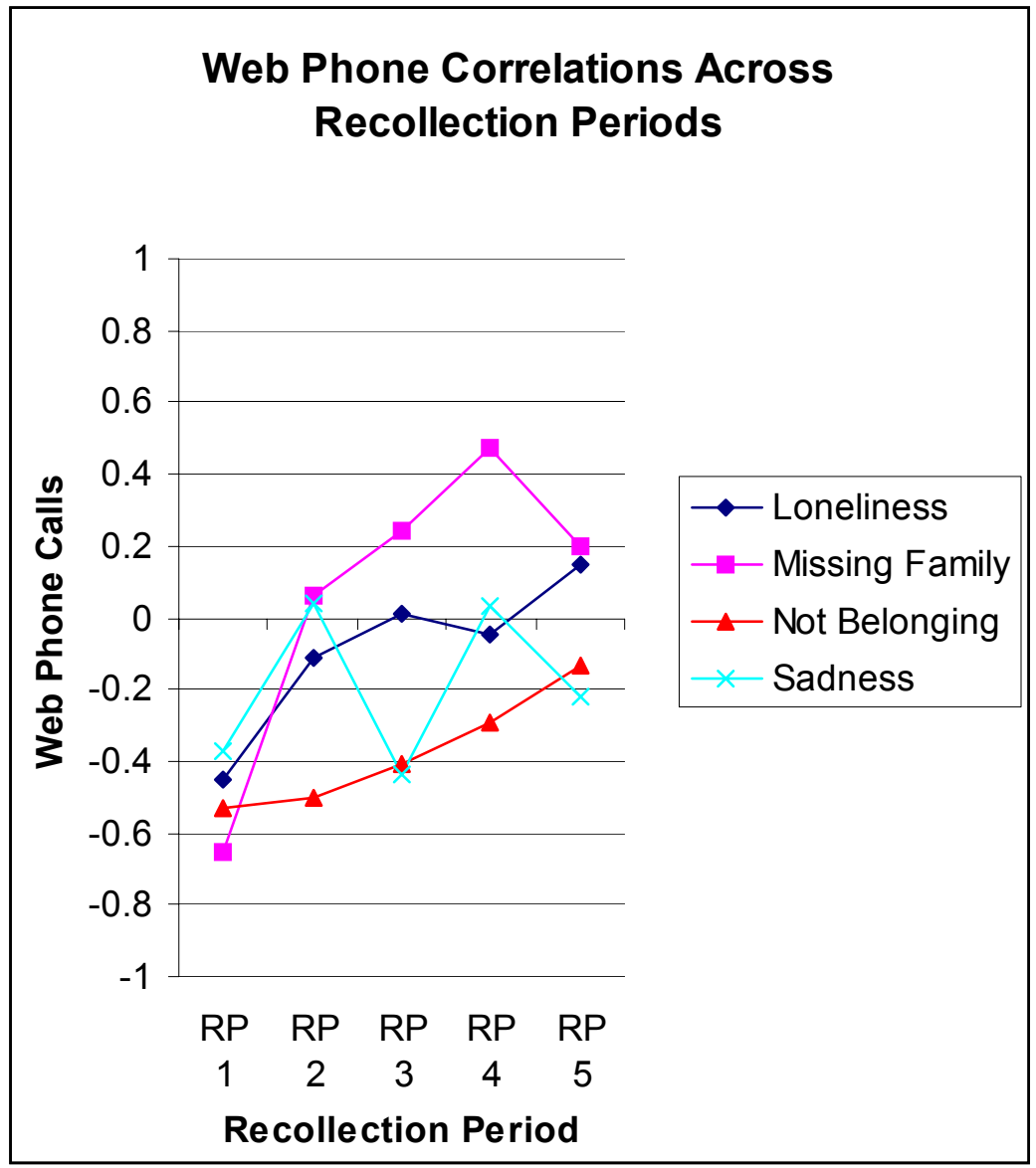


for emails to be correlated with feelings of sadness because ways of doing things here are not familiar, $r=-0.20, p<.10$ (trend). When correlation analyses were separated by recollection period, at Recollection Period One, there was a significant correlation between email and feelings of missing family and people of national origin, $r=-0.72, p<.01$ and between email and feelings of not belonging here, $r=-0.59, p<.05$. There was also a trend between email and feelings of loneliness and isolation, $r=-0.49, p<.10$ (trend). There were no significant correlations at other time periods. The correlations across recollection periods for Research Question 4 are illustrated in Figure 7.

Research Question 5

Research Question 5 concerned whether there is a correlation between number of chats and levels of feelings of loneliness and isolation, missing family and people of national origin, not belonging here, and sadness because ways of doing things here are not familiar. To provide a partial answer to this question, Pearson correlations were computed between number of chats and feelings of loneliness and isolation, between number of chats and feelings of missing family and people of national origin, between number of chats and feelings of not belonging here, and between number of chats and feelings of sadness because ways of doing things here are not familiar. The results are summarized in Table 5. When 
Figure 7

Pearson Correlation Coefficients Ratings Email Across Recollection Periods

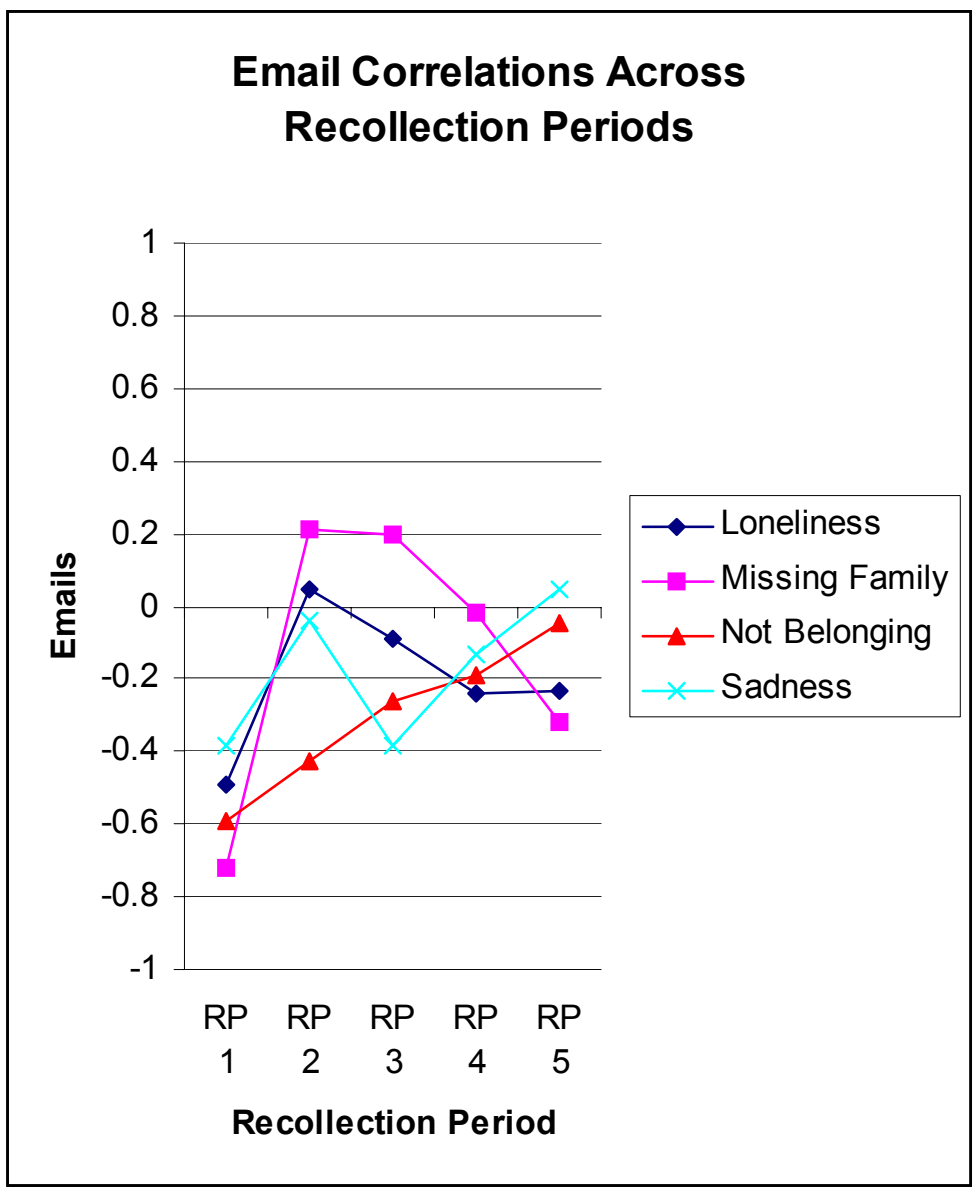


the observations were not separated by recollection period, there were significant correlations between chat and loneliness and isolation, $r=-0.37, p<.01$, between chat and feelings of not belonging here, $r=-0.33, p<.01$, and between chat and feelings of sadness because ways of doing things here are not familiar, $r=-0.39, p$ $<.01$. When correlation analyses were separated by recollection period, in Recollection Period One, significant correlations were found between chat and feelings of sadness because ways of doing things here are not familiar, $r=-0.63, p$ $<.01$, between chat and feelings of missing family and people of national origin, $r$ $=-0.62, p<.01$, between chat and feelings of loneliness and isolation, $r=-0.60, p$ $<.05$, and between chat and feelings of not belonging here, $r=-0.54, p<.05$. In Recollection Period Two, no significant correlations were found. In Recollection Period Three, significant correlations were found between chat and feelings of loneliness and isolation, $r=-0.54, p<.05$ and between chat and feelings of sadness because ways of doing things here are not familiar, $r=-0.51, p<.05$. In Recollection Period Four, there were no significant correlations, but there was a trend between chat and feelings of not belonging here, $r=-0.56, p<.10$ (trend). In Recollection Period Five, there were no significant correlations, but there was a trend between chat and feelings of missing family and people of national origin, $r$ $=-0.47, p<.10$ (trend). The correlations across recollection periods for Research Question 5 are illustrated in Figure 8. 
Figure 8

Pearson Correlation Coefficients Ratings Chat Across Recollection Periods

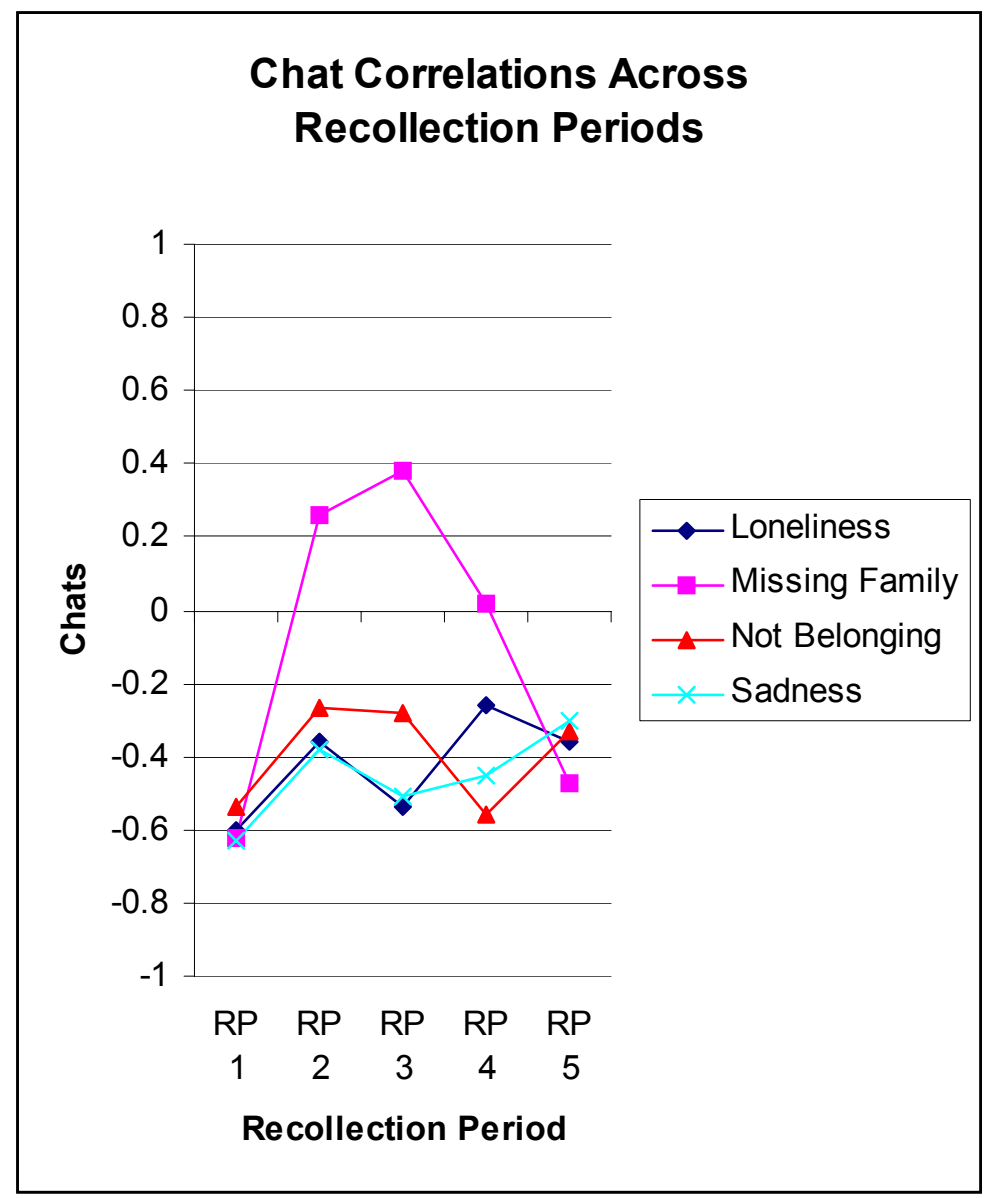




\section{Research Question 6}

Research Question 6 concerned whether there is a correlation between number of times an online newspaper is read and levels of feelings of loneliness and isolation, missing family and people of national origin, not belonging here, and sadness because ways of doing things here are not familiar. To provide a partial answer to this question, Pearson correlations were computed between number of times an online newspaper is read and feelings of loneliness and isolation, between number of times an online newspaper is read and feelings of missing family and people of national origin, between number of times an online newspaper is read and feelings of not belonging here, and between number of times an online newspaper is read and feelings of sadness because ways of doing things here are not familiar. The results are summarized in Table 5. When the observations were not separated by recollection period, there were no significant correlations. When correlation analyses were separated by recollection period, there were no significant correlations. The correlations across recollection periods for Research Question 6 are illustrated in Figure 9. 
Figure 9

Pearson Correlation Coefficients Ratings Reading Online Newspaper Across Recollection Periods

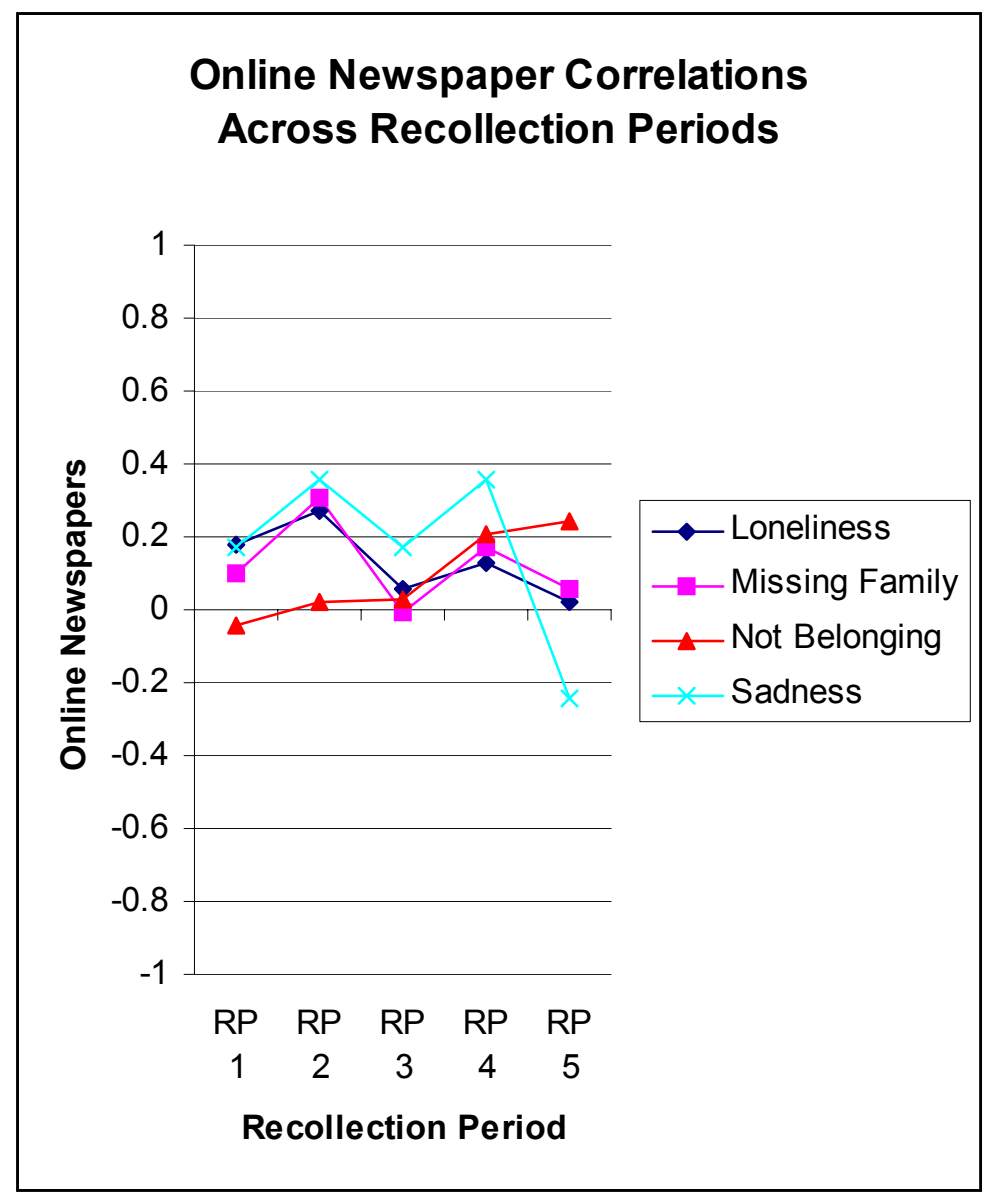


Supplementary Analyses Related to Research Questions Two through Six Chi-square

Supplementary chi-square analyses were computed to provide further information concerning the relationships of concern between rated feelings of the participants and modes of electronic communication technologies. That is, relationships of the electronic communication modes to levels of feelings of loneliness and isolation, missing family and people of national origin, not belonging here, and sadness because ways of doing things here are not familiar are further elucidated in this section. A total of 20 chi-square analyses were computed, as reported in Table 6. Each of these analyses was a four-cell format with two levels of the feelings variable (e.g., at or above the median for feelings of loneliness versus below the median for feelings of loneliness) by two levels of electronic communication (e.g., used versus not used). The number of observations in each of these $2 \times 2$ chi-square analyses was 72 (five recollection periods by 15 people, with three people not reporting for one of the recollection periods). These chi-square analyses yielded six significant findings $(p<.05)$ and are summarized in Table 6.

The analysis for the feelings of loneliness and isolation variable (median split) by chat (used versus not used) yielded $X^{2}=7.08, p<.01$, indicating a 
Table 6

Chi-Square Analyses

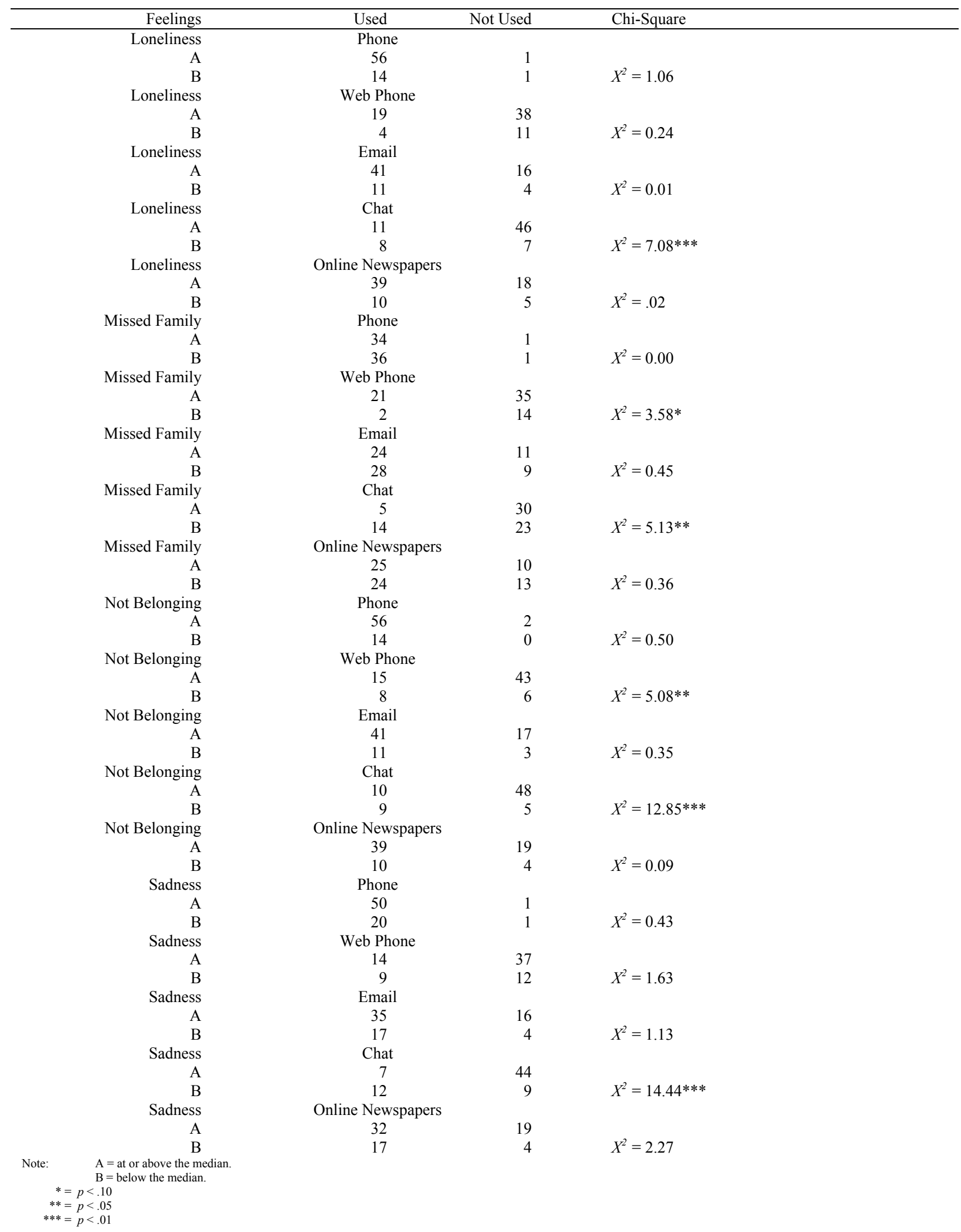


statistically significant relationship between feelings of loneliness and the use of chat. As shown in Table 6, most of the participants did not use chat. Of those who did use chat, about one and one-half times as many were at or above the median for loneliness as were below. Additionally, this relationship is illustrated in Figure 10.

The analysis for the feelings of missing family and people of national origin variable (median split) by web phone calls (used versus not used) yielded $X^{2}=$ $3.58, p<.10$ (trend), indicating a trend toward a statistically significant relationship between feelings of missing family and people of national origin and the use of web phone calls. As shown in Table 6, half as many of the participants did use web phone calls as did not use web phone calls. Of those who did use web phone calls, about one tenth were at or above the median for feelings of missing family and people of national origin as were below. Additionally, this relationship is illustrated in Figure 11.

The analysis for the feelings of missing family and people of national origin variable (median split) by chat (used versus not used) yielded $X^{2}=5.13, p<.05$, indicating a statistically significant relationship between feelings of missing family and people of national origin and the use of chat. As shown in Table 6, most of the participants did not use chat. Of those who did use chat, about one-third as many 
Figure 10

Chi-Square Analysis for Feelings of Loneliness and Isolation by Chat

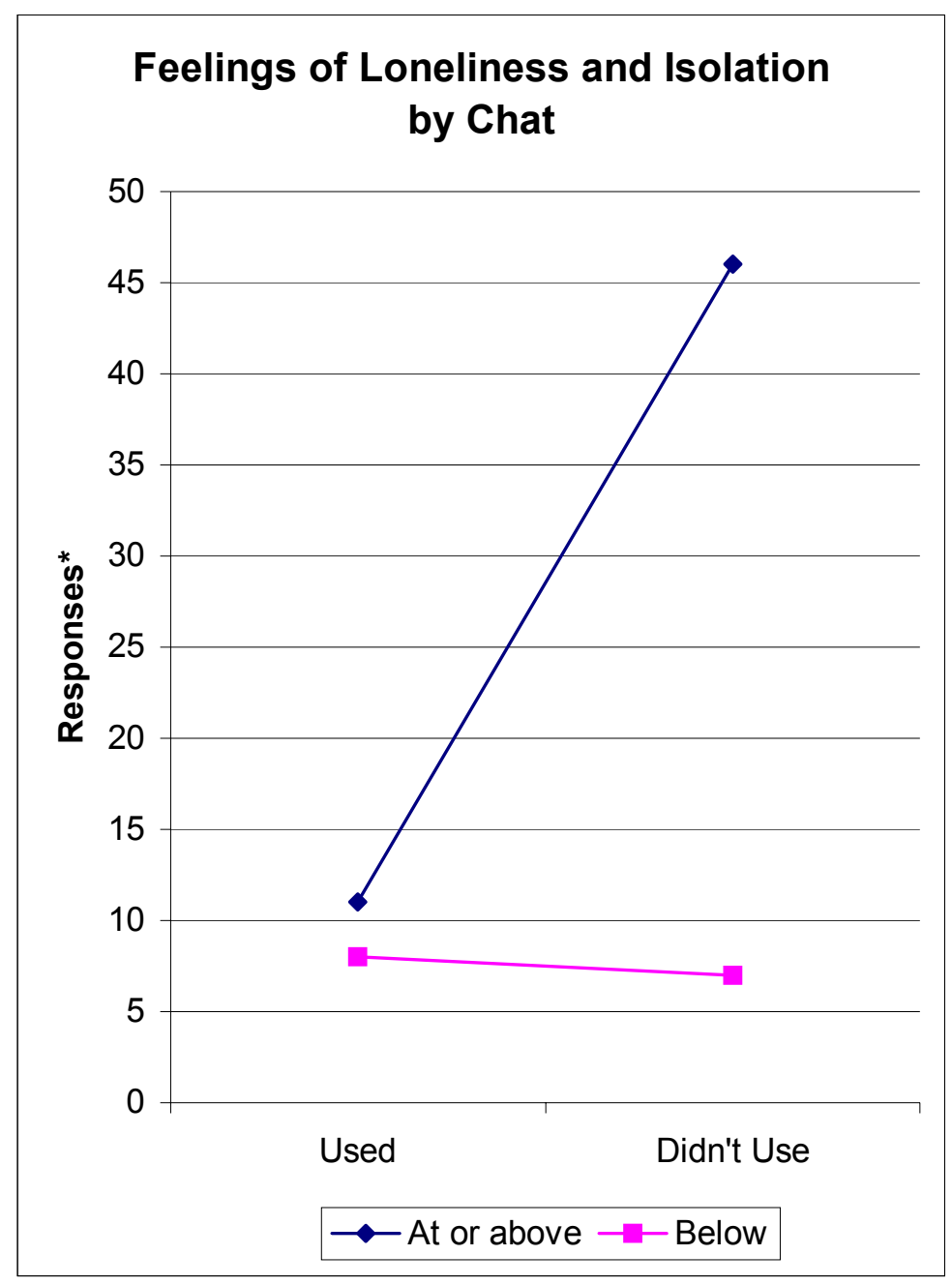

$X^{2}=7.08, p<.01$

*Indicates number of responses out of a possible 72: 15 people times 5 recollection periods (minus 3 recollection periods where 3 participants did not report).

Note: At or above in the legend indicates at or above the median. Below in the legend indicates below the median. 
Figure 11

Chi-Square Analysis for Feelings of Missing Family and People of National Origin by Web Phone

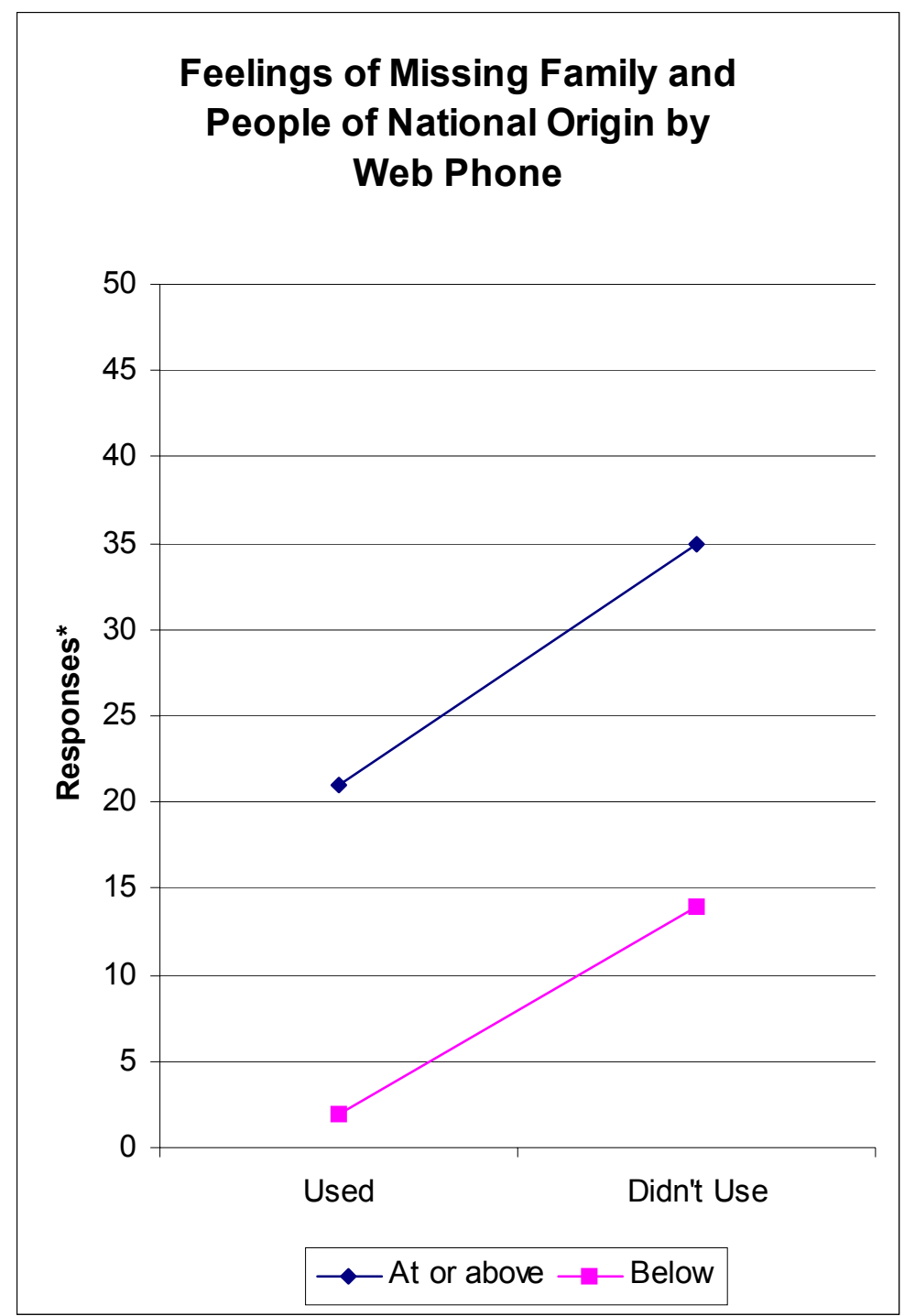

$X^{2}=3.58, p<.10$

*Indicates number of responses out of a possible 72: 15 people times 5 recollection periods (minus 3 recollection periods where 3 participants did not report).

Note: At or above in the legend indicates at or above the median. Below in the legend indicates below the median. 
were at or above the median for feelings of missing family and people of national origin as were below. Additionally, this relationship is illustrated in Figure 12.

The analysis for the feelings of not belonging variable (median split) by web phone calls (used versus not used) yielded $X^{2}=5.08, p<.05$, indicating a statistically significant relationship between feelings of not belonging and the use of web phone calls. As shown in Table 6, most of the participants did not use web phone calls. Of those who did use web phone calls, about twice as many were at or above the median for feelings of missing family and people of national origin as were below. Additionally, this relationship is illustrated in Figure 13.

The analysis for the feelings of not belonging variable (median split) by chat (used versus not used) yielded $X^{2}=12.85, p<.01$, indicating a statistically significant relationship between feelings of not belonging and the use of chat. As shown in Table 6 , most of the participants did not use chat. Of those who did use chat, one more was at or above the median for feelings of not belonging than were below. Additionally, this relationship is illustrated in Figure 14.

The analysis for the feelings of sadness because ways of doing things here are not familiar variable (median split) by chat (used versus not used) yielded $X^{2}=$ $14.44, p<.01$, indicating a statistically significant correlation between feelings of sadness because ways of doing things here are not familiar and the use of chat. As shown in Table 6, most of the participants did not use chat. Of those who did 
Figure 12

Chi-Square Analysis for Feelings of Missing Family and People of National Origin by Chat

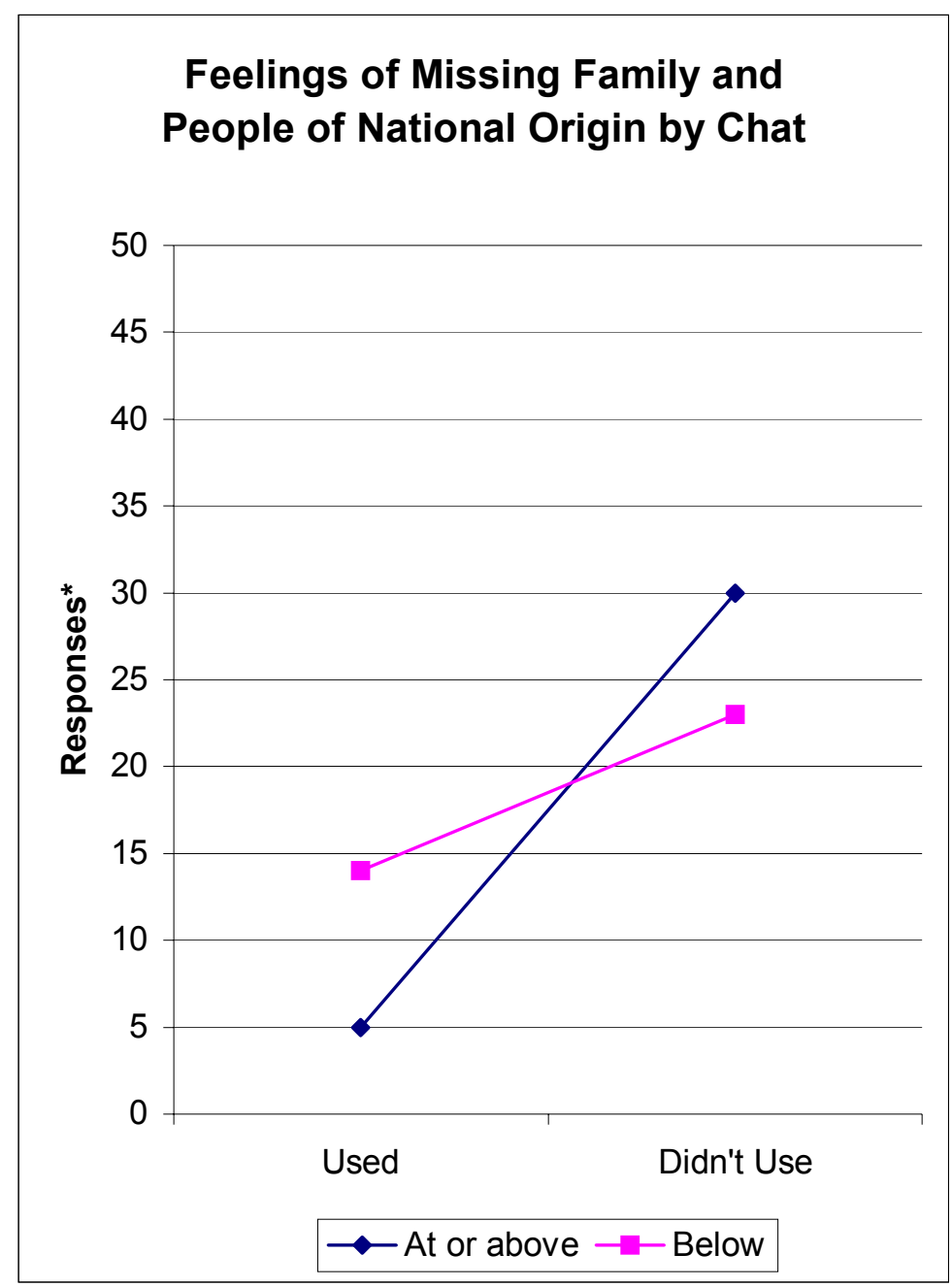

$X^{2}=5.13, p<.05$

*Indicates number of responses out of a possible 72: 15 people times 5 recollection periods (minus 3 recollection periods where 3 participants did not report).

Note: At or above in the legend indicates at or above the median. Below in the legend indicates below the median. 
Figure 13

Chi-Square Analysis for Feelings of Not Belonging by Web Phone

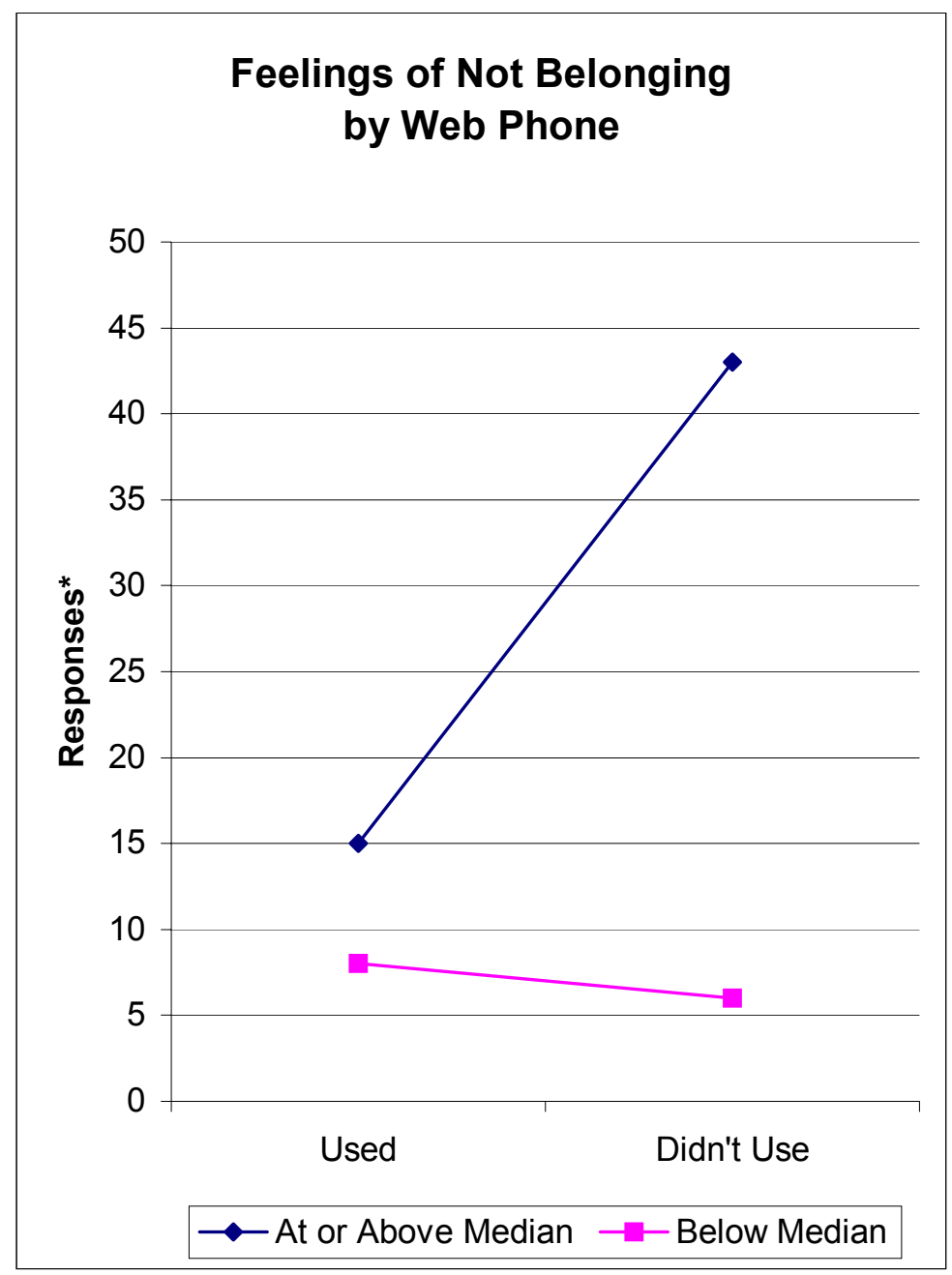

$X^{2}=5.08, p<.05$

*Indicates number of responses out of a possible 72: 15 people times 5 recollection periods (minus 3 recollection periods where 3 participants did not report).

Note: At or above in the legend indicates at or above the median. Below in the legend indicates below the median. 
Figure 14

Chi-Square Analysis for Feelings of Not Belonging by Chat

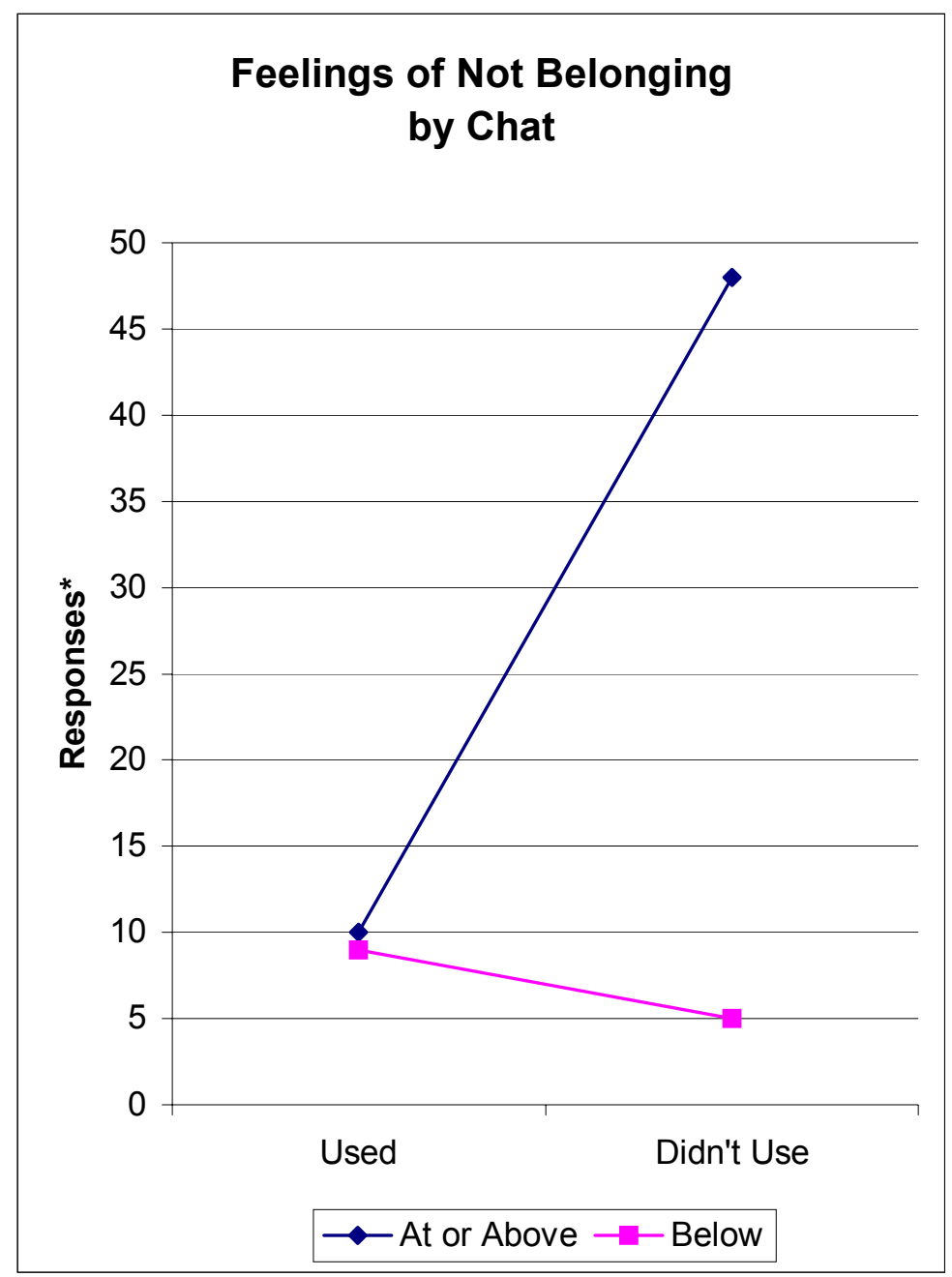

$X^{2}=12.85, p<.01$

*Indicates number of responses out of a possible 72: 15 people times 5 recollection periods (minus 3 recollection periods where 3 participants did not report).

Note: At or above in the legend indicates at or above the median. Below in the legend indicates below the median. 
use chat, about half as many were at or above the median for feelings of sadness because ways of doing things here are not familiar as were below. Additionally, this relationship is illustrated in Figure 15.

\section{Multiple Stepwise Regressions}

Supplementary analyses related to research questions $2,3,4,5$, and 6 were conducted and the predictors are summarized in Table 7. These were stepwise regressions, regressing the communication technologies on feelings of loneliness and isolation, missing family and people of national origin, not belonging here, and sadness because ways of doing things here are not familiar.

A stepwise multiple regression analysis with feelings of loneliness and isolation as the dependent variable, included phone calls, web phone calls, emails, chats, and reading online newspapers as potential predictor variables. This analysis included 72 observations across the five recollection periods. Two variables entered the model for prediction of feelings of loneliness and isolation, accounting for $17.2 \%$ of the variance. These predictors were chat, $\mathrm{F}=14.22, p<.01$, and web phone, $\mathrm{F}=2.94, p<.10$ (trend) and are shown in Table 7 .

A stepwise multiple regression analysis with feelings of missing family and people of national origin as the dependent variable, included phone calls, web phone calls, emails, chats, and reading online newspapers as potential predictor 
Figure 15

Chi-Square Analysis for Feelings of Sadness Because Ways of Doing Things Here Are Not Familiar by Chat

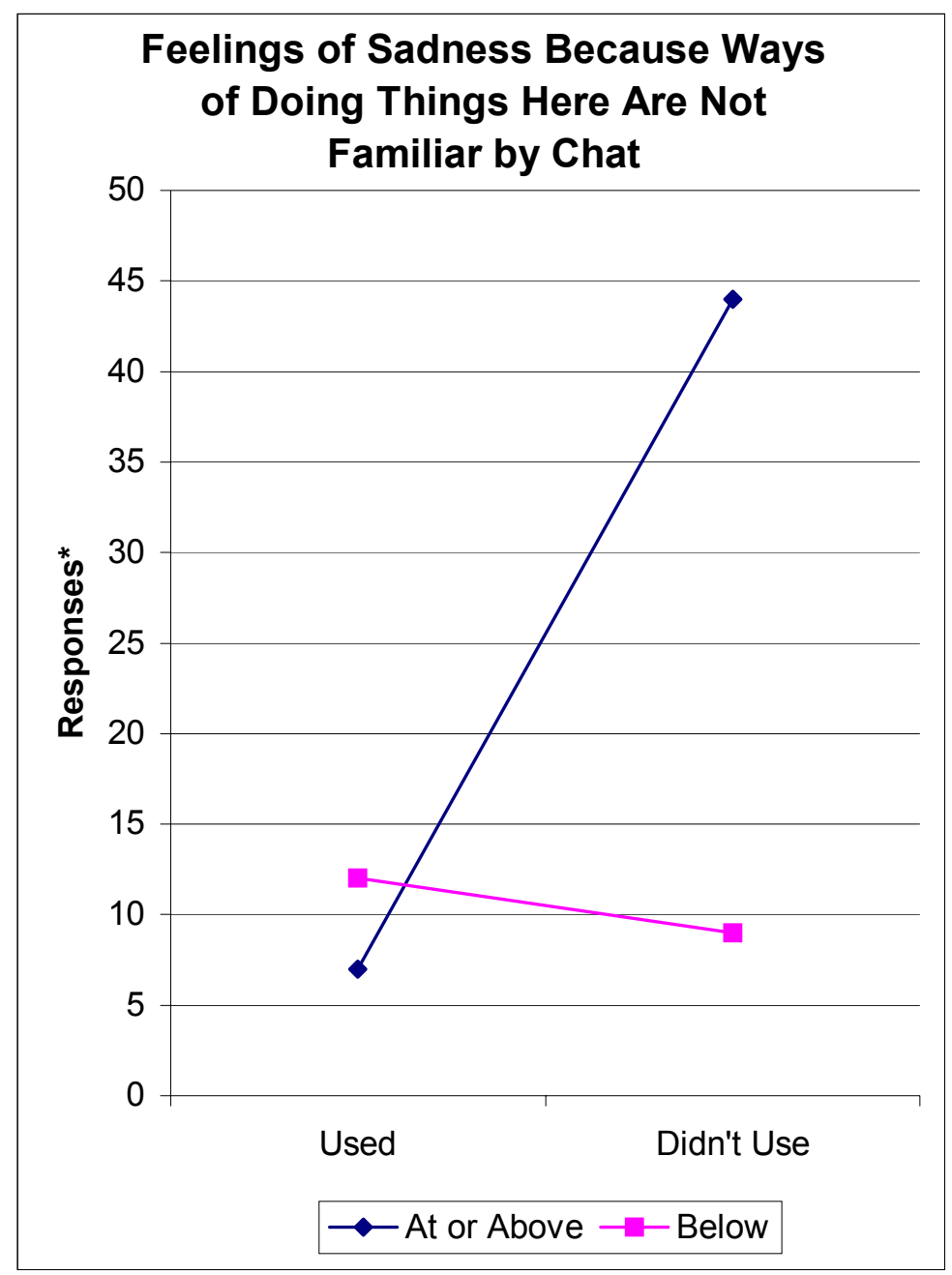

$X^{2}=14.44, p<.01$

*Indicates number of responses out of a possible $72-15$ people times 5 recollection periods (minus 3 recollection periods where 3 participants did not report).

Note: At or above in the legend indicates at or above the median. Below in the legend indicates below the median. 
Table 7

Multiple Stepwise Regressions Analyses for Feelings by Potential Correlates

Dependent Variable

Predictor

F

Feelings of Loneliness and Isolation

Chat

$14.22 * * *$

Feelings of Loneliness and Isolation

Web

$2.94 *$

Phone

Feelings of Not Belonging

Chat

$8.28 * * *$

Feelings of Sadness Because Ways of Doing

Chat

$13.17 * * *$

Things Here Are Not Familiar

Feelings of Sadness Because Ways of Doing

Phone

$4.51 * *$

$$
\begin{array}{r}
* * * p<.01 \\
* * p<.05 \\
* p<.10
\end{array}
$$


variables. This analysis included 72 observations across the five recollection periods. No significant predictors occurred.

A stepwise multiple regression analysis with feelings of not belonging here as the dependent variable, included phone calls, web phone calls, emails, chats, and reading online newspapers as potential predictor variables. This analysis included 72 observations across the five recollection periods. One predictor accounted for $10.6 \%$ of the variance. This predictor was chat, $\mathrm{F}=8.28, p<.01$ and is shown in Table 7.

A stepwise multiple regression analysis with feelings of sadness because ways of doing things here are not familiar as the dependent variable, included phone calls, web phone calls, emails, chats, and reading online newspapers as potential predictor variables. This analysis included 72 observations across the five recollection periods. Two variables entered the model for prediction of feelings of sadness because ways of doing things here are not familiar, accounting for $17.7 \%$ of the variance. These predictors were chat, $\mathrm{F}=13.17, p<.01$, and phone, $\mathrm{F}=$ $4.51, p<.05$ and are shown in Table 7.

\section{Open-Ended Questions}

To allow further interpretation of the dependent variables (feelings of loneliness and isolation, missing family and people of national origin, not belonging here, and sadness because ways of doing things here are not familiar), 
three open-ended questions per Recollection Period were analyzed to further interpret the feelings that the participants reported. These three items are shown in the following sentences: (1) When you first arrived here, what would have helped you to feel more at home? (2) When you first arrived here, what things made your move here hard (or difficult)? (3) When you first arrived here, what did you do to feel better or to make things easier? The prefixes were changed to reflect each recollection period (first arrived in the US, during the first six months in the US, during the second six months in the US, during the third six months in the US, and right now (at the time of the interview). These open-ended items were sorted into various themes, summarized, and analyzed for possible relationships to the Likertrated variables (feelings).

Nine themes emerged and are reported in Table 8. These themes include Language, Study, Transportation, Work, Customs, Personal, Communication, People, Socializing, which were reported by the participants as components that helped them to feel better or made things easier or that made their move here difficult. As problems, the most recurring themes were Language, its co-theme Study, and Transportation. Even those who were fluent in English in their country of origin found that many of the names, such as trousers (pants), or full stop (period), that they had learned for nouns were not the same names used in the 


\title{
Table 8
}

\section{Themes and Categories from Open-Ended Questions}

\author{
Theme Comments by Participants \\ Language $\quad$ Easier to speak in my language \\ Difficulty with special terminology: medical, mechanical \\ Have to think about what I want to say and how to say it before I can say it \\ Worry about grammar, listening, speaking, understanding \\ Because of language, can't shop, understand TV or answer the telephone. \\ I'm excited when others understand my English \\ Study Study English, attend English class \\ Prepare for ToEFL (Test of English as a Foreign Language) \\ Learn English at home, read English \\ English classes from Robert \\ Have to study hard to learn English \\ Part-time IEP (Intensive English Program) student \\ Worry about classes, tests, homework, technology, typing, Power Point presentations for \\ school \\ Entered university \\ Finishing masters \\ Want to go to university, but rules prevent; baby prevents; too expensive \\ Took computer class \\ Teaching myself \\ Attend meetings and conferences \\ Study helps make things easier \\ Transportation \\ No car, lack of transportation, poor transportation, difficulty getting around \\ Can't drive, no license, difficulty getting license \\ Difficult to get groceries, shop, etc \\ Sit at home all day alone with nothing to do \\ Comments for things that made life better included now have car, got my license, can go \\ where I want, getting familiar with environment \\ Work Miss good job \\ Not working here, can't get job here \\ My job not job of my dream \\ Not enough money; things are expensive \\ Have to depend on husband \\ Sit at home with nothing to do \\ Working and earning money helps me to feel better \\ Worked for brother in laundry; gave me money, something to do, self-esteem, a chance to \\ practice English \\ To have good work, getting a good job is hard \\ Babysitting and teaching my language of origin \\ Work helps make things easier \\ Green card obtained
}


Table 8 continued

Theme

Customs

Personal
Comments by Participants

Knew what to expect (adjusted) or wasn't what I expected (not adjusted)

New rules, regulations, what is good to do and what is not

Wanted spices, food, cooking from home, home country life style here, cook like in my country, food is different here

Mementos, pictures from home help

Different culture here makes you lonely

Sharing my culture helps me feel better

Loneliest at Christmas because the customs are so different

Thought about Christmas to feel better

Really miss family at Christmas

I like the society and freedom here

Entry was hard, visa, proofs, visa good for only 6 months

See what others do and follow them

Hear music from my country

Feeling more American

Have adopted this country, this country has many good things to offer, this town has lots to offer and we take advantage

Information from back home is falsified, my country is marginalized, I have no voice, I had to develop a second layer of skin

Things are bad in my country

Better environment in this country, sights

Weather, climate

Knowing there are other internationals in the same process

Keep trying, resign self, try to think all will be okay, accepted, try to cope, meet problem head on, prayer, left behind sad things

Went home to see family (one for a wedding), This was very helpful, I felt worse than ever when I returned to the US

Knowing I can go home some day

Knowing I can't even go home for a visit

Feeling more capable, becoming independent

Tell parents I got good grades

I've learned things and grown in ways that I probably wouldn't have if I had stayed in my country. Kind of new me.

Need strategy to learn faster and easier. It takes a long time to learn to cope.

Deciding what to do and where for the rest of my life

Knowing we were coming to stay when we arrived helped us to adjust

Situation at home is bad, things are bad in my country, better environment in this country

Pregnancy, c-section, felt really alone in hospital, jealous daughter

Second part of pregnancy was better

Work hard, long hours, fall asleep as soon as get home

Information from back home is falsified; my country is marginalized, I have no voice, I had to develop a second layer of skin

Want to travel but can't afford it

Travel helps

Change from large city to small rural town, this town seemed like an ugly farm

Since September 11, I worry that people might mistake me for a terrorist 
Table 8 continued

Theme Comments by Participants

Communication

Talk with friends

Talk with American friends and teachers and other conversations in English

Communicate with other students

Communicate with those back home continually

Communicate with family back home and in the US

Contact with family and friends so they could give me lots of support, keep me going, cheer me up

Keep in touch with family

Don't feel isolated, know the news

More in control, know what's going on

Calling friends and family back home lets me feel like I am home

Can talk to your family and it's like you never left, find out what's going on

Talk with friends and or family by phone is helpful

Many phone calls every day while I was in the hospital helped me feel better.

I called my mother every day to tell her I was bored

Mom has a mobile phone now, so I can reach her anytime

Phone cards are getting cheaper

Calling rates to home cheaper now

Grandmother back home has phone and we can call her cheaply

Sometimes because of the mountains, there is an echo for phone; and other times there is an echo for web phone. It switches back and forth

Internet phone to communicate with family and friends back home as they have email, phone, and web phone

Email friends and family back home

Can email in my language

Technology helps overcome homesickness because use own language

Emails are helpful in getting through the hard times, can't imagine living here without phone and email to keep in touch back home, cheap, fast way to get and send information

Everyone has access now for chat

Chatted with relatives in Croatia. Used net meeting, web phone, and email a lot. Emailing a lot now to family in the Caribbean and London

Used web to find out news about my country

Can design home pages and send to server so friends back home can know about me

Technology makes peoples' lives very easy

Technology is helpful in a good cheap way

The technology helps me relate to my country and family there so I can stay here better

Radio news on Internet

Watch TV, best friend in America

Writing back and forth helped

Now have computer, learning computer, have laptop, can write emails from home now

Got Phone and TV

No books in my language; it's hard to read in English

Brought back books in my language

Big change in technology available back home and here since I've been in the US

Difficult and expensive to get access back home 
Table 8 Continued

Theme Comments by Participants

People

People from my country to help, people to help

People from my country to speak language

New friends from my country, met people from my country

New friends from US, meet new people, American friends, more friends so I don't feel so alone

Spouse and family here

Stay with people from my country or people from my country stay with me

Time with spouse

Spouse typed and prepared Power Point presentations for me for my class

Other students

A confidant, Someone to talk to and do things with

People here are friendly

Everyone was very kind when my baby was born

Neighbors not neighborly

Don't have a lot of friends

Home not a place, but the people

Someone to go with you so you don't get lost

Bring my mom here

Mother came

If my daughter were here

If family and friends were here

Miss family from back home, so far away, miss family and friends and want to be with them

Children complicated life, made it difficult to work or go to school, hard to go out with baby in bad weather, new baby

Family and friends from home now living in US

Our children (cousins) are friends

My children have lived here longer than in my home country

My family likes being here

Lived with grandmother as a child and am very independent

Robert, the English teacher, is very kind and helpful

My child's preschool teacher was very helpful

Play group for child(ren) important

People at OISS were very helpful

Socializing

Spend time outside home, movies, shop, socialize, go fishing, exercise, play with friends, parties, festivals, Lair events, cultural groups, church meetings in native language, Women across Cultures, walk to new places, community activities

Organizing for talks except when reports get it wrong

Wanted to go out, but couldn't

Wanted to invite friends to house, parties, play with child 
United States. Many of those for whom English is a second language had great difficulty with medical terms, which made communication with doctors and hospitals a problem, and with mechanical terms, which made car repairs a challenge. These problems of understanding the terminology not only made communication difficult, but also could have been dangerous if doctor's or mechanic's instructions were misinterpreted. For example, one participant gave birth by Caesarean section while she was here. She was very unhappy because she didn't understand many of the explanations given to her by the doctors and nurses. She felt very alone in spite of receiving many phone calls on a daily basis from friends and family, as well as daily visits from her husband and older daughter.Study was important to the participants. The participants came to the United States with levels of English on a scale of 1 to 5 with 5 being totally fluent, self-rated all the way from 1, not knowing any English to 4. Modesty may have kept them from indicating their level as a 5. All participants were working on developing their level of English, some with formal English classes, some with English classes taught in a local church, and others by watching television, reading and otherwise trying to build their skills on their own. Most, if not all, were interested in pursuing university education while they were here. Some had become university students by the time of the interview and others were working 
toward that objective. For some that was not possible due to visa problems. For others money was an issue.

Most of the participants came from a homeland that had more public transportation than private transportation. Most did not own a car at the time of their arrival and had great difficulty managing tasks like grocery shopping without one. Although there are busses available, many had trouble understanding the schedules which were also inconvenient. One participant expressed concern that someone would become ill and they would not be able to get that person to a doctor due to a lack of timely transportation.

Another very common problem theme was related to Work. Most of the participants had employment in their country of origin, many as professionals. There were an accountant, two college professors, a reporter, a kindergarten teacher, another teacher, an engineer, a research assistant, a technician, two dentists, a commercial loan officer, a bank clerk, and a secretary in a bank. Only one participant was not employed back home. The dentist could get a job only at minimum wage as a dental assistant here. Four of the participants were graduate assistants and one was a research assistant at the time of the interview. One participant was a store clerk. The others were not employed. Some could not get a job because of visa problems. Others had problems with discrimination. Some 
were full-time students. Being without a job made them feel sad and dependent on their husbands. Being without a job also gave them financial worries.

Several of the participants mentioned problems with Customs in the United States. They weren't sure whether something was good to do or not good to do. They didn't understand how friendship and family relationships in this country work. Differences in the ways holidays are observed here from the ways they are celebrated back home increased feelings of homesickness during those holiday times, particularly Christmas and New Year's. For example, in Hispanic countries, Christmas is a nine-day celebration with lots of visiting and singing. Extended families are together during this time. The crèche is more of a focal point there while in the United States, the Christmas tree takes first notice. Some missed music from back home. Some felt that their country was marginalized here. Customs with raising children also created feelings of sadness. One participant reported that in her country the village was responsible for the child, and the behavior that was normal there would be considered child neglect here. One participant said that he knew what to expect because he had attended an American University in his home country and so was very comfortable here, while another participant said that if she had known what to expect, she probably would only have come for occasional visits rather than to live here with her husband while he finished school. 
The theme labeled Personal included components personal to the participant. For one the weather and climate were reported as a problem, because it was hard to take her baby out in cold, snowy weather. For another, the fact that she had come to a small, rural town in the United States from a large, urban area in her country or origin led her to say that her town here seemed like an "ugly farm" to her. Bad political situations at home caused concern for those left behind while producing gratitude for the safety here. One participant reported that since September 11, she was not as comfortable here because she was afraid she might be mistaken for a terrorist because she was a "foreigner." On the other hand, she felt more comfortable with our society than with the one back home, which was much more restrictive for women. Women were not allowed to go out without their husbands, nor were they allowed to eat before the rest of the family and any guests were finished. She stated that she likes the freedoms here.

The participants all listed Communication as being very important to their adjustment here. This communication included face-to-face communication with family, friends, and others, phone calls, emails, chats, web phone calls, reading newspapers online, watching television, listening to Internet radio, and reading books. Benefits of communication included staying informed, being able to communicate in their first language, not feeling isolated, feeling in control, keeping in touch, feeling "like I am home," not feeling left out, receiving moral 
support, and receiving needed information in a rapid fashion. The participants praised electronic communication methods as fast, cheap or free, and easy. They pointed out that phone cards are getting cheaper and cheaper and that accessibility is growing all the time, especially with the use of mobile phones. However, others pointed out that access is still expensive and difficult in their countries of origin.

For all of the participants, People was a theme of great importance in their adjustment to being here. This included spouses and family that were here with them, new friends from their country of origin, new friends from countries other than the United States, and new friends from the United States, as well as family and friends from back home that they were able to communicate with regularly. Most reported missing family and friends back home as a major problem although one participant indicated that she had not been raised by her parents and so she had learned to be independent at a very young age. The participants talked about the importance of being able to speak to others in their language of origin, to be able to get help from others from their country of origin, and to be able to communicate with people here in the English language. One said the people here were kind; another said they were friendly; still another said they were not neighborly, but they all needed to feel close to the people. Friendship was very important to them to have someone to help them find out things, to help them with the language, to talk with as a confidant, and just to provide support in general. 
The theme of Socializing was where people listed many of the things they do to get over feelings of loneliness, missing family, not belonging, and sadness. Activities included going for walks, going fishing, shopping, going to movies, exercising, playing with friends, going to parties, festivals, and cultural events, attending church services in their first language, attending community activities, organizing talks, inviting friends for parties, and playing with their children. Also mentioned was Women Across Cultures, a group that gets together weekly to share cultural information from member countries of origin, to visit places of interest in the area, and to learn about the local culture and customs.

\section{Summary of Results}

In order to answer six research questions, 15 participants were asked to rate over five recollection periods (independent variables) their feelings (dependent variables) related to culture shock. They also were asked to respond to three openended questions for each recollection period. Five modes of electronic communication (potential correlates) were also compared across recollection periods (see Appendix B). Means, Standard Deviations, and Ranges were reported in Table 3 for the four dependent variables. A summary of significant findings is shown in Table 9.

In order to answer the first research question, analyses of variance were computed for each of the dependent variables with Recollection Period as the 
Table 9

Summary of Significant Results

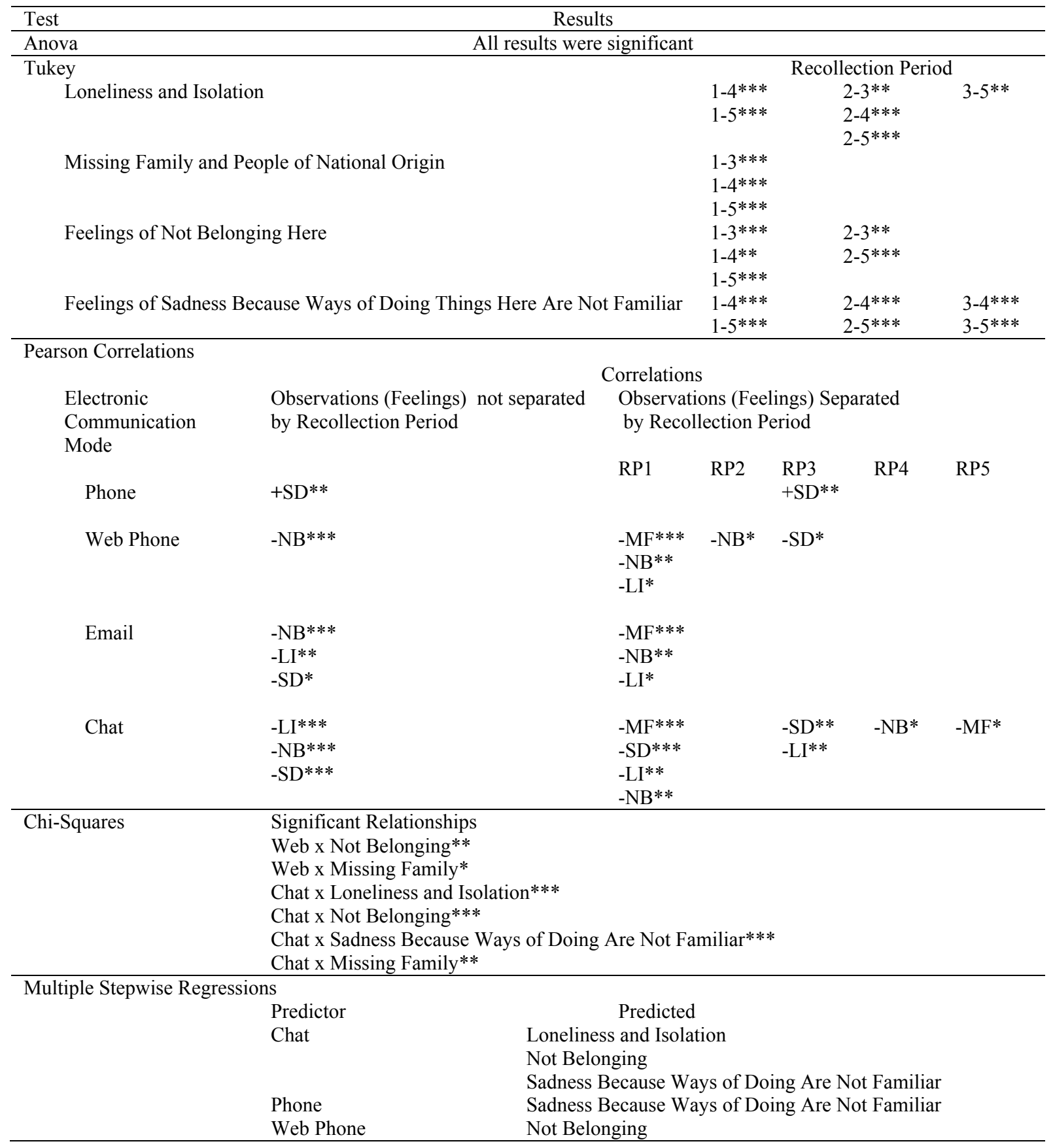

Note: Explanation of Abbreviations in Table:

$\mathrm{LI}=$ Feelings of Loneliness and Isolation

$\mathrm{MF}=$ Feelings of Missing Family and People of National Origin

$\mathrm{NB}=$ Feelings of Not Belonging Here

$\mathrm{SD}=$ Feelings of Sadness Because Ways of Doing Things Here Are Not Familiar

$\mathrm{RP}=$ Recollection Period

$* p<.10$

$* * p<.05$

$* * * p<.01$ 
independent variable. These analyses of variance showed statistically significant results for each of the dependent variables by recollection period and are summarized in Table 4. Tukey tests were computed to see where the significant differences occurred. The significant results are summarized in Table 9.

To provide answers for Research Questions Two through Six, Pearson correlations, Chi-squares, and multiple stepwise regressions were computed. The significant results were summarized in Table 9. Open-ended questions were analyzed to provide further interpretation of the quantitative data. Nine themes emerged and were summarized in Table 8 . These themes included: Language, Study, Transportation, Work, Customs, Personal, Communication, People, and Socializing. 


\section{CHAPTER V}

Discussion, Conclusions, Recommendations

This chapter includes a discussion of the findings and conclusions that were made in relation to six research questions along with recommendations for future research. These research questions are listed in Chapter III.

\section{Research Question 1}

Is there a difference across time in the levels experienced by participants of feelings of loneliness and isolation, missing family and people of national origin, not belonging here, and sadness because ways of doing things here are not familiar?

Analyses of variance showed that there were changes in levels of feelings of loneliness and isolation, missing family and people of national origin, not belonging here, and sadness because ways of doing things here are not familiar, as was reported in Table 4. Some of the participants expressed that they had experienced excitement during their first-arrival recollection period, "Everything was wonderful, pretty, so nice," which fits with Winkelman's (1994) “honeymoon phase.” Others discussed going through a period when they couldn't go out, couldn't answer the telephone, didn't trust the neighbors to help in an emergency. This compares with Winkelman's and Olson's (1985) second phase or crisis phase. Participants 
talked about accepting the situation or resigning themselves to be here as Winkelman described as an important step in adapting to a new culture. One participant talked about feeling angry toward her spouse, which Winkelman mentioned as a symptom of culture shock. McKinlay et al. (1996) recommended pairing co-nationals and having links home rather than emphasizing integrating international students to help them adjust. The participants talked about their need to communicate with family back home. They also described the importance of being able to make a phone call to someone who had been here for a while to ask a question, in their own language, such as, how to find something for cooking or even just for moral support. Shigaki and Smith (1997) pointed out the need to learn the language to express oneself. They also indicated that those international students who have positive relationships with American students adjust better. Nearly all students indicated that language was a major problem in adjusting here. Many participants mentioned English classes and the Women Across Cultures group as helping them to acquire the skills they needed to survive in their new culture. Several participants expressed how helpful it had been to develop friendships with Americans and other international students. They said talking with other international students helped them to realize that others were experiencing similar difficulties. Churchman and Mitrani 
(1997) indicated that in order to adjust to a new culture, one needs a social support network, an ability to control and predict, and an ability to choose. Those who were most comfortable with the culture according to their scores on the ratings questions, had developed these abilities through a social support network including their spouses, other international students and spouses, especially co-nationals, and friends and teachers they had met here. In conclusion, most of the participants reached at least the third stage, adjustment, reorientation, and gradual recovery as described by Winkelman (1994) or the move to accept the new culture as described by Olson (1985). A few even appeared to be in the fourth stage of assimilating the new culture or becoming bicultural. That is to say that in answer to Research Question One, there was a positive difference across time in the levels experienced by participants of feelings of loneliness and isolation, missing family and people of national origin, not belonging here, and sadness because ways of doing things here are not familiar, especially after being here for 1.5 years.

\section{Research Question 2}

Is there a correlation between number of phone calls and levels of feelings of loneliness and isolation, missing family and people of national origin, not belonging here, and sadness because ways of doing things here are not familiar? 
Pearson correlations (summarized in Table 5) showed that there was a positive correlation $(p<.05)$ between making phone calls and feelings of sadness because ways of doing things here are not familiar when the observations were not separated by recollection period and also during their second six months in the United States. In other words, when feelings of sadness increased, the number of telephone calls increased. Multiple stepwise regressions showed phone as a predictor $(p<.05)$ for feelings of sadness because ways of doing things here are not familiar. In the openended questions, participants indicated that they did indeed call home when they were feeling sad and confused. It is likely that this correlation did not show up with a higher level of significance here or at any level of significance during other times because phone calls were something that all the participants used during all recollection periods. The only exception was during the first time period of one participant who came to the U.S. in the middle of a telephone company strike and was not able to make phone calls during her first week here. In conclusion, increased feelings of sadness because ways of doing things here are not familiar led participants to use the telephone more, perhaps because they could find out how to do things and probably because using the telephone to communicate with others did make 
them feel better, and when there was less sadness, they didn't use the phone as much.

It is interesting to note that phone had a positive correlation with feelings of sadness because ways of doing things here are not familiar, while chat had a negative correlation. All the participants used phone calls over all the recollection periods (with the exception of one participant who experienced a telephone company strike during her first two recollection periods). The number of phone calls decreased over time, but all participants continued to use phone calls. Less than half of the participants ever used chat. Some participants did not have access to chat until the fourth or fifth recollection periods. The lack of access to chat and the lack of use, along with the small $n$, most likely skewed the data. Participants who had access to chat in the earlier recollection periods decreased their use in the latter recollection periods as they got busy with other things such as school or work. Therefore, chat users increased, while individual chat use decreased. Research Question 3

Is there a correlation between number of web phone calls and levels of feelings of loneliness and isolation, missing family and people of national origin, not belonging here, and sadness because ways of doing things here are not familiar? 
Pearson correlations (summarized in Table 5) showed that there was a significant negative correlation between web phone calls and feelings of not belonging here when the observations were not separated by recollection period $(p<.01)$ and also at the time of arrival $(p<.05)$. Pearson correlations also indicated a trend toward a significant negative correlation $(p<.10)$ during the first six months here. When separated by recollection period, the correlation coefficients, though not all significant, went down each successive recollection period $(\mathrm{RP} 1=-0.53, \mathrm{RP} 2=-0.50, \mathrm{RP} 3=-0.41, \mathrm{RP} 4$ $=-.29$, and RP5 $=-0.13$ ). Mean levels of feelings of not belonging also declined from recollection periods one to three, and from four to five (RP1 $=$ $2.93, \mathrm{RP} 2=2.73, \mathrm{RP} 3=2.20, \mathrm{RP} 4=2.33$, and RP5 $=2.00)$. In general, as feelings of not belonging here decreased, the negative correlations with web phone also decreased. Therefore, even though the negative correlations indicated that when feelings of not belonging here were high, use of web phone was low, and when feelings of not belonging were low, use of web phone was high, the fact that this negative correlation weakened over time indicated that web phone calls may have helped to reduce the feelings of not belonging. This conclusion is supported by the Chi-square test, which indicated a significant relationship $(p<.05)$ between web phone and feelings of not belonging. Most people did not use web phone. Web phone is a fairly 
new technology and some participants indicated that they didn't know that it existed while others said they knew about it but didn't know how to use it or that they had tried to use it unsuccessfully. Of those who did use web phone, nearly twice as many were at or above the median for feelings of not belonging than were below the median. In other words, more of those who used web phone felt like they didn't belong here than felt like they did belong here. This relationship indicates that they were more likely to use web phone if they were feeling they did not belong here than if they felt they did belong here. Participants who used web phone did indicate, in their responses to open-ended questions, that they felt so much better when they could talk to friends and family by web phone. In conclusion, most did not use web phone. Of those who did use web phone, more felt like they did not belong here than felt like they did. As web phone helped the participants to feel better, they used it less. Also, web phone was free when the participants arrived in the United States, but after the participants had been here awhile, it was no longer free to make international calls.

Pearson correlations (summarized in Table 5) showed that there was a significant negative correlation $(p<.01)$ between web phone calls and feelings of missing family and people of national origin on arrival of the participants. In other words, the more they missed their families, the less 
they used web phone. This could have indicated that they were so despondent that they didn't use web phone calls. It could also have meant that when they felt better they felt more like learning to use the new technology. Many people did not have access to computers at home when they first arrived and some did not have people to call who had access to web phone. Over time, the correlation, though not significant, became positive $(\mathrm{RP} 1=-0.65, \mathrm{RP} 2=0.06, \mathrm{RP} 3=0.24, \mathrm{RP} 4=0.47$, and $\mathrm{RP} 5=.20)$ as median levels of missing family and people of national origin decreased $(\mathrm{RP} 1=3.73, \mathrm{RP} 2=3.27, \mathrm{RP} 3=2.93, \mathrm{RP} 4=2.83$, and $\mathrm{RP} 5=2.80)$, which indicated that web phone calls may have helped decrease feelings of missing family and people of national origin. A chi-square test indicated that there was a relationship between use of web phone and feelings of missing family and people of national origin with a trend toward significance $(p<.10)$. Most people did not use web phone. Of those who did use web phone, ten times as many were above the median in feelings of missing family and people of national origin as were below, which indicated that they were more likely to use web phone if they were missing family than if they were not. This indicated that they thought using web phone would make them feel better and, in fact, many reported in the open-ended questions that talking with family and friends back home did make them feel better. In conclusion, 
web phone probably did help to decrease feelings of missing family and people of national origin.

Pearson correlations (summarized in Table 5) showed that there was a trend $(p<.10)$ toward a significant negative correlation between web phone calls and feelings of loneliness and isolation upon arrival of the participants. In other words, of those who used web phone, more felt lonely and isolated than did not. When separated by recollection period, the correlation coefficients, though not all significant, went toward positive correlation (except from recollection period three to recollection period four when it was barely negative), even reaching positive correlation in recollection periods four and five $(\mathrm{RP} 1=-0.04, \mathrm{RP} 2=-0.45, \mathrm{RP} 3=-0.11, \mathrm{RP} 4=.01$, and RP5 $=0.15$ ). Mean levels of feelings of loneliness and isolation increased slightly from the first to the second recollection periods but then declined for each succeeding recollection period $(\mathrm{RP} 1=3.07, \mathrm{RP} 2=3.13$, $\mathrm{RP} 3=2.50, \mathrm{RP} 4=2.08$, and RP5 $=1.67)$ following the same pattern as the correlation coefficients. In general, as feelings of loneliness and isolation decreased, the negative correlations with web phone also decreased. Therefore, even though the negative correlations indicated that when feelings of loneliness and isolation were high, use of web phone was low, and when feelings of loneliness and isolation were low, use of web phone 
was high, the fact that this negative correlation weakened over time indicated that web phone calls reduced the feelings of loneliness and isolation. Most did not use web phone. Of those who did, five times as many were at or above the median for feelings of loneliness and isolation than were below. In other words, the more they felt lonely and isolated, the more they used web phone. This conclusion is supported by the multiple stepwise regressions, which indicated that web phone was a predictor for loneliness and isolation with a trend toward significance. Open-ended question responses also indicated that using web phone to call home reduced loneliness and isolation. In conclusion, most did not use web phone. Of those who did use web phone, those who felt lonely and isolated were more likely to use web phone. As web phone helped them to feel better, they used it less.

Pearson correlations (summarized in Table 5) indicated a trend $(p<$ .10) toward a significant negative correlation between web phone calls and feelings of sadness because ways of doing things here are not familiar during the second six months the participants were here. This means that as use of web phone increased, feelings of sadness because ways of doing things here are not familiar decreased. However, since this was only a trend and not supported by significant correlations or other tests, it was ignored. 


\section{Research Question 4}

Is there a correlation between number of emails and levels of feelings of loneliness and isolation, missing family and people of national origin, not belonging here, and sadness because ways of doing things here are not familiar?

Pearson correlations (summarized in Table 5) showed that there was a significant negative correlation between email and feelings of not belonging here when the observations were not separated by recollection period $(p<$ $.01)$ and also at the time of arrival $(p<.05)$. Most of the participants used email. Of those who did use email, about four times as many were at or above the median for feelings of not belonging. That is to say, the more they felt they didn't belong, the more they used email. When separated by recollection period, the correlations, though not all significant, went down each recollection period $(\mathrm{RP} 1=-.59, \mathrm{RP} 2=-.43, \mathrm{RP} 3=-.26, \mathrm{RP} 4=-.19$, and RP5 $=-.05$ ). The means for feelings of not belonging also declined each period except the fourth, when it rose only slightly $(\mathrm{RP} 1=2.93, \mathrm{RP} 2=2.73$, $\mathrm{RP} 3=2.20, \mathrm{RP} 4=2.33$, and RP5 $=2.00)$. Generally, as feelings of not belonging here decreased, the negative correlations with email also decreased. This mutual decline may have indicated that the use of email slightly reduced feelings of not belonging. Therefore, even though the 
negative correlations indicated that when feelings of not belonging were high, use of email was low, and when feelings of not belonging were low, use of email was high, the fact that this negative correlation weakened over time indicated that email may have helped to reduce the feelings of not belonging. In the open-ended questions, participants who did use email pointed out that it was very helpful to them, especially because they could email in their own language. In conclusion, most did use email. Of those who did use email, more felt like they did not belong than felt like they did. Participants stated that emails helped them to get through the hard times. They also mentioned that as they started school or employment, they had less time to use email. Therefore, as email helped the participants to feel better, they used it less due to a lack of need and a lack of time.

Pearson correlations showed a significant negative correlation between email and feelings of loneliness and isolation when the observations were not separated by recollection period $(p<.05)$ and also a trend toward significance at the time of arrival $(p<.10)$. Most of the participants used email. Of those who did use email, about four times as many were at or above the median for feelings of loneliness and isolation. That is to say, the more they felt lonely and isolated, the less they used email. This negative correlation indicated that as the use of email went up, loneliness and 
isolation went down. This could have meant that email made the participants feel better so they no longer felt the need to use it, or at least not as much. The fact that correlations were not significant when separated by recollection period could have been caused by the fact that most of the participants used email most of the time so changes might not have been related to the use of email. The small $n$ may have skewed the data as well. However, in the open-ended questions, those who used email indicated that it was very helpful in dealing with their feelings of loneliness and isolation. In conclusion, most of the participants did use email. Of those who did use email, more felt lonely and isolated than did not. As email helped the participants to feel better, they used it less. Participants pointed out that email helped them to get through the hard times. Also, as they became busy with school, employment, and just getting out and meeting other people, they had less time and less need to use email.

Pearson correlations showed a significant negative correlation between email and feelings of missing family and people of national origin at the time of arrival $(p<.01)$. This indicated that as use of email went up, feelings of missing family and people of national origin went down. This is, in fact, what the participants reported in the open-ended questions. They said 
they couldn't imagine living here without email to keep in touch with friends and family back home.

Pearson correlations showed a trend $((p<.10)$ toward a significant negative correlation between email and feelings of sadness because ways of doing things here are not familiar when observations were not separated by recollection period. This means that as use of email increased, feelings of sadness decreased. However, since this was only a trend and not supported by significant correlations across recollection periods or by other tests, it was ignored.

\section{Research Question 5}

Is there a correlation between number of chats and levels of feelings of loneliness and isolation, missing family and people of national origin, not belonging here, and sadness because ways of doing things here are not familiar?

Pearson correlations (summarized in Table 5) showed that there was a significant negative correlation between chat and feelings of sadness because ways of doing things here are not familiar when the observations were not separated by recollection period $(p<.01)$, and when observations were separated by recollection period, at the time of arrival $(p<.01)$ and during the second six months $(p<.05)$. That is to say that as the use of chat 
increased, the feelings of sadness because ways of doing things here are not familiar decreased. A chi square test indicated a significant relationship $(p<$ $.01)$ between chat and feelings of sadness because ways of doing things here are not familiar. Most did not use chat, but of those who did use chat, about half as many were above the median for feelings of sadness because ways of doing things here are not familiar than were below. The multiple stepwise regressions indicated that chat was a predictor for feelings of sadness because ways of doing things here are not familiar $(p<.01)$. All significant test results indicated that the more participants used chat, the less they felt sadness because ways of doing things here are not familiar. Despite a very small $n$ of users, significant results were obtained for all three tests. In conclusion, the use of chat appeared to decrease feelings of sadness because ways of doing things here are not familiar.

Pearson correlations showed a significant negative correlation between chat and feelings of not belonging when the observations were not separated by recollection period $(p<.01)$ and also at the time of arrival $(p<$ $.05)$ and a trend $(p<.10)$ toward a significant correlation during the third six months. As mean levels of not belonging decreased, the negative correlation decreased, which may have indicated that using chat helped reduce levels of feelings of not belonging here. A chi square test indicated a significant 
relationship $(p<.01)$ between chat and feelings of not belonging. Most did not use chat, but of those who did use chat, one more was above the median for feelings of not belonging than were below. The multiple stepwise regressions indicated that chat was a predictor for feelings of not belonging $(p<.01)$. All of these tests indicated a relationship between chat and feelings of not belonging here. As chat increased, feelings of not belonging here decreased. Therefore the use of chat appeared to decrease feelings of not belonging.

Pearson correlations showed a significant negative correlation between chat and feelings of loneliness and isolation when the observations were not separated by recollection period $(p<.01)$ and also at the time of arrival $(p<.05)$ and during the second six months here $(p<.05)$. This indicated that the more they used chat, the less they felt lonely and isolated. A chi square test indicated a significant relationship $(p<.01)$ between chat and feelings of loneliness and isolation. Most did not use chat, but of those who did use chat, 1.5 times as many were above the median for feelings of loneliness and isolation as were below, probably a result of the low $n$. The multiple stepwise regressions indicated that chat was a predictor for feelings of loneliness and isolation $(p<.01)$. 
Pearson correlations showed a significant negative correlation between chat and feelings of missing family and people of national origin at the time of arrival $(p<.01)$ and a trend toward a significant negative correlation $(p<.10)$ during the recollection period right now. This indicated that the more they used chat, the less they had feelings of missing family and people of national origin. A chi square test indicated a significant relationship $(p<.05)$ between chat and feelings of missing family and people of national origin. Most did not use chat, but of those who did use chat, one third as many were above the median for feelings of loneliness and isolation as were below, which indicated that chat may have reduced feelings of missing family and people of national origin.

\section{Research Question 6}

Is there a correlation between the number of times an online newspaper is read and levels of feelings of loneliness and isolation, missing family and people of national origin, not belonging here, and sadness because ways of doing things here are not familiar?

There were no significant findings for the effects of the use of online newspapers. This may be because almost every participant used online newspapers at every level of feelings of loneliness and isolation, missing family and people of national origin, not belonging here, and sadness 
because ways of doing things here are not familiar. In the open-ended discussion, participants indicated that reading online newspapers helped them to feel better by keeping them informed about what was going on back home. This was especially important to those who were from countries that were experiencing political upheaval.

\section{Summary of Electronic Communication Indications}

Electronic communication did make a difference for the participants in this study. The use of chat provided the most significant correlations and relationships, especially with feelings of loneliness and isolation, not belonging, and missing family and people of national origin. Next was email, followed by web phone. There was limited evidence that phone use affected feelings of sadness because ways of doing things here are not familiar, and there was no quantitative evidence that reading online newspapers had any effect on the dependent variables.

\section{Recommendations}

Keep complete records of marital status, whether spouse is in the United States, address, and phone number of students. Update these records often as students change any of the information. Provide information to students and spouses as they arrive or even before they arrive of electronic communication possibilities. This could be distributed with admissions 
information. Once they arrive here, provide orientation to electronic communication. Demonstrate what is available and then provide training in its use. Provide access to electronic communication for students and their spouses. Electronically network those with the same language and similar cultural backgrounds. Provide a web board with general information for international spouses. This information should include, but not be limited to, information about bus schedules and other transportation available and how to access the transportation; places to shop, especially for foods and spices for ethnic cuisine; electronic communication, English classes and upcoming events for international students and/or spouses. Invite spouses who are already here to submit articles for the web board with information they believe will be helpful to new arrivals. It would be useful if this web board had a link to a translation site or if it could be provided in the languages represented in the student population of the university. The web board could also have a chat room so that students and spouses could get specific questions answered - such as "Just what is $2 \%$ milk?" Opportunities should be provided for international spouses to meet and interact. A library with books in the languages of the international students and spouses would also be helpful. Provide outings, perhaps an initial tour of the area showing students and spouses where things are that have interest to them such as 
shops, theaters, malls, bus depots, libraries, and computer labs. Perhaps people in the community who speak a given language could be recruited to act as direct points of contact to provide at least one "friend" for each spouse on arrival.

Implications for Further Research

Culture shock continues to be a significant problem for spouses of international university students. Because this study found significant correlations between the use of electronic communication, particularly chat, and feelings that indicate culture shock, it is recommended that further research investigate these correlations. The results from this research are not conclusive, but highly suggestive that the use of electronic communication does have an effect on the reduction of culture shock of spouses of international students, at least for the small sample used at one mid-Atlantic university in the United States. There is ample evidence in the anecdotal data that participants believed that the modes of electronic communication examined in this study helped them to cope with the culture shock they experienced in coming to this country. A controlled study needs to be completed to compare electronic communication users with a control group of non-users in order to clarify what communication modes are really having an effect and exactly what that effect is in relation to culture shock. 
Other suggestions for possible research include investigating the differences between males and females, between participants from different continents, among age groups, among those with children here, those who left children back in their country of origin, and those without children, between those who become students and those who do not, between those who were employed in their country of origin and those who were not, or between those who were professionals in their country of origin and those who were not, between those who are employed in the United States and those who are not, between those who have been in the United States for a long time and those who have not, and between those who have traveled to other foreign countries and those who have not. It would be interesting to know the impact of holidays such as New Year's and Christmas and whether those holiday times increased usage of communication technologies. One might compare those who came from a rural setting to an urban setting with those who came from an urban setting to a rural setting and those who came from a rural setting to a rural setting and those who came from an urban setting to an urban setting. It would be useful to investigate why usage of the various technologies changed over time along with why some participants used all of the technologies while others did not. Was it due to access issues? Were the access issues problems for the participants or did those with whom 
they wanted to communicate have access issues? One might dichotomize the levels of use of the electronic communication modes and determine if higher use or lower use had an effect as well as use and nonuse. It would also be interesting to investigate the effects of traditional mail, traditional newspapers, television, and radio. 


\section{BIBLIOGRAPHY}

Al-Ibrahim, F.Y. (1983). Adjustment problems facing Syrian students and their families in New York. Dissertation Abstracts International, 44 (01A), 0082.

Armes, K., \& Ward, C. (1989, April). Cross-cultural transitions and sojourner adjustment in Singapore. The Journal of Social Psychology, 129, 273-275.

Bock, P.K. (1970). Culture shock: A reader in modern cultural anthropology. NY: Knopf.

Broome, B.J. (1985, May). A context-based approach to intercultural adjustment. Paper presented at the annual meeting of the Eastern Communication Association, Providence, RI.

Bu, K.Y. (1988, September). Dateline: Between two cultures. Social Education, 52, 378+.

Byrnes, F. (1966). Role shock: An occupational hazard of American technical assistants abroad. Annals of the American Academy of Political and Social Science, 368, 95-108.

Canada and the World Backgrounder, 63. (1998, January). 20.

Church, A.T. (1982). Sojourner adjustment. Psychological Bulletin, 91, 540572.

Churchman, A. \& Mitrani, M. (1997, January). The role of the physical environment in culture shock. Environment and Behavior, 29, 64-86.

Dodge, S. (1990, May 7). Culture shock and alienation remain problems for many foreign students on U.S. campuses. The Chronicle of Higher Education, 36, A33+.

Fisher, S. (1990). Helping the homesick: Attentional management strategy, commitment, and adaptation. In Fisher, S., \& Cooper, C.L. (Eds.) On the move: The psychology of change and transition. London: Wiley.

Gao, Z. (1997). The sojourning life as problematic: Marital crises of Chinese students who are studying in the United States. Dissertation Abstracts International, 58 (12A), 4825.

Gilster, P. (1994). Finding it on the internet. New York: Wiley. Hall, G.E., \& Hord, S.M. (1987). Change in schools: Facilitating the process. NY: SUNY Press.

Hannigan, T.P. (1988, October). Culture shock with a happy ending. Journal of Counseling and Development, 67, 91.

Harris, J. (1994). Way of the ferret. Eugene, OR: International Society for Technology in Education. 
Hefferon, D.D. (1997, Fall). Adjusting to U.S. college life: The experiences of American overseas school graduates. The College Board Review, 82, 22-29+.

Hord, S.M., Rutherford, W.L., Huling-Austin, L., \& Hall, G.E. (1987). Taking charge of change. Alexandria, VA: ASCD.

Hycner, R. (1985). Some guidelines for the phenomenological analysis of interview data. Human Studies, 8(5), 279-303.

Kahin, B., \& Abbate, J. (1995). Standards policy for information infrastructure. Cambridge: MIT Press.

Kelly, N.T., \& Reekie, S.H.M. (1987, November/December). Culture shock: Adjusting to a different culture. Journal of Physical Education, Recreation and Dance, 58, 42-45.

Kerr, S. (1985, Spring). Morality and faith from a First World-Third World perspective. Religious Education, 80, 173-193.

Kinnell, M. (1990). The marketing and management of courses. In Kinnell, M. (Ed.) The learning experiences of overseas students. Bristol, PA: Society for Research into Higher Education and Open University Press.

Kohák, E. (1985, Fall). A letter from Europe. Dissent, 32, 407-411.

Kohls, R. (1979). Survival kit for overseas living. Chicago, IL: Intercultural Press.

Lalive d'Epinay, C.J. (1985, December). Depressed elderly women in Switzerland: An example of testing and of generating theories. The Gerontologist, 25, 597-604.

Ling, S., O'Shea, R.M., Pszonak, P. \& Bertram, D.A. (1994, July). Culture shock in a university health service: A case and commentaries. Journal of American College Health, 43, 39-44.

Loyd, B.H., \& Gressard, C. (1986, Summer). Validation studies of a new computer attitude scale. AEDS Journal, p. 297.

McKinlay, N.J., Pattison, H.M., \& Gross, H. (1996, April). An exploratory investigation of the effects of a cultural orientation programme on the psychological well being of international university students. Higher Education, 31, 379-395.

Merta, R.J., Stringham, E.M., \& Ponterotto, J.G. (1988, January). Simulating culture shock in counselor trainees: An experiential exercise for crosscultural training. Journal of Counseling and Development, 66, 242-245.

Murdock, G.P. (1971). How culture changes. In Shapiro, H.L. (Ed.) Man, culture and society. London: Oxford University Press.

Neves, J.S. \& Sanyal, R.N. (1992, September). Upside down: A crosscultural experiential exercise. Simulation \& Gaming, 23, 370-375. 
Ninggal, M.T. (1998). The role of ethnicity among international students in adjustment to acculturative stress. Dissertation Abstracts International, 59 (03A), 0738.

Oberg, K. (1954). Culture shock. Indianapolis, IN: Bobbs-Merrill.

Oberg, K. (1960). Culture shock: Adjustments to new cultural environments. Practical Anthropology, 4, 177-182.

Olson, M.L. (1985, April/June). Culture shock: Help after the honeymoon. Japan Quarterly, 32, 189-193.

Ory, F., Simons, M., Verhulst, F.C., Leenders, F.R.H., \& Wolters, W.H.G. (1991). Children who cross cultures. Social Science \& Medicine, 32, 2934.

Pennebaker, G.W., Colder, M., \& Sharp, L.K. (1990). Accelerating the coping process. Journal of Personality and Social Psychology, 58, 528537.

Renata, F. (1996, November-December). Facilitating cross-cultural adjustment: A newsletter by and for international students' spouses. Journal of College Student Development, 37, 699-701.

Rhinesmith, S. (1985). Bring home the world: A management guide for community leaders of international exchange programs. New York: Walker.

Sandhu, D.S., \& Asrabadi, B.R. (1994). Development of an acculturative stress scale for international students: Preliminary findings. Psychological Reports, 75, 435-448.

Scheper-Hughes, N. (1987, Spring). A children's diary in the strict sense of the term: Managing culture-shocked children in Brazil. Human Organization, 46, 78-83.

Shigaki, I.S. \& Smith, S. (1997, Fall). A cultural sharing model: American buddies for international students. International Education, 27, 5-21.

Simpson, E.B. (1990, November). Culture shock. Travel Holiday, 173, 3335.

Spencer, J.L. (1997). Chinese student sojourners and narratives of cultural adjustment at an American university. Masters Abstracts International, 36 (01), 0011.

Storti, C. (1989), The art of crossing cultures. Yarmouth, ME: Intercultural Press.

Taft, R. (1977). Coping with unfamiliar cultures. In Warren, N. (Ed.) Studies in cross-cultural psychology (Vol. 1, p. 121-153). London: Academic Press.

Taylor, S.A. (1990). France. Portland, OR: Graphic Arts Center Publishing Co. 
Tian, J. (1994, February). Of gifts and gaffes. The Unesco Courier, 47, 3841.

Tobin, J.J. \& Friedman, J. (1983, July). Spirits, shamans, and nightmare death: Survivor stress in a Hmong refugee. American Journal of Orthopsychiatry, 53, 439-48.

Tompson, H.B., \& Tompson, G.H. (1996, September/October). Confronting diversity issues in the classroom with strategies to improve satisfaction and retention of international students. Journal of Education for Business, 72, 53-57.

Tsai, H.Y. (1995, September). Sojourner adjustment: The case of foreigners in Japan. Journal of Cross-Cultural Psychology, 26, 523-536.

Van Leeuwen, M.S. (1987, November 20). Culture shock on the prairie. Christianity Today 31, 9.

Webster's new world dictionary of the American language. (1968). New York: World.

Weissman, D., \& Furnham, A. (1987, May). The expectations and experiences of a sojourning temporary resident abroad: A preliminary study. Human Relations, 40, 313-26.

Wilson, P. (1991, December). Trauma of Sioux Indian high school students. Anthropology \& Education Quarterly, 22, 367-383.

Winkelman, M. (1994, November-December). Cultural shock and adaptation. Journal of Counseling and Development 73, 121-127.

Zapf, M.K. (1993, November). Remote practice and culture shock: Social workers moving to isolated northern regions. Social Work, 38, 694-704.

Zwingman, C.A.A., \& Gunn, A.D.G. (1983). Uprooting and health: Psychological problems of students from abroad. Geneva: World Health Org. 


\section{APPENDIX A}

\section{Biographical Data}

First Name

Middle Name

Last or Family Name

$\operatorname{Sex} \mathrm{M} \square \mathrm{F} \square$

Age

Spouse Name

Do you have children Yes $\square$ No $\square$

If yes, are your children here with you? Yes $\square$ No $\square$

What are the names, sexes, and ages of your children?

Is your spouse a WVU student?

Are you a WVU student?

What is your level of education?

Do you have a job in the US?

Did you have a job in your country of origin? Yes $\square$ No $\square$

If yes, what kind of work did you do?

What is your street address?

City?

State? 
Zip code?

Telephone Number?

Email address?

Do you use a computer? Yes $\square$ No $\square$

Do you have a computer at home? Yes $\square$ No $\square$

Do you have an Internet connection? Yes $\square$ No $\square$

Do you use email? Yes $\square$ No $\square$

Do you read newspapers on the Internet? Yes $\square$ No $\square$

Do you use web phone? Yes $\square$ No $\square$

What is your first language?

What is your country of origin?

Please rank your level of English proficiency when you arrived in the US with 0 being I didn't know any English at all and 5 being totally proficient in English.

Listening

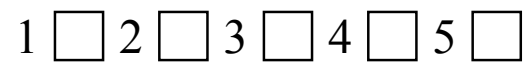

Speaking

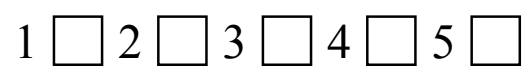

Reading

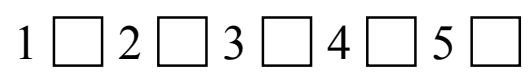

Writing

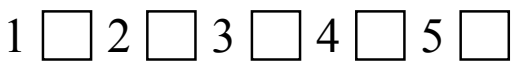


Please rank your level of English proficiency right now with 0 being I don't know any English at all and 5 being totally proficient in English.

Listening

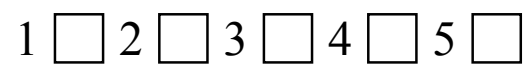

Speaking

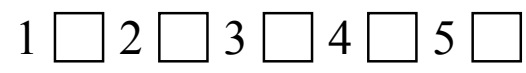

Reading

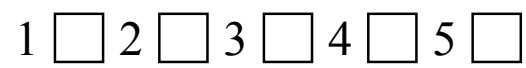

Writing

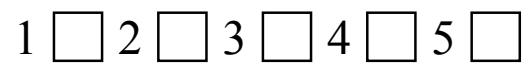

When did you arrive in the US?

Is this your first visit to the US?

Have you visited other foreign countries? Yes $\square$ No $\square$

If yes, which one(s)? 
APPENDIX B

Test Design

\begin{tabular}{|c|c|c|c|c|c|c|c|c|c|}
\hline $\begin{array}{l}\text { Question } \\
\text { Number }\end{array}$ & Arrival & Rating* & e-devices & $1^{\text {st }} 6$ Months & Rating* & e-devices & 2nd 6 Months & Rating* & e-devices \\
\hline Rated 1 & $\begin{array}{l}\text { When I first } \\
\text { arrived here, I felt } \\
\text { lonely and } \\
\text { isolated. }\end{array}$ & $\begin{array}{l}\square \square \square \square \\
1234 \\
\end{array}$ & $\begin{array}{l}\text { \# of phone calls } \\
\text { per week to } \\
\text { family back } \\
\text { home } \square\end{array}$ & $\begin{array}{l}\text { During the first } 6 \\
\text { months I was here, } \\
\text { I felt lonely and } \\
\text { isolated. }\end{array}$ & $\begin{array}{c}\square \square \square \square \\
1234 \\
\end{array}$ & $\begin{array}{l}\text { \# of phone calls } \\
\text { per week to } \\
\text { family back home } \\
\square\end{array}$ & $\begin{array}{l}\text { During the second } \\
6 \text { months I was } \\
\text { here, I felt lonely } \\
\text { and isolated. }\end{array}$ & $\begin{array}{c}\square \square \square \square \\
1234 \\
\end{array}$ & $\begin{array}{l}\# \text { of phone calls } \\
\text { per week to } \\
\text { family back home } \\
\square\end{array}$ \\
\hline Rated 2 & $\begin{array}{l}\text { When I first } \\
\text { arrived here, I } \\
\text { missed my family } \\
\text { and people of my } \\
\text { national } \\
\text { origin. }\end{array}$ & $\begin{array}{l}\square \square \square \square \\
1234\end{array}$ & $\begin{array}{l}\# \text { of phone calls } \\
\text { per week to } \\
\text { friends back } \\
\text { home } \square\end{array}$ & $\begin{array}{l}\text { During the first } 6 \\
\text { months I was here, } \\
\text { I missed my family } \\
\text { and people of my } \\
\text { national origin. }\end{array}$ & $\begin{array}{l}\square \square \square \square \\
1234\end{array}$ & $\begin{array}{l}\# \text { of phone calls } \\
\text { per week to } \\
\text { friends back } \\
\text { home } \square\end{array}$ & $\begin{array}{l}\text { During the second } \\
6 \text { months I was } \\
\text { here, I missed my } \\
\text { family and people } \\
\text { of my national } \\
\text { origin. }\end{array}$ & $\begin{array}{l}\square \square \square \square \\
1234\end{array}$ & $\begin{array}{l}\# \text { of phone calls } \\
\text { per week to } \\
\text { friends back } \\
\text { home } \square\end{array}$ \\
\hline Rated 3 & $\begin{array}{l}\text { When I first } \\
\text { arrived here, I } \\
\text { didn't feel like I } \\
\text { belonged here. }\end{array}$ & $\begin{array}{l}\square \square \square \square \\
1234\end{array}$ & $\begin{array}{l}\text { \# of phone calls } \\
\text { per week to } \\
\text { family in US } \square\end{array}$ & $\begin{array}{l}\text { During the first } 6 \\
\text { months I was here, } \\
\text { I didn't feel like I } \\
\text { belonged here. }\end{array}$ & $\begin{array}{c}\square \square \square \square \\
1234\end{array}$ & $\begin{array}{l}\text { \# of phone calls } \\
\text { per week to } \\
\text { family in US } \square\end{array}$ & $\begin{array}{l}\text { During the second } \\
6 \text { months I was } \\
\text { here, I didn't feel } \\
\text { like I belonged } \\
\text { here. }\end{array}$ & $\begin{array}{l}\square \square \square \square \\
1234\end{array}$ & $\begin{array}{l}\text { \# of phone calls } \\
\text { per week to } \\
\text { family in US } \square\end{array}$ \\
\hline Rated 4 & $\begin{array}{l}\text { When I first } \\
\text { arrived here, I felt } \\
\text { sad because ways } \\
\text { of doing things } \\
\text { here are not } \\
\text { familiar. }\end{array}$ & $\begin{array}{l}\square \square \square \square \\
1234\end{array}$ & $\begin{array}{l}\text { \# of phone calls } \\
\text { per week to } \\
\text { friends in US } \square\end{array}$ & $\begin{array}{l}\text { During the first } 6 \\
\text { months I was here, } \\
\text { I felt sad because } \\
\text { ways of doing } \\
\text { things here are not } \\
\text { familiar. }\end{array}$ & $\begin{array}{l}\square \square \square \square \\
1234\end{array}$ & $\begin{array}{l}\text { \# of phone calls } \\
\text { per week to } \\
\text { friends in US } \square\end{array}$ & $\begin{array}{l}\text { During the second } \\
6 \text { months I was } \\
\text { here, I felt sad } \\
\text { because ways of } \\
\text { doing things here } \\
\text { are not familiar. }\end{array}$ & $\begin{array}{l}\square \square \square \square \\
1234\end{array}$ & $\begin{array}{l}\text { \# of phone calls } \\
\text { per week to } \\
\text { friends in US } \square\end{array}$ \\
\hline $\begin{array}{l}\text { Open- } \\
\text { Ended } 1\end{array}$ & $\begin{array}{l}\text { When you first } \\
\text { arrived here, what } \\
\text { would have helped } \\
\text { you to feel more at } \\
\text { home? }\end{array}$ & & $\begin{array}{l}\text { \# of web phone } \\
\text { calls per week to } \\
\text { family back } \\
\text { home } \square\end{array}$ & $\begin{array}{l}\text { During your first } 6 \\
\text { months here, what } \\
\text { would have helped } \\
\text { you to feel more at } \\
\text { home? }\end{array}$ & & $\begin{array}{l}\text { \# of web phone } \\
\text { calls per week } \\
\text { to family back } \\
\text { home } \square\end{array}$ & $\begin{array}{l}\text { During your } \\
\text { second } 6 \\
\text { months here, what } \\
\text { would have helped } \\
\text { you to feel more at } \\
\text { home? }\end{array}$ & & $\begin{array}{l}\text { \# of web phone } \\
\text { calls per week } \\
\text { to family back } \\
\text { home } \square\end{array}$ \\
\hline $\begin{array}{l}\text { Open- } \\
\text { Ended } 2\end{array}$ & $\begin{array}{l}\text { When you first } \\
\text { arrived here, what } \\
\text { things made your } \\
\text { move here hard (or } \\
\text { difficult)? }\end{array}$ & & $\begin{array}{l}\text { \# of web phone } \\
\text { calls per week to } \\
\text { friends back } \\
\text { home } \square\end{array}$ & $\begin{array}{l}\text { During your first } 6 \\
\text { montts here, what } \\
\text { things made your } \\
\text { move here hard (or } \\
\text { difficult? }\end{array}$ & & $\begin{array}{l}\# \text { of web phone } \\
\text { calls per week to } \\
\text { friends back } \\
\text { home } \square\end{array}$ & $\begin{array}{l}\text { During your } \\
\text { second } 6 \text { months } \\
\text { here, what things } \\
\text { made your move } \\
\text { here hard (or } \\
\text { difficult? }\end{array}$ & & $\begin{array}{l}\# \text { of web phone } \\
\text { calls per week to } \\
\text { friends back } \\
\text { home } \square\end{array}$ \\
\hline
\end{tabular}




\begin{tabular}{|c|c|c|c|c|c|c|}
\hline $\begin{array}{l}\text { Open- } \\
\text { Ended } 3\end{array}$ & $\begin{array}{l}\text { When you first } \\
\text { arrived here, what } \\
\text { did you do to feel } \\
\text { better or to make } \\
\text { things easier? }\end{array}$ & $\begin{array}{l}\text { \# of web phone } \\
\text { calls per week to } \\
\text { family in US } \square\end{array}$ & $\begin{array}{l}\text { During your first } 6 \\
\text { months here, what } \\
\text { did you do to feel } \\
\text { better or to make } \\
\text { things easier? }\end{array}$ & $\begin{array}{l}\text { \# of web phone } \\
\text { calls per week to } \\
\text { family in US } \square\end{array}$ & $\begin{array}{l}\text { During your } \\
\text { second } 6 \text { months } \\
\text { here, what did you } \\
\text { do to feel better or } \\
\text { to make things } \\
\text { easier? }\end{array}$ & $\begin{array}{l}\text { \# of web phone } \\
\text { calls per week to } \\
\text { family in US } \square\end{array}$ \\
\hline & & $\begin{array}{l}\# \text { of web phone } \\
\text { calls per week to } \\
\text { friends in US } \square\end{array}$ & & $\begin{array}{l}\# \text { of web phone } \\
\text { calls per week to } \\
\text { friends in US } \square\end{array}$ & & $\begin{array}{l}\text { \# of web phone } \\
\text { calls per week to } \\
\text { friends in US } \square\end{array}$ \\
\hline & & $\begin{array}{l}\text { \# of emails per } \\
\text { week to family } \\
\text { back home } \square\end{array}$ & & $\begin{array}{l}\text { \# of emails per } \\
\text { week to family } \\
\text { back home } \square\end{array}$ & & $\begin{array}{l}\text { \# of emails per } \\
\text { week to family } \\
\text { back home } \square\end{array}$ \\
\hline & & $\begin{array}{l}\text { \# of emails per } \\
\text { week to friends } \\
\text { back home } \square\end{array}$ & & $\begin{array}{l}\text { \# of emails per } \\
\text { week to friends } \\
\text { back home } \square\end{array}$ & & $\begin{array}{l}\text { \# of emails per } \\
\text { week to friends } \\
\text { back home } \square\end{array}$ \\
\hline & & $\begin{array}{l}\text { \# of emails per } \\
\text { week to family } \\
\text { in US } \square\end{array}$ & & $\begin{array}{l}\text { \# of emails per } \\
\text { week to family in } \\
\text { US } \square\end{array}$ & & $\begin{array}{l}\text { \# of emails per } \\
\text { week to family in } \\
\text { US } \square\end{array}$ \\
\hline & & $\begin{array}{l}\text { \# of emails per } \\
\text { week to friends } \\
\text { in US } \square\end{array}$ & & $\begin{array}{l}\text { \# of emails per } \\
\text { week to friends in } \\
\text { US } \square\end{array}$ & & $\begin{array}{l}\text { \# of emails per } \\
\text { week to friends in } \\
\text { US } \square\end{array}$ \\
\hline & & $\begin{array}{l}\text { \# of chats per } \\
\text { week to family } \\
\text { back home } \square\end{array}$ & & $\begin{array}{l}\text { \# of chats per } \\
\text { week to family } \\
\text { back home } \square\end{array}$ & & $\begin{array}{l}\text { \# of chats per } \\
\text { week to family } \\
\text { back home } \square\end{array}$ \\
\hline & & $\begin{array}{l}\text { \# of chats per } \\
\text { week to friends } \\
\text { back home }\end{array}$ & & $\begin{array}{l}\text { \# of chats per } \\
\text { week to friends } \\
\text { back home } \square\end{array}$ & & $\begin{array}{l}\text { \# of chats per } \\
\text { week to friends } \\
\text { back home } \square\end{array}$ \\
\hline & & $\begin{array}{l}\text { \# of chats per } \\
\text { week to family } \\
\text { in US } \square\end{array}$ & & $\begin{array}{l}\# \text { of chats per } \\
\text { week to family in } \\
\text { US } \square\end{array}$ & & $\begin{array}{l}\# \text { of chats per } \\
\text { week to family in } \\
\text { US } \square\end{array}$ \\
\hline & & $\begin{array}{l}\text { \# of chats per } \\
\text { week to friends } \\
\text { in US } \square\end{array}$ & & $\begin{array}{l}\text { \# of chats per } \\
\text { week to friends in } \\
\text { US } \square\end{array}$ & & $\begin{array}{l}\# \text { of chats per } \\
\text { week to friends in } \\
\text { US } \square\end{array}$ \\
\hline & & $\begin{array}{l}\text { \# of times per } \\
\text { week online } \\
\text { newspapers } \\
\text { read from back } \\
\text { home } \square\end{array}$ & & $\begin{array}{l}\text { \# of times per } \\
\text { week online } \\
\text { newspapers } \\
\text { read from back } \\
\text { home } \square\end{array}$ & & $\begin{array}{l}\text { \# of times per } \\
\text { week online } \\
\text { newspapers } \\
\text { read from back } \\
\text { home } \square\end{array}$ \\
\hline
\end{tabular}




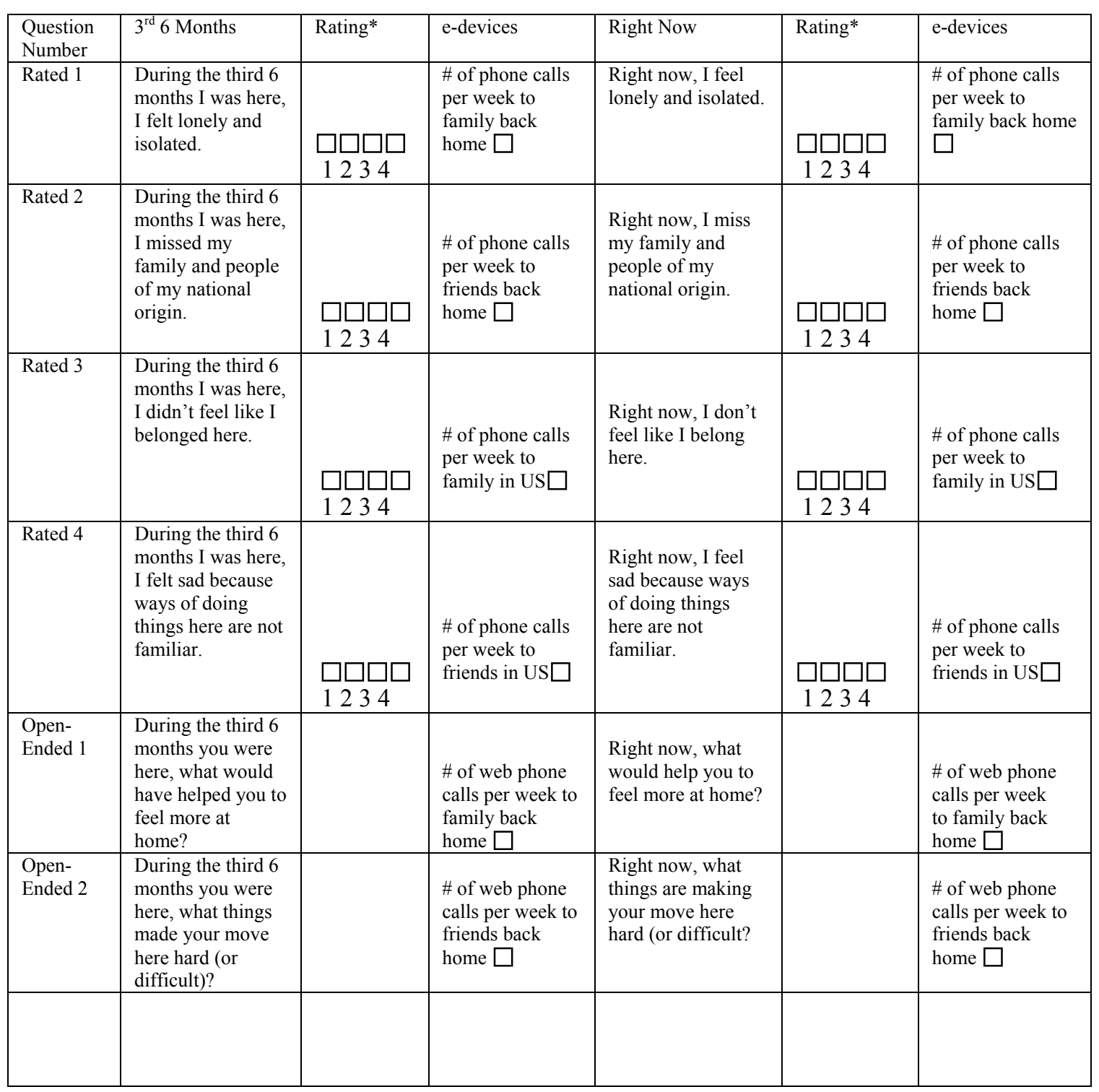




\begin{tabular}{|c|c|c|c|c|}
\hline $\begin{array}{l}\text { Open- } \\
\text { Ended } 3\end{array}$ & $\begin{array}{l}\text { During the third } 6 \\
\text { months you were } \\
\text { here, what did you } \\
\text { do to feel better or } \\
\text { to make things } \\
\text { easier? }\end{array}$ & $\begin{array}{l}\text { \# of web phone } \\
\text { calls per week to } \\
\text { family in US } \square\end{array}$ & $\begin{array}{l}\text { Right now, what } \\
\text { are you doing to } \\
\text { feel better or to } \\
\text { make things easier? }\end{array}$ & $\begin{array}{l}\text { \# of web phone } \\
\text { calls per week to } \\
\text { family in US } \square\end{array}$ \\
\hline & & $\begin{array}{l}\text { \# of web phone } \\
\text { calls per week to } \\
\text { friends in US } \square\end{array}$ & & $\begin{array}{l}\text { \# of web phone } \\
\text { calls per week to } \\
\text { friends in US } \square\end{array}$ \\
\hline & & $\begin{array}{l}\text { \# of emails per } \\
\text { week to family } \\
\text { back home } \square\end{array}$ & & $\begin{array}{l}\text { \# of emails per } \\
\text { week to family } \\
\text { back home } \square\end{array}$ \\
\hline & & $\begin{array}{l}\text { \# of emails per } \\
\text { week to friends } \\
\text { back home } \square\end{array}$ & & $\begin{array}{l}\text { \# of emails per } \\
\text { week to friends } \\
\text { back home } \square\end{array}$ \\
\hline & & $\begin{array}{l}\text { \# of emails per } \\
\text { week to family } \\
\text { in US } \square\end{array}$ & & $\begin{array}{l}\text { \# of emails per } \\
\text { week to family in } \\
\text { US } \square\end{array}$ \\
\hline & & $\begin{array}{l}\text { \# of emails per } \\
\text { week to friends } \\
\text { in US } \square\end{array}$ & & $\begin{array}{l}\text { \# of emails per } \\
\text { week to friends in } \\
\text { US } \square\end{array}$ \\
\hline & & $\begin{array}{l}\# \text { of chats per } \\
\text { week to family } \\
\text { back home } \square\end{array}$ & & $\begin{array}{l}\text { \# of chats per } \\
\text { week to family } \\
\text { back home } \square\end{array}$ \\
\hline & & $\begin{array}{l}\# \text { of chats per } \\
\text { week to friends } \\
\text { back home } \square\end{array}$ & & $\begin{array}{l}\text { \# of chats per } \\
\text { week to friends } \\
\text { back home } \square\end{array}$ \\
\hline & & $\begin{array}{l}\text { \# of chats per } \\
\text { week to family } \\
\text { in US } \square\end{array}$ & & $\begin{array}{l}\# \text { of chats per } \\
\text { week to family in } \\
\text { US } \square\end{array}$ \\
\hline & & $\begin{array}{l}\text { \# of chats per } \\
\text { week to friends } \\
\text { in US } \square\end{array}$ & & $\begin{array}{l}\# \text { of chats per } \\
\text { week to friends in } \\
\text { US } \square\end{array}$ \\
\hline & & $\begin{array}{l}\text { \# of times per } \\
\text { week online } \\
\text { newspapers } \\
\text { read from back } \\
\text { home } \square\end{array}$ & & $\begin{array}{l}\text { \# of times per } \\
\text { week online } \\
\text { newspapers } \\
\text { read from back } \\
\text { home } \square\end{array}$ \\
\hline
\end{tabular}

* $1=$ strongly disagree, $2=$ disagree, $3=$ agree, $4=$ strongly agree 


\section{VITA}

Diana Bennett

245 Old Water Works Road

Dilliner, PA 15327-9635

724.324 .2401

email: dbennett@alltel.net

\section{Degrees:}

Ed.D., West Virginia University, 2002, Technology Education Dissertation: "Effects of Electronic Communication on the Culture Shock of Spouses of International Students"

M.A., West Virginia University, 1980

Major: Reading Education

B.S. in Elementary Education, West Virginia University, 1979

Major: Early Childhood Education

\section{Other Educational Activities:}

University of Guanajuato, Gunajuato, Mexico, Summer, 1992

Six credit hours in Spanish and Mexican Culture

Universidad Internacional Menéndez y Pelayo, Santander, Spain, Summer, 1993

Six credit hours in Spanish and Spanish Culture

\section{Research Interests:}

International Students and Culture Shock

Writing Using Computers in Elementary School

Electronic Communication 


\section{Employment:}

Monongalia County Schools, Morgantown, WV, USA - Taught kindergarten, first grade, second grade, combined first and second grade, all subjects, including English as a second language; taught k-5 computer classes; taught k-6 Spanish

Part-time projects as listed in other sections of this document

\section{Courses Taught}

\section{College Level:}

West Virginia University - Introduction to Education, Introduction to Computers - Windows, Word, Excel

International Society for Technology Education (ISTE) Integrating Technology into the Curriculum - Word, Excel, Access, PowerPoint, Internet, Email, Acceptable Use. Business English, Using Computers in Education, Spanish I, Intensive English (for international students)

Westmoreland County Community College - Beginning computer class, including Windows, Word, Excel, Internet, email

\section{K12 Level:}
All subjects K-2

Spanish K-6

English as a second language 


\section{Projects:}

Trek-21, West Virginia University, Summers, 2001, 2002

Assisted K12 teachers with adding technology (such as, PowerPoint, Web quests, pdf documents, Word documents, sounds, video, digital photographs) to units they developed and helped them post their units to the Web.

Online Multimedia Development Project (OMDP), Summer, 1995

Developed an online unit on Japan as part of a grant to WVU from Bell Atlantic.

WVU Adult Learning Focus Group

Discussed issues related to experiences of WVU non-traditional students

Helped re-write early childhood education goals and objectives for Monongalia County Schools, Morgantown, West Virginia

Monongalia County Technology Study Group

Helped to decide direction technology should take in Monongalia County Schools

Technology Practica co-coordinator for Benedum foundation of West Virginia University

Planned technology practica for teachers in Professional Development Schools of WVU.

Monongalia County Technology Training Cadre

Taught technology classes for Monongalia County public school teachers to increase their skills and provide information on integrating technology into their teaching

Young Author's Contest for Monongalia County Reading Association from 1985-1989

Initiated this contest in Monongalia County for students in kindergarten through twelfth grade 


\section{Presentations:}

Hands-on Math Workshop for kindergarten teachers

Hands-on Math Workshops for K-6 teachers

Work Sampling Training (portfolios in the elementary school)

Many computer software presentations, especially Word, PowerPoint, Internet, Email, Excel, and Access

WVU Forestry Department Forestry Economics Workshop - lesson planning

\section{Additional Learning Opportunities:}

West Virginia Governor's Institute

Bureau of Educational Research, Inc. Seminar: Increasing the success of atrisk learners through whole language

Wright Group whole language seminars

Society for Developmental Education seminar on whole language

Work Sampling Train-the-Trainer Workshop for portfolio development in the elementary school

West Virginia Writing Project

West Virginia Advanced Writing Project

Math Their Way workshops

Math, a Way of Thinking workshop

International Society for Technology Education (ISTE) Integrating

Technology into the Curriculum

Jostens' ICLAS System Operator Training

Compass Learning System Tomorrow's Promise System Operator Training WVU Faculty Academy

\section{Other Activities:}

Monongalia County Math Textbook Adoption committee Monongalia County School Technology Contact Monongalia County Reading Council President, Vice-President After-school tutor in K-6 general subject matter and for high school Spanish 


\section{Awards:}

Faltis Scholarship

Kappa Delta Pi Honorary

Phi Kappa Phi Honorary

BS Magna Cum Laude

Monongalia County Eddie C. Kennedy Reading Teacher of the Year

Monongalia County Teacher of the Month

NTE Exam 99 percentile

\section{Grants:}

Mini-grant to obtain Spanish materials for teaching Spanish to grades 1-6

OMDP Bell-Atlantic/WVU grant for developing online unit for the Internet - developed unit on Japan

Professional Development School grant for staff development in computer and information systems technology

Technology Enhancement grant for training first through third grade students to be classroom computer mentors 